\title{
Comparação dos Efeitos do Sufentanil e da Clonidina Administrados por Via Endovenosa para Sedação em Pacientes Submetidos a Cateterismo Cardíaco
}

Tese apresentada ao Programa de Pós-Graduação em Anestesiologia da Faculdade de Medicina de Botucatu, Universidade Estadual Paulista-UNESP, para obtenção do título de Doutor em Anestesiologia

Orientador: Prof Dr Guilherme Antonio Moreira Barros

Botucatu - SP

2010 
$A_{\text {quele que possui a sinceridade não se limita a }}$ realizar a perfeição de si mesmo. Com essa qualidade completa também os outros homens $e$ coisas. $\bigcirc$ completar-se a si mesmo mostra a sua perfeita virtude. $O$ completar aos outros homens $e$ coisas mostra o seu conhecimento. Estas são duas virtudes que correspondem à natureza, este o modo pelo qual se efetua uma união no exterior e no interior. Portanto, sempre que ele, o homem inteiramente sincero, as utiliza - seus atos serão justos."

Confúcio

Trecho do livro Chung Yung (Doutrina do meio) 


\footnotetext{
Dedico estas páginas a Deus por ser o maior responsável pela minha existência e por nunca ter permitido que eu me sentisse só.
} 


\footnotetext{
$A_{\text {os meus pais }}$ Antonio e $P_{\text {erpétua, pelo exemplo }}$ e por sempre acreditarem nos meus sonhos e me apoiarem em cada investida.
} 
f̀ pedro, meu companheiro e meu amor 
$\hat{A}_{\text {meus filhos, }} p_{\text {edro e Rafael, que são as }}$ motivações maiores de minha vida. 


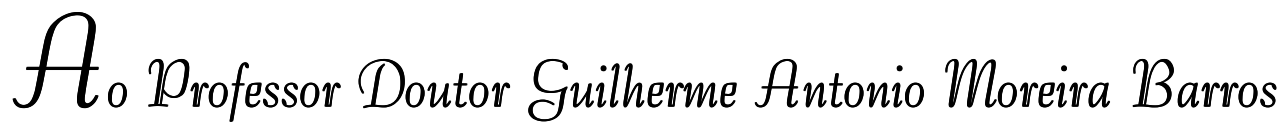

Meus agradecimentos pela compreensão, orientação, amizade e exemplo, mas principalmente por ensinar-me que a busca do conhecimento e a humildade são os principais elementos para o crescimento de cada um de nós como pessoas e como profissionais. 


\section{AGRADECIMENTOS}

A realização deste trabalho só foi possível graças a colaboração direta ou indireta de muitas pessoas. Manifesto a todas elas a minha gratidão e, em particular:

- aos meus irmãos, Antonio Miranda Rocha Júnior, Anício Marcel Carvalho Rocha e Aparecida Gabriela Carvalho Rocha, que me ensinaram a compartilhar e a dividir todas as minhas conquistas;

- aos meus mestres que confiaram em mim e me incentivaram a buscar o melhor, particularmente ao Prof. Lino Lemônica e ao amigo Jedson da Silva Nascimento;

- a todos os amigos e funcionários do Hospital Santa Izabel que ajudaram na realização deste trabalho, principalmente a equipe da hemodinâmica;

- aos amigos do Grupo de Anestesiologia do Hospital Santa Izabel, pela compreensão e auxílio nos momentos que precisei me ausentar das minhas atividades profissionais em Salvador para a realização deste trabalho;

- à amiga Lilian Mendes de Vasconcelos pela amizade e por todo o tempo que esteve envolvida na realização desta pesquisa;

- aos funcionários da secretaria e do serviço de computação do Departamento de Anestesiologia da Faculdade de Medicina de Botucatu, em especial, Nelí Aparecida Pavan, Danilo Godoy, Joana Jacirene Costa Teixeira e Sônia Maria Martins, pelas orientações quanto às disciplinas e normas de publicação. 


\section{SUMÁRIO}

Resumo

Abstract

1. Introdução e Literatura .......................................................... 20

1.1. Clonidina ............................................................... 25

1.2. Fármacos opióides............................................................. 38

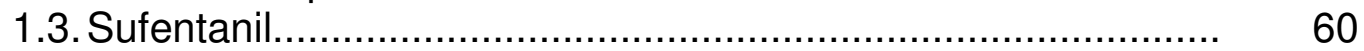

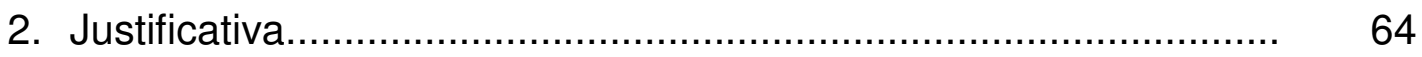

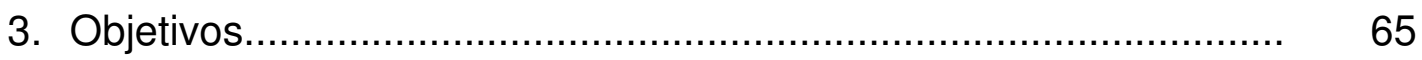

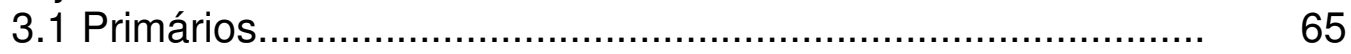

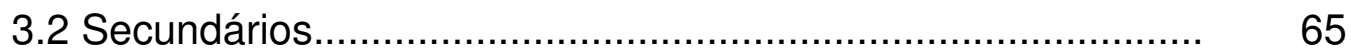

4. Pacientes e métodos............................................................... 66

4.1. Grupos estudados e cálculo amostral.................................... 69

4.2. Atributos estudados........................................................... $\quad 70$

4.3. Descrição do procedimento.................................................. 71

4.4. Momentos estudados........................................................ 74

4.5. Técnica empregada........................................................ $\quad 74$

4.6. Métodos estatísticos............................................................. $\quad 76$

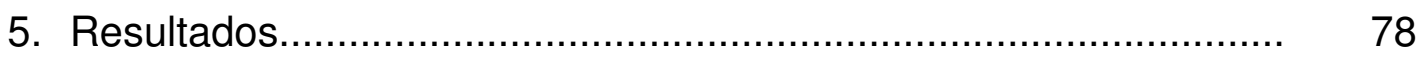

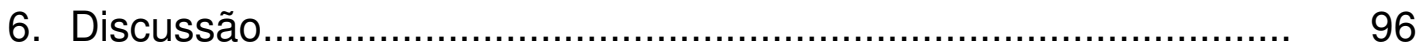

6.1. Discussão da metodologia................................................ 96

6.2. Discussão dos resultados................................................ 97

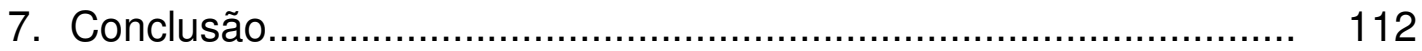

8. Referências bibliográficas....................................................... 113 


\section{LISTA DE FIGURAS}

Figura 1 - Receptor alfa-2A ………………………...... 26

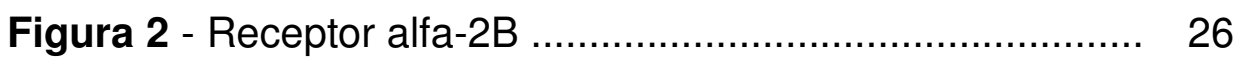

Figura 3 - Receptor alfa-2C ………………………...... 26

Figura 4 - Receptor opióide …………………………....... 42

Figura 5 - Ação dos opióides ……………………................. 43

Figura 6 - Localização dos receptores opióides .................... 44 


\section{LISTA DE TABELAS}

Tabela 1 Comparação das características demográficas e de avaliação clínica inicial dos grupos antes da realização do procedimento..................................... 78

Tabela 2 Comparação das morbidades e fatores de risco........ 79

Tabela 3 Freqüência de uso de medicamentos em domicílio para as comorbidades apresentadas entre os grupos

Tabela 4 Comparação entre os grupos das características hemodinâmicas e Ramsay para cada momento do procedimento.

Tabela 5 Frequência de escores de Ramsay dos grupos para cada momento.

Tabela 6 Comparação das PAS entre os momentos dos indivíduos do Grupo S

Tabela 7 Comparação das PAD entre os momentos dos indivíduos do Grupo S

Tabela 8 Comparação das FC entre os momentos dos indivíduos do Grupo S.

Tabela 9 Comparação das FR entre os momentos dos indivíduos do Grupo S.

Tabela 10 Comparação das $\mathrm{SPO}_{2}$ entre os momentos dos indivíduos do Grupo S.

Tabela 11 Comparação dos escores das escalas de sedação deRamsay entre os momentos dos indivíduos do Grupo S

Tabela 12 Comparação das PAS entre os momentos dos indivíduos do Grupo C

Tabela 13 Comparação das PAD entre os momentos dos indivíduos do Grupo C

Tabela 14 Comparação das FC entre os momentos dos indivíduos do Grupo C

Tabela 15 Comparação das FR entre os momentos dos indivíduos do Grupo C

Tabela 16 Comparação das $\mathrm{SPO}_{2}$ entre os momentos dos indivíduos do Grupo C

Tabela 17 Comparação das Ramsay entre os momentos dos indivíduos do Grupo C 


\section{LISTA DE GRÁFICOS}

Gráfico 1 Escores de Ramsay para cada momento dos grupos $S$ e C.

Gráfico 2 Escores de Ramsay para cada momento do grupo S....

Gráfico 3 Escores de Ramsay para cada momento do grupo C....

Gráfico 4 Satisfação do hemodinamicista quanto ao fármaco empregado

Gráfico 5 Satisfação dos pacientes quanto ao procedimento ....... 94

Gráfico 6 Queda de Saturação dos pacientes durante 0 procedimento. 


\section{LISTA DE QUADROS}

Quadro 1 Classificação e efeitos dos receptores opióides........ 46

Quadro 2 Escala de Ramsay ............................................... 68 


\section{LISTA DE SIGLAS E ABREVIATURAS}

$\begin{array}{ll}\text { ASA III } & \text { estado fisco III } \\ \mathrm{bpm} & \text { batimento por minuto } \\ \mathrm{mmHg} & \text { milímetro de mercúrio } \\ \mathrm{RPA} & \text { recuperação pós-anstésica } \\ \mathrm{kg} & \text { quilograma } \\ \mathrm{ml} & \text { mililitro } \\ \mathrm{L} / \mathrm{kg} & \text { litros por quilograma } \\ \mathrm{L} / \mathrm{min} & \text { litros por minuto } \\ \mathrm{mg} / \mathrm{kg} & \text { miligrama por quilograma } \\ \mathrm{mcg} / \mathrm{kg} & \text { microgramas por kilograma } \\ \mathrm{mcg} / \mathrm{ml} & \text { micrograma por mililitro } \\ \mathrm{ng} / \mathrm{ml} & \text { nanograma por mililitro } \\ \mathrm{mcg} / \mathrm{kg} / \mathrm{dose} & \text { micrograma por quilograma por dose } \\ \mathrm{mcg} / \mathrm{kg} / \mathrm{min} & \text { micrograma por quilograma por minuto } \\ \mathrm{ml} / \mathrm{kg} / \mathrm{h} & \text { mililitro por quilograma por hora } \\ \mathrm{pH} & \text { potencial hidrogeniônico } \\ \mathrm{IMC} & \text { índice de massa corpórea } \\ \mathrm{AMP} & \text { adenosina monofosfato } \\ \mathrm{AMPc} & \text { adenosina monofosfato cíclico } \\ \mathrm{SpO} 2 & \text { saturação periférica da oxihemoglobina } \\ \mathrm{ECA} & \text { enzima conversora da angiotensina } \\ \mathrm{PA} & \text { pressão arterial } \\ \mathrm{PAS} & \text { pressão arterial sistólica } \\ \mathrm{PAD} & \text { pressão arterial diastólica } \\ \mathrm{PAM} & \text { pressão arterial média } \\ \mathrm{FC} & \text { freqüência cardíaca } \\ \mathrm{FR} & \text { freqüência respiratória } \\ \mathrm{SNC} & \text { sistema nervoso central } \\ \mathrm{ASA} & \text { american society of anesthesiologists }\end{array}$




$\begin{array}{ll}\text { GABA } & \text { ácido gama-aminobutírico } \\ \text { UTI } & \text { unidade de terapia intensiva } \\ \text { GTP } & \text { trifosfato de guanosina } \\ \text { CDP } & \text { difosfato de guanosina } \\ \text { PEPI } & \text { computer programs for epidemiologists } \\ \text { GC } & \text { grupo clonidina } \\ \text { GS } & \text { grupo sufentanil } \\ \text { NVPO } & \text { náusea e vômito pós-operatório } \\ \text { CO2 } & \text { dióxido de carbono } \\ \text { K+ } & \text { potássio } \\ \text { NMDA } & \text { N-metil-D-aspartato } \\ \alpha & \text { alfa } \\ \beta & \text { beta } \\ \mu & \text { mu } \\ \delta & \text { delta } \\ \kappa & \text { kapa } \\ \gamma & \text { sigma } \\ \varepsilon & \text { épsilon } \\ \text { HIO } & \text { hiperalgesia induzida por opióides } \\ \text { HAS } & \text { hipertensão arterial sistêmica } \\ \text { DM } & \text { diabetes mellitus } \\ \text { ICO } & \text { insuficiência coronariana } \\ \text { DPOC } & \text { doença pulmonar obstrutiva crônica } \\ \text { Grupo S } & \text { grupo sufentanil } \\ \text { Grupo C } & \text { grupo clonidina } \\ & \end{array}$


Rocha APC - Comparação dos efeitos do sufentanil e da clonidina administrados por via endovenosa em pacientes submetidos a cateterismo cardíaco. Botucatu, 2010, 129p Tese (Doutorado em Anestesiologia). Faculdade de Medicina, Universidade Estadual Paulista "Julio de Mesquita Filho".

\section{RESUMO}

Justificativa e objetivos - A sedação para a realização de cateterismo cardíaco, apesar de pouco estudada, tem sido alvo de preocupação de alguns anestesiologistas. Os benzodiazepínicos, os agonistas alfa-2 adrenérgicos e os opióides são comumente utilizados para este fim, entretanto, cada um destes medicamentos possui vantagens e desvantagens. O objetivo deste trabalho é avaliar a eficácia do sufentanil e da clonidina como medicação sedativa em pacientes submetidos a cateterismo cardíaco, comparando o impacto dos mesmos sobre os parâmetros hemodinâmicos e respiratórios apresentados, observando a presença de efeitos colaterais, além da satisfação do paciente e do hemodinamicista durante o exame.

Métodos - Trata-se de um ensaio clínico prospectivo, duplo-cego, randomizado e controlado, que envolveu sessenta pacientes divididos igualmente em dois grupos: GS e GC que receberam respectivamente, 0,1 $\mathrm{mcg} / \mathrm{kg}$ de sufentanil e $0,5 \mathrm{mcg} / \mathrm{kg}$ de clonidina. Estes fármacos foram administrados antes da realização do cateterismo cardíaco. O escore de sedação segundo a escala de Ramsay, a necessidade de utilização de midazolam, os efeitos colaterais, a PAS, a PAD, a FC, a $\mathrm{FR}$ e a $\mathrm{SpO}_{2}$ foram 
registrados a cada cinco minutos, sendo os dados analisados em 06 diferentes momentos.

Resultados - Os grupos foram homogêneos em relação aos dados demográficos e avaliação clínica inicial. O comportamento da PAS, da PAD, da FC e da FR foi semelhante nos dois grupos, entretanto os pacientes do GS apresentaram menor escore de sedação segundo a escala de Ramsay no momento 2 e $\mathrm{SpO}_{2}$ menor que o $\mathrm{GC}$ no momento 6 . Os pacientes do GS apresentaram maior incidência de NVPO que os pacientes do GC. A satisfação dos pacientes foi maior no GC. Os hemodinamicistas mostraram-se igualmente satisfeitos nos dois grupos.

Conclusões - O sufentanil e a clonidina se mostraram efetivos como fármacos sedativos em pacientes submetidos a cateterismo cardíaco.

PALAVRAS-CHAVE: Sedação, sufentanil, clonidina, cateterismo cardíaco. 
Rocha APC - Comparison of sufentanil and clonidine effects administered endovenously in patients submitted to cardiac catheterization. Botucatu, 2010, 129p. Thesis. (Anesthesiology Doctorate). Faculdade de Medicina, Universidade Estadual Paulista "Júlio de Mesquita Filho".

\section{ABSTRACT}

Background and objectives - Sedation for cardiac catheterization, although not largely studied, has worried a number of anesthesiologists presently. Not only benzodiazepinic medicine, but also alpha- 2 adrenergic agonist and opioids are commonly used drugs to this end. Each one of these medicaments presents a series of advantages as well as disadvantages. The objective of this paper is to evaluate the effectiveness of sufentanil and clonidine as a sedative medicament to patients submitted to cardiac catheterization, comparing their impact over the hemodynamic and respiratory parameters witnessed, observing the occurrence of side effects, besides patient's and hemodynamicist's satisfaction during the examination.

Methods - This consists of a prospective, double-blinded, randomized and controlled clinical essay, which involved sixty patients equally divided in two different groups: GS and GC, who, respectively, received $0,1 \mathrm{mcg} / \mathrm{kg}$ of sufentanil and $0,5 \mathrm{mcg} / \mathrm{kg}$ of clonidine. Both administered before cardiac catheterization. The sedation score, according to Ramsay's scale, the necessity of utilizing midazolam, side effects, SAP, DAP, $\mathrm{CF}$ and $\mathrm{SpO}_{2}$ were registered every five minutes and data analyzed in six different moments. 
Results - The studied groups were homogeneous regarding demographic data and initial clinical evaluation. The behavior of SAP, DAP, CF and RF was similar in both groups. However, a lower sedation score regarding Ramsay's scale was observed in GS patients at moment 2 and at moment $6 \mathrm{SpO}_{2}$ was found to be lower than GC. All GS patients seemed to have had higher incidence of PONV compared to GC patients. Considering patients' satisfaction, it was higher in GC. Hemodynamicists seemed equally satisfied in both groups.

Conclusions - Sufentanil and clonidine seemed to have been more effective as sedative medicaments in patients submitted to cardiac catheterization.

KEY-WORDS - Sedation, sufentanil, clonidine, cardiac catheterization. 


\section{INTRODUÇÃO E LITERATURA}

O número de intervenções terapêuticas e diagnósticas realizadas fora do centro cirúrgico aumentou significativamente nos últimos 10 anos. Isto é especialmente verdadeiro para os procedimentos realizados no serviço de hemodinâmica. Intervenções comuns incluem cateterismo cardíaco, angiografia coronariana e implantação de stent, estudos eletrofisiológicos e ablação, além da colocação de dispositivos de marca-passo e de desfibrilação. Frequentemente, estas intervenções necessitam ser acompanhadas de monitorização do paciente e de sedação leve a moderada (GROSS ET AL., 2002).

Pesquisas médicas, novas tecnologias, o envelhecimento da população e o aumento da expectativa de vida de pacientes portadores de diferentes patologias alteram a complexidade das intervenções realizadas e a frequência dos procedimentos nos serviços de hemodinâmica. Nestes, os anestesiologistas são comumente solicitados para auxiliar no manejo de pacientes com doenças congênitas avançadas, valvulopatas e portadores de insuficiência coronariana, com comorbidades que podem implicar em maior possibilidade de complicações relacionadas ao controle hemodinâmico e a via aérea.

Assim como a assiduidade dos pacientes e a crescente complexidade dos procedimentos, o papel do anestesiologista, na sala de hemodinâmica, continua a crescer. Consistentes "guidelines" devem ser 
estabelecidos nas avaliações pré-anestésicas e ensaios clínicos necessitam ser realizados para aumentar a segurança e garantir um melhor atendimento aos pacientes submetidos a procedimentos cardiológicos e não-cardiológicos realizados.

Estudos têm demonstrado que a incidência de eventos coronarianos indica aumento nos últimos anos. Sabe-se que sessenta milhões de americanos sofrem de doença cardiovascular, e um milhão destes indivíduos morrem por ano. Aproximadamente, 100.000 a 400.000 pacientes, ao ano, nos Estados Unidos da América, são submetidos à cirurgia cardíaca e 1,5 milhão, de 30 milhões dos pacientes submetidos à cirurgia não-cardíaca, apresentam enfermidades cardiovasculares no período perioperatório implicando num custo superior a 20 bilhões de dólares anualmente (MANGANO et al., 1990; MANGANO; GOLDMAN, 1995). Em função desse contexto, cresce a preocupação acerca de uma melhor assistência a estes pacientes. No Brasil, em 2004, o Ministério da Saúde publicou a Portaria $\mathrm{N}^{\circ}$ 1169/GM que instituiu a Política Nacional de Atenção Cardiovascular de Alta Complexidade e estabelece a formação de centros de atenção cardiovascular de alta complexidade (CAVALCANTI et al., 2007). Dentre os serviços oferecidos nesses centros, o cateterismo cardíaco tem papel de destaque e é conceituado como um procedimento hemodinâmico e angiográfico realizado com fins diagnóstico e, frequentemente, terapêutico. Encontra-se indicado em casos selecionados de angina estável, angina instável e infarto do miocárdio com elevação do segmento ST. O princípio básico é que o cateterismo cardíaco é recomendado para confirmar a presença de condições clinicamente 
suspeitas, definir a anatomia e severidade da lesão, assim como determinar a presença ou ausência de condições associadas. Em geral, a intervenção terapêutica é planejada em pacientes sintomáticos. Desta forma, a indicação mais usual para cateterismo cardíaco, nos dias atuais, consiste na presença de síndrome isquêmica coronariana aguda quando uma intervenção terapêutica invasiva é almejada. O objetivo da cateterização cardíaca, nesses pacientes, é identificar a lesão (“culprit”) alvo e, então, restaurar a patência do vaso através de um acesso percutâneo (BRAIN, 2006).

O cateterismo cardíaco pode desempenhar papel diagnóstico e terapêutico. O cateterismo cardíaco diagnóstico permite a avaliação anatômica dos vasos coronarianos, dessa forma, analisam-se as lesões obstrutivas ateroscleróticas e se indica o seu tratamento. Este, quando realizado por via percutânea, na sala de hemodinâmica, origina um procedimento que é denominado cateterismo cardíaco terapêutico. Seja qual for o tipo de cateterismo cardíaco ele envolve a participação do anestesiologista, o qual tem como função administrar e monitorar o nível de sedação, acompanhar os parâmetros respiratórios e hemodinâmicos, além de tratar as possíveis complicações.

Segundo a Resolução 1.670/03 do Conselho Federal de Medicina, de 13 de junho de 2003, a sedação é um ato médico realizado mediante a utilização de medicamentos com o objetivo de proporcionar conforto ao paciente, podendo ser classificada como leve, moderada e profunda (CAVALCANTI et al., 2007). Durante a sedação leve, o paciente responde ao 
comando verbal, não obrigatoriamente, havendo preservação da função cognitiva e da coordenação. As funções cardiovascular e respiratória não apresentam comprometimento. A sedação moderada é um estado de depressão da consciência, no qual o paciente responde ao estímulo verbal isolado ou acompanhado de estímulo tátil. Não são necessárias intervenções para manter a via aérea permeável; a ventilação espontânea é suficiente e a função cardiovascular, geralmente, é mantida de maneira adequada. $\mathrm{Na}$ sedação profunda, o paciente dificilmente é despertado por comandos verbais, mas responde a estímulos dolorosos. A ventilação espontânea pode estar comprometida e ser insuficiente, e pode ocorrer a necessidade de assistência para a manutenção da via aérea permeável. A função cardiovascular, geralmente, é mantida. É importante lembrar que as respostas dos pacientes são individuais e que pode haver transição entre os níveis de sedação, portanto, faz-se necessário um acompanhamento contínuo do paciente quando da realização deste procedimento anestésico (CAVALCANTI et al., 2007).

$\mathrm{Na}$ maioria dos procedimentos realizados na sala de hemodinâmica, a sedação leve a moderada é almejada. Medicações intravenosas são administradas no intuito de alcançar a sedação adequada com mínima alteração respiratória, o que permitirá conforto e um efetivo controle dos parâmetros hemodinâmicos. Benzodiazepínicos, agonistas alfa-2 adrenérgicos e opioides são os fármacos comumente utilizados com este fim, entretanto, cada um destes fármacos possui vantagens e desvantagens. 
Os benzodiazepínicos, midazolam e diazepam, apesar de não apresentarem efeito analgésico, têm atividade ansiolítica e produzem amnésia em maior extensão quando comparados com os agonista alfa-2 adrenérgicos e com os opioides. Os agonistas alfa-2 adrenérgicos, principalmente a clonidina, mostram-se efetivos para o controle dos parâmetros hemodinâmicos, enquanto propiciam uma leve sedação, o que é desejável na sala de hemodinâmica (NASCIMENTO et al., 2006), porém devem ser utilizados com cautela nos pacientes portadores de hipotensão, de bradicardia e em usuários de betabloqueadores, pois estes medicamentos possuem efeito sinérgico no que diz respeito à redução da pressão arterial e da frequência cardíaca. Já os opioides, representam uma classe de fármaco frequentemente utilizada pelos anestesiologistas no centro cirúrgico, na sala de hemodinâmica e na enfermaria, com o intuito de obter sedação e controle da dor aguda e crônica. Os opioides mais comumente administrados na prática clínica são a morfina, a meperidina e o fentanil. Sabe-se que outras opções encontram-se disponíveis, representadas principalmente pelo alfentanil, remifentanil e sufentanil. Em contraste com os opioides mais antigos, como a morfina e a meperidina, eles possuem um rápido início de ação e seus efeitos estão mais intimamente relacionados à sua concentração sérica, principalmente quando utilizados em baixas doses (SCOTT et al., 1985; SCOTT et al., 1991).

Neste trabalho será abordada a administração de clonidina e sufentanil como fármacos sedativos em pacientes submetidos a cateterismo cardíaco diagnóstico, procedimento este realizado no laboratório de hemodinâmica. 


\subsection{CLONIDINA}

A clonidina, fármaco sintetizado em 1960, é um composto imidazólico altamente lipossolúvel que interage com receptores adrenérgicos alfa-1 e alfa-2, localizados no sistema nervoso central e na periferia. Difere de agentes anestésicos e analgésicos por propiciar potente efeito sedativo e bom controle da dor, ao atuar em receptores específicos pré e pós-sinápticos encontrados em diferentes regiões do organismo, como tecidos neurais, plaquetas, fígado, pâncreas, rim e olhos, onde exercem funções fisiológicas específicas (KAHN et al., 1999).

Após administração venosa, a clonidina inicia a sua ação em menos de cinco minutos, atinge um pico plasmático em 10 a 15 minutos e sua duração é de quatro horas aproximadamente. Apresenta grande volume de distribuição, equivalente a 1,7-2,5 L/kg, e meia-vida de eliminação de 9 a 12 horas. Sua metabolização é hepática, gerando metabólitos inativos. Entretanto, cerca de metade da dose administrada é eliminada de forma inalterada na urina. A clonidina liga-se a proteínas plasmáticas na proporção de $20 \%$ (HOFFMAN; LEFKOWITZ, 1996).

Os receptores adrenérgicos alfa-2 podem ser classificados conforme o efeito clínico a eles associado em alfa-2A, alfa-2B e alfa-2C (Figuras 1, 2 e 3) (BYLUND et al., 1988). O subtipo alfa-2A é encontrado predominantemente no cérebro e na medula, estando envolvido com a maioria dos efeitos farmacológicos associados à regulação central da pressão arterial, à atividade simpática, aos efeitos anestésicos e aos analgésicos (MACMILLAN 
et al., 1996; IHALAINEN; TANILA 2004). O subtipo alfa-2B, presente na musculatura lisa dos vasos, quando estimulado, resulta em vasoconstrição e consequente hipertensão tendo efeito antagônico ao receptor alfa-2A (LINKRE et al., 1996). Adicionalmente, o receptor alfa-2B parece estar envolvido com a hipertensão associada ao sal (MAKARISISK et al., 1999), provavelmente, é responsável pelo efeito antitremor dos agonistas alfa-2 ao atuar na termorregulação central. $\mathrm{O}$ subtipo alfa-2C modula a neurotransmissão dopaminérgica e está envolvido com a integração sensório-motora (TAKADA et al., 2002). Em modelos animais, o receptor alfa-2C está relacionado à ação antinociceptiva espinhal da moxonidina e midazolina (FAIRBANKS et al., 2002).

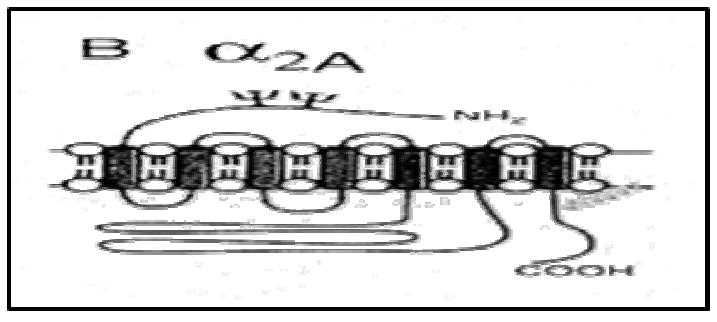

Figura 1 - receptor alfa-2A

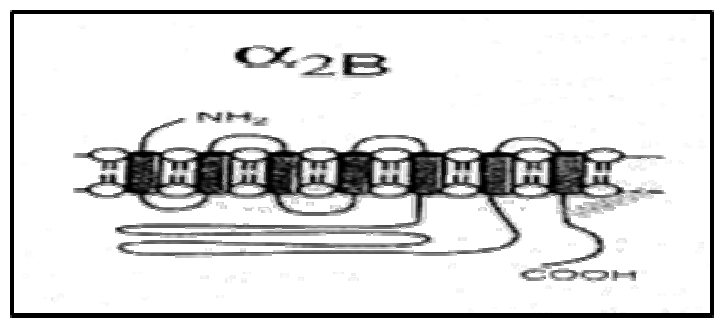

Figura 2 - Receptor alfa-2B

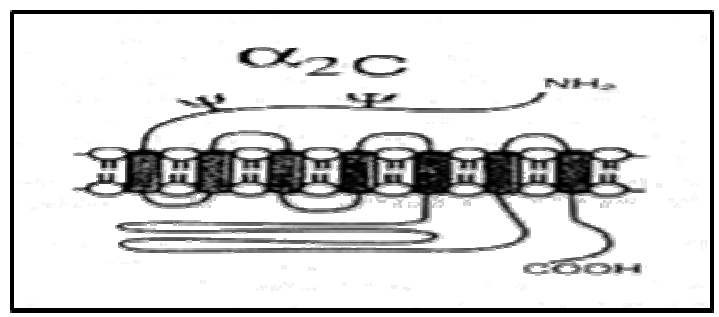

Figura 3 - Receptor alfa-2C 
A clonidina, em baixas doses, tende a ser seletiva aos receptores alfa-2A e promove analgesia e sedação, também, podendo ocasionar bradicardia e diminuição da pressão arterial sistêmica. Em doses elevadas, atua junto aos receptores alfa-1, alfa-2B e alfa-2 C, assim, perdendo sua seletividade, o que reduz a incidência de hipotensão arterial (ALVES et al., 2000).

Os receptores alfa-2 também podem ser classificados de acordo com sua localização cromossômica em alfa-2C2, alfa-2C4 e alfa-2C10, porém o significado clínico desta classificação ainda não foi estabelecido (SCHOLZ; TONNER, 2000).

Os receptores alfa-2 podem ser pré ou pós-sinápticos, exercendo papéis diferentes no organismo, em função da sua localização. Os receptores pré-sinápticos regulam a liberação de noradrenalina através de um mecanismo de retroalimentação negativa, ou seja, quando ativados, inibem a liberação de noradrenalina. Por sua vez, os receptores pós-sinápticos, quando ativados, promovem vasoconstrição (CASEY; GILMAN, 1988; BIRNBAUMER, 1990; CLAPHAM; NEER, 1993; HAYASHI; MAZE, 1993).

Os receptores adrenérgicos alfa-2 são classificados como metabotrópicos, estando funcionalmente ligados à proteína G, que exerce o papel de segundo mensageiro, acoplando-se ao adrenorreceptor alfa-2 e aos seus sistemas efetores. Quando ativados por um agonista, os receptores alfa-2 adrenérgicos inibem a enzima adenilciclase com consequente redução dos 
níveis de AMP cíclico (AMPc) intracelular (LIU et al., 1993; CORREA et al., 1992; CORREA et al., 1992; CORREA et al., 1999).

Sabidamente, uma diminuição no AMPc causa atenuação da ativação das proteínas alvo-reguladoras, dessa forma, impedindo sua fosforilação, que, por sua vez, altera a resposta biológica celular. Outro mecanismo efetor conhecido é o efluxo de potássio através de um canal ativado e posterior hiperpolarização da membrana (BIRNBAUMER, 1990).

A ativação dos receptores alfa-2 adrenérgicos pré-sinápticos bloqueia a atividade de cálcio no terminal nervoso exercendo ação inibitória sobre a exocitose de neurotransmissores, como a noradrenalina (HAYASHI; MAZE, 1993).

A clonidina, protótipo dos agonistas alfa-2, é um agonista parcial alfa-2 adrenérgico seletivo e apresenta uma seletividade de 200:1 $\left(\alpha_{2}: \alpha_{1}\right)$. Esta seletividade é importante quando as ações sobre os receptores alfa-1 se opõem àquelas sobre os receptores alfa-2, como na produção de analgesia pelo “lócus coeruleus”, núcleo noradrenérgico predominante no cérebro, que funciona como o principal modulador do estado de vigília no sistema nervoso central (ALVES et al., 2000).

\subsubsection{Ações farmacológicas da clonidina}

A clonidina, inicialmente, utilizada como descongestionante nasal, demonstrou-se como possuidora de efeito hipotensor, sedativo, analgésico e bradicardizante (HOFFMAN; LEFKOWITS, 1996), o que possibilitou a sua utilização na anestesiologia a partir da década de noventa. 


\subsubsection{Sedação}

A sedação é um dos efeitos mais importantes promovidos pela administração de fármacos alfa-2 agonistas. Primeiramente, vista como efeito indesejável em pacientes que faziam uso de clonidina como hipotensor, mostrou-se benéfica na prática anestésica, pois permite uma menor utilização de outros anestésicos e propicia menor incidência de efeitos colaterais (HAYASHI; MAZE, 1993; BLOOR et al., 1992).

A literatura descreve que a clonidina apresenta efeito sedativo e hipnótico dose-dependente, o qual tem início minutos após a administração do fármaco e alcança um pico de ação com 10 a 15 minutos de utilização do mesmo (KARHUVAARA et al., 1991). Os agonistas alfa-2 produzem sedação quando administrados por via endovenosa sem, no entanto, promover depressão respiratória significativa (HALL et al., 2001). A administração de 3 $\mathrm{mcg} / \mathrm{kg}$, em adultos, não resulta em alteração no $\mathrm{CO} 2$ expirado, frequência respiratória e volume minuto; porém há diminuição da resposta ao $\mathrm{CO} 2(\mathrm{OOI}$ et al., 1991).

Acredita-se que a ativação dos receptores alfa-2 adrenérgicos localizados no "lócus coeruleus" seja a responsável pela sedação (HAYASHI; MAZE, 1993). O "lócus coeruleus" é um pequeno núcleo neuronal localizado bilateralmente na parte superior do tronco cerebral; considerado o maior grupo de células noradrenérgicas do cérebro (ALVES et al., 2000; DYCK et al., 1993). Após a ativação dos receptores alfa-2 adrenérgicos, ocorre supressão da atividade noradrenérgica, com consequente aumento da atividade de neurônios 
inibitórios da via do ácido gama-aminobutírico (GABA) e depressão do sistema nervoso central. O efeito ansiolítico dos agonistas alfa-2 é comparável aos dos benzodiazepínicos (GERTLER et al., 2001), entretanto doses elevadas devem ser evitadas, visto que estas possibilitam a perda da seletividade e a ativação de receptores alfa-1 adrenérgicos os quais estão implicados com a ansiogênese e com a ocorrência de alterações hemodinâmicas significativas.

\subsubsection{Analgesia}

Embora numerosos experimentos, durante as últimas dez décadas, tenham investigado o mecanismo de ação analgésica dos agonistas dos receptores alfa-2 adrenérgicos, este mecanismo ainda não está completamente esclarecido. Diferentes estudos experimentais têm demonstrado que a clonidina melhora a eficácia analgésica de agentes antiinflamatórios e, também, possui efeito antinociceptivo periférico. Ensaios clínicos em voluntários têm evidenciado efeito analgésico após administração sistêmica, pois a sua ação local é limitada (intra-articular, regional intravenosa). A maior utilização da clonidina tem sido como adjuvante a outros analgésicos, como demonstrado em um número de estudos, nos quais, a clonidina foi investigada em associação com anestésico local, opioides e cetamina (TRYBA; GEHLING, 2002).

Estudos realizados em crianças demonstram que a clonidina, nas doses de $0,08 \mathrm{mcg} / \mathrm{kg} / \mathrm{min}$ e $0,12 \mathrm{mcg} / \mathrm{kg} / \mathrm{min}$, associada à ropivacaína $0,008 \%$ para bloqueio peridural produziram o efeito desejado com primeiras doses de 
analgesia complementar 18 e 32h após o início da infusão, em comparação com soluções sem adição de clonidina ou com doses menores (DE NEGRI et al., 2001). O nível de sedação entre os grupos não foi significativamente diferente, mas houve uma tendência a maior sedação nos pacientes que utilizaram a maior dose deste fármaco (DE NEGRI et al., 2001). A adição de clonidina ao anestésico local propicia que menores concentrações destes sejam empregadas, assim, diminuindo os efeitos tóxicos e o bloqueio motor decorrentes dos mesmos (NISHINA et al., 1999). É importante enfatizar que, ao contrário da morfina, a clonidina não tem ascensão rostral no espaço peridural e nem tem a capacidade de cobrir todos os segmentos envolvidos na cirurgia caso o nível de punção seja inadequado ou se o cateter não estiver corretamente posicionado. A clonidina é uma molécula lipofílica, similar ao fentanil e sufentanil, e, consequentemente, os seus efeitos são limitados aos segmentos próximos ao local de infusão (CUCCHIARO; DAGHER, 2003).

Em unidade de terapia intensiva (UTI), o uso de clonidina endovenosa, com finalidade analgésica e sedativa, não tem evidenciado depressão respiratória, tolerância ou dependência química, mesmo com uso prolongado. A clonidina tem sido utilizada como substituta da morfina em pacientes que se tornaram tolerantes aos opioides ou que apresentavam dificuldade de sedação (SMANIA; GARCIA, 2005). 


\subsubsection{Efeitos cardiovasculares}

Os agonistas alfa-2 são fármacos utilizados na prática anestésica objetivando a melhora da qualidade do procedimento anestésico e o controle dos parâmetros hemodinâmicos. Estudos demonstram que a clonidina, quando administrada de maneira profilática, significativamente, reduz a incidência de isquemia miocárdica perioperatória e a mortalidade pós-operatória em pacientes com insuficiência coronariana ou tidos como de risco para doença arterial coronariana submetidos à cirurgia cardíaca e não-cardíaca, dessa forma, apresentando-se como alternativa aos betabloqueadores (WALLACE et al., 2004), fármacos que apresentam como mecanismo de ação principal a inibição competitiva dos efeitos das catecolaminas no local do receptor beta.

Os agonistas alfa-2 diminuem o tônus simpático e aumentam o tônus parassimpático, reduzindo a frequência cardíaca, o metabolismo sistêmico, a contratilidade miocárdica e a resistência vascular sistêmica e levando a uma diminuição do consumo miocárdico de oxigênio (KAHN et al., 1999; WALLACE, 2006).

A ação dos agonistas alfa-2 adrenérgicos sobre o sistema cardiovascular ocorre por mecanismos periféricos e centrais. Sabe-se que, após ativação dos receptores pré-sinápticos localizados nas terminações nervosas periféricas, há inibição da exocitose de noradrenalina com consequente hipotensão e bradicardia (JONGE et al., 1981). A incidência de hipotensão arterial, com redução maior que $20 \%$ dos valores basais, chega a perfazer $30 \%$ dos casos (GERTLER et al., 2001). 
Algumas pesquisas observam que a ativação de receptores póssinápticos, presentes na musculatura lisa dos vasos sanguíneos venosos e arteriais, produz vasoconstrição, o que justifica a ocorrência de hipertensão arterial transitória após a utilização de fármacos agonistas alfa-2 (BONNET, 1997).

Os efeitos dos agonistas alfa-2 na vasculatura coronária em seres humanos ainda não estão bem-estabelecidos. Acredita-se que a estimulação dos receptores alfa-2 produz vasoconstrição das pequenas artérias, efeito este que é contrabalançado pela vasodilatação decorrente da liberação de óxido nítrico e adenosina no endotélio das artérias coronarianas (FLACK et al., 1987). É importante observar que há considerável variação interespécies na distribuição e subtipos dos receptores alfa-2 agonistas (KANH et al.,1999) os quais contribuem para aumentar a estabilidade hemodinâmica perioperatória (KANH et al.,1999; WALLACE, 2006).

No sistema nervoso central, a ativação dos receptores alfa-2 do centro vasomotor diminui o efluxo simpático, reduzindo as catecolaminas circulantes, com potencialização da atividade nervosa parassimpática e consequente redução da pressão arterial (RUFFOLO JR., 1985). O principal local de ação dos agonistas alfa-2 no sistema nervoso central é o núcleo do trato solitário, embora outras estruturas também estejam envolvidas, como o núcleo reticular lateral, o "locus coeruleus" e o núcleo motor dorsal do vago (KUBO; MISU, 1981). 
Os agonistas adrenérgicos alfa-2 impõem um efeito bifásico e dose-dependente na pressão arterial. Quando administrados na dose de 1-3 ng/ml, provocam redução da pressão arterial; e, na dose de $10 \mathrm{ng} / \mathrm{ml}$, levam a um aumento da mesma acima da linha de base. Este efeito dos agonistas alfa2 sobre a pressão arterial é resultante de duas ações alfa-2 distintas: a simpatólise e a vasoconstrição que se contrabalançam para que ocorra o efeito final (TALKE, 2000).

Com o aumento da dose, o efeito simpaticolítico central passa a ser mais pronunciado, sendo que até a mensuração da concentração de catecolaminas plasmáticas pode mostrar-se abaixo do limite de quantificação. Após alguns minutos da administração do fármaco, a pressão sanguínea diminui, e a redução máxima é alcançada entre 10 e 60 minutos (GHIGNONE et al.,1987). Simultaneamente aos efeitos simpaticolíticos, os agonistas alfa-2 circulantes estimulam a musculatura vascular periférica determinando vasoconstrição, ação esta que é responsável pelo aumento imediato e transitório da pressão arterial (TALKE, 2000). Uma elevação persistente da pressão sanguínea ocorre somente com elevada concentração deste fármaco (QUINTIN et al., 1990).

Em doses baixas, a vasoconstrição é observada quando a clonidina é administrada rapidamente, por via intravenosa, causando elevação transitória da sua concentração plasmática com consequente aumento da pressão arterial. Deve-se, portanto, evitar a injeção rápida deste fármaco ou optar por outras vias de administração, como a oral ou a intramuscular, que 
não estão associadas a picos na sua concentração plasmática. Da mesma forma que a frequência cardíaca, os efeitos na pressão sanguínea são dependentes do tônus simpático individual (TALKE, 2000).

Outros receptores parecem estar envolvidos com o mecanismo de ação da clonidina. Dentre eles, destaca-se o receptor imidazólico I1 o qual está presente no sistema nervoso central. Quando ativado, leva à redução da pressão arterial, o que reforça a utilização deste fármaco com anti-hipertensivo (ERNSBERGER et al., 1987).

A clonidina causa diminuição gradual e dose-dependente da frequência cardíaca, que tem início minutos após a sua injeção, alcançando efeito máximo com 15 a 60 minutos. A redução da frequência cardíaca é decorrente da diminuição da ação do sistema nervoso simpático e depende da frequência cardíaca basal de cada indivíduo (KARHUVAARA et al., 1991), sendo reduzida em graus variáveis após a administração dos agonistas alfa-2 adrenérgicos (EISENACH et al., 1996). Esta ação pode ser explicada pela ativação dos receptores alfa-2 pré-sinápticos das terminações nervosas periféricas, com redução da exocitose da noradrenalina e pelo efeito simpaticolítico da clonidina no sistema nervoso central (DE JONGA et al., 1981).

Após a administração da clonidina, observa-se uma redução das descargas pós-ganglionares nos nervos cardíacos e uma estimulação do fluxo parassimpático, com consequente aumento do tono vagal e redução da frequência cardíaca (LANGER et al., 1980). 
Outros mecanismos parecem estar envolvidos na promoção da bradicardia pela clonidina. Quando injetada rapidamente por via intravenosa, a alta concentração plasmática do fármaco estimula receptores alfa-2 da musculatura lisa vascular periférica causando aumento da pressão arterial e desencadeando bradicardia reflexa, a qual poderia ser evitada pela administração lenta deste fármaco (TALKE, 2000).

Os efeitos adversos dos agonistas alfa-2 são representados principalmente por hipotensão arterial acentuada, hipertensão arterial e bradicardia. A hipotensão arterial pode ser revertida pela administração de agonistas alfa1, tais como a efedrina e a fenilefrina, sendo que a resposta vasoconstrictora a esses fármacos pode estar aumentada (NISHIKAWA et al., 1991). A hipertensão, por sua vez, é autolimitada e pode ser prevenida pela injeção lenta dos agonistas alfa-2, quando administrados por via intravenosa (NISHIKAWA et al., 1991).

A bradicardia pode ser contornada pela utilização de atropina, mas, eventualmente, doses elevadas são necessárias (NISHIKAWA; DOHI, 1991). Pesquisas relatam que os melhores candidatos ao uso de clonidina são os pacientes que apresentam aumento basal do tônus simpático (TALKE, 2000).

\subsubsection{Efeitos respiratórios}

Os agonistas alfa-2 adrenérgicos são fármacos seguros do ponto de vista respiratório. Alguns estudos indicam que a clonidina pode induzir 
depressão respiratória leve quando administrada em doses terapêuticas (PENON et al., 1991), embora hipoxemia significativa não tenha sido observada em seres humanos (HAYASHI; MAZE, 1993).

A clonidina, geralmente, é utilizada na anestesia e no tratamento de dor rebelde em associação a diferentes opioides, sem que isto implique em aumento da incidência de depressão respiratória. Sabe-se que os agonistas alfa-2 adrenérgicos não potencializam a depressão respiratória induzida por opioides (GERTLER et al., 2001), sendo esta uma combinação segura.

\subsubsection{Efeitos gastrointestinais}

Os efeitos dos agonistas alfa-2 adrenérgicos no trato digestório são representados principalmente pela ação antissialogoga dos mesmos, traduzida pela queixa de "boca seca". Alguns estudos relatam aumento da presença de náusea, com uma incidência de $11 \%$ em pacientes sedados com dexmedetomidina (DYCK; SHAFER, 2000).

A estimulação dos receptores alfa-2 adrenérgicos, no trato digestório, pode aumentar a absorção de cloreto de sódio e de líquido e inibir a secreção de bicarbonato. Esta ação pode explicar o efeito da clonidina sobre a diarreia em pacientes diabéticos com neuropatia autonômica (ALVES et al., 2000). 


\subsubsection{Efeitos sobre o sistema urinário}

Há evidências de que os agonistas alfa-2 inibem a liberação do hormônio antidiurético, com isso, antagonizam a sua ação no túbulo renal e, assim, contribuem para o aumento da taxa de filtração glomerular (STRANDHOY, 1985). Em várias pesquisas, assinala-se que a clonidina está envolvida com o aumento da liberação do fator natriurético atrial, tendo, como efeito final, uma maior diurese (HAMAYA et al., 1994).

\subsubsection{Efeitos sobre o sistema endócrino}

Os pacientes que recebem agonistas alfa-2 apresentam redução da resposta ao estresse cirúrgico, o que é facilmente percebido pela menor necessidade de utilização de anestésicos e analgésicos no período perioperatório, quando comparados com aqueles pacientes que não receberam este fármaco (AANTAA et al., 1997).

\subsection{FÁRMACOS OPIOIDES}

Os fármacos opioides foram inicialmente conceituados, por Acheson, como medicações com ação semelhante à da morfina, porém com estrutura química diferente (MARTIN, 1983). O termo opioide, atualmente, inclui todas as substâncias naturais, semissintéticas ou sintéticas que reagem com os receptores opioides como agonista ou antagonista (MARTIN, 1983). 
Os opioides são a pedra angular no manejo da dor do câncer e da dor pós-operatória de moderada a elevada intensidade, também administrados, com frequência, para o tratamento da dor crônica não-oncológica.

\subsubsection{Mecanismo de ação dos opioides}

Os opioides têm como mecanismo de ação principal sua interação com receptores específicos, denominados receptores opioides, localizados no sistema nervoso central e na periferia.

Os receptores opioides são do tipo metabotrópico, ou seja, não são canais iônicos. Por este motivo, a transmissão da mensagem química ocorre indiretamente, a partir de reações intracelulares, que podem fosforilar canais iônicos independentes do receptor opioide e que estão situados nas regiões adjacentes da membrana, ou, então, desencadear outros efeitos. Essas reações intracelulares são iniciadas por uma molécula intermediária ancorada ao receptor pela face interna da membrana pós-sináptica, chamada proteína G, a "proteína que liga trifosfato de guanosina (GTP)". Enquanto nãoativada, a proteína $G$ tem três subunidades ( $\alpha, \beta$ e $\gamma$ ) com uma molécula de difosfato de guanosina (GDP) ligada à subunidade $\alpha$. Quando o neurotransmissor ou o neuromodulador mudam a conformação alostérica do receptor, a proteína G libera o seu GDP e o substitui por um GTP retirado do citosol. A incorporação do GTP separa a subunidade $\alpha$ do complexo, e esta "desliza" internamente na membrana até encontrar, nas proximidades, outras

proteínas que realizam diferentes funções. Estas últimas são chamadas 
proteínas efetoras, porque completam o efeito da transmissão sináptica, seja transformando a mensagem química em um potencial pós-sináptico, seja provocando reações químicas diversas no neurônio pós-sináptico que influenciarão de maneira indireta a transmissão (LENT, 2004).

No caso dos neurotransmissores, a proteína efetora ativada pela subunidade a da proteína $G$ é frequentemente um canal iônico. Ocorre então que esse canal se abre desencadeando um potencial pós-sináptico. É isso que se passa nas sinapses autonômicas com as células cardíacas que apresentam receptores colinérgicos muscarínicos: uma vez ligados à acetilcolina, eles ativam proteínas $\mathrm{G}$ cujas subunidades a provocam a abertura de canais de $\mathrm{K}^{+}$, abundantes na membrana das células musculares do coração. $\mathrm{O}$ fluxo de $\mathrm{K}^{+}$, como se sabe, é hiperpolarizante, resultando em um potencial inibitório. Mecanismo semelhante ocorre com os receptores $G A B A_{B}$ : a proteína efetora é também um canal de $\mathrm{K}^{+}$, e o resultado é o aparecimento de um potencial póssináptico inibitório no neurônio pós-sináptico (LENT, 2004).

Após a formação do complexo receptor-ligante, há inibição do segundo mensageiro, alteração do transporte de cálcio na membrana celular e redução da liberação de neurotransmissores em um processo semelhante ao descrito anteriormente (LENT, 2004).

Os opioides ligam-se a receptores serpentínicos acoplados à proteína Gp, assim, inibindo a adenilciclase. A ativação dos receptores $\mu$ aumenta a condutância ao potássio e hiperpolariza os neurônios centrais e aferentes primários. Já a ativação dos receptores $\kappa$ e $\delta$ leva ao fechamento dos 
canais de cálcio dependentes de voltagem, promovendo diminuição da atividade neuronal (OLIVEIRA JR., 2001).

\subsubsection{Receptores opioides}

Há vários anos, o conceito de receptores opioides era estudado, porém, somente em 1971, eles foram identificados. Goldstein e col., na Universidade de Stanford, foram os pioneiros na sua identificação (GOLDSTEIN et al., 1971).

Os receptores opioides estão localizados principalmente no sistema nervoso central, embora, na presença de inflamação, eles possam ser expressos no sistema nervoso periférico, o que justifica a utilização dos opioides de maneira tópica (McQUAY, 1999).

Vários tipos e subtipos de receptores foram propostos, entretanto os mais comumentes citados são: $\mu$, que é dividido em duas subclasses $\mu 1 \mathrm{e}$ $\mu 2 ; \delta$ e $\kappa$. Propõem-se também a existência dos receptores épsilon e sigma os quais não parecem ter papel relevante no mecanismo de analgesia (PASTERNAK; CHILDERS, 1992).

Os receptores opioides consistem de um terminal- $\mathrm{N}$ extracelular, sete hélices transmembranas, três alças intra e extracelulares e um terminal-C intracelular (Figura 4) (DAVIS et al., 2005). Como anteriormente citado, quando o receptor opioide é ativado, ele libera uma porção da proteína G que se difunde pela célula até alcançar seu alvo (enzima ou canal iônico). Os alvos alteram a fosforilação proteica via inibição do AMPc que atua como segundo 
mensageiro com a célula, resultando na ativação de proteínas cinases (potenciação de curto termo) e de genes (potenciação de longo termo) (Figura 5) (CHAHL, 1996). Receptores opioides localizados em terminais pré-sinápticos das fibras A-delta e C, quando ativados por um agonista opioide, irão indiretamente inibir os canais de cálcio voltagem-dependentes, dessa forma, diminuindo os níveis de AMPc e bloqueando a liberação de neurotransmissores da dor presentes em fibras nociceptivas, tais como glutamato, substância P e peptídeo geneticamente relacionado à calcitonina, resultando em analgesia (Figura 6) (McCLEANE; SMITH, 2007).

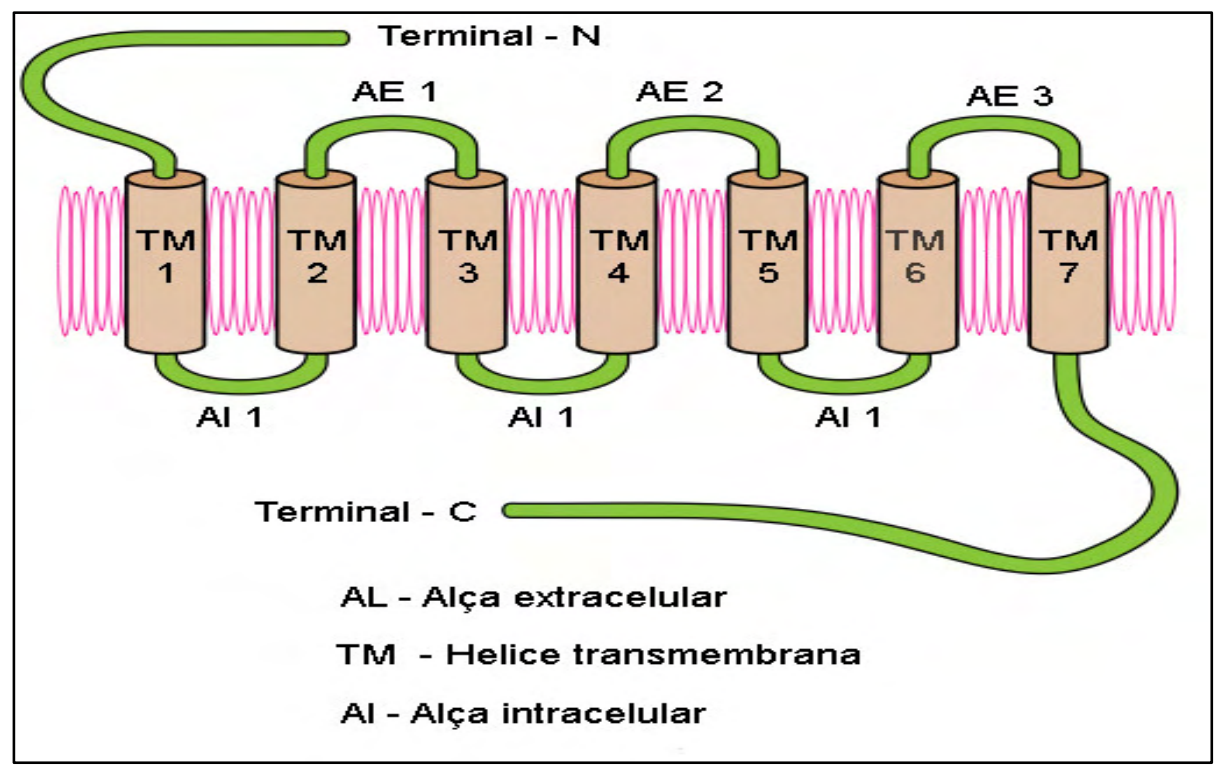

Figura 4 - Receptor opioide - Adaptado da referência Trescot et al. (2008) 


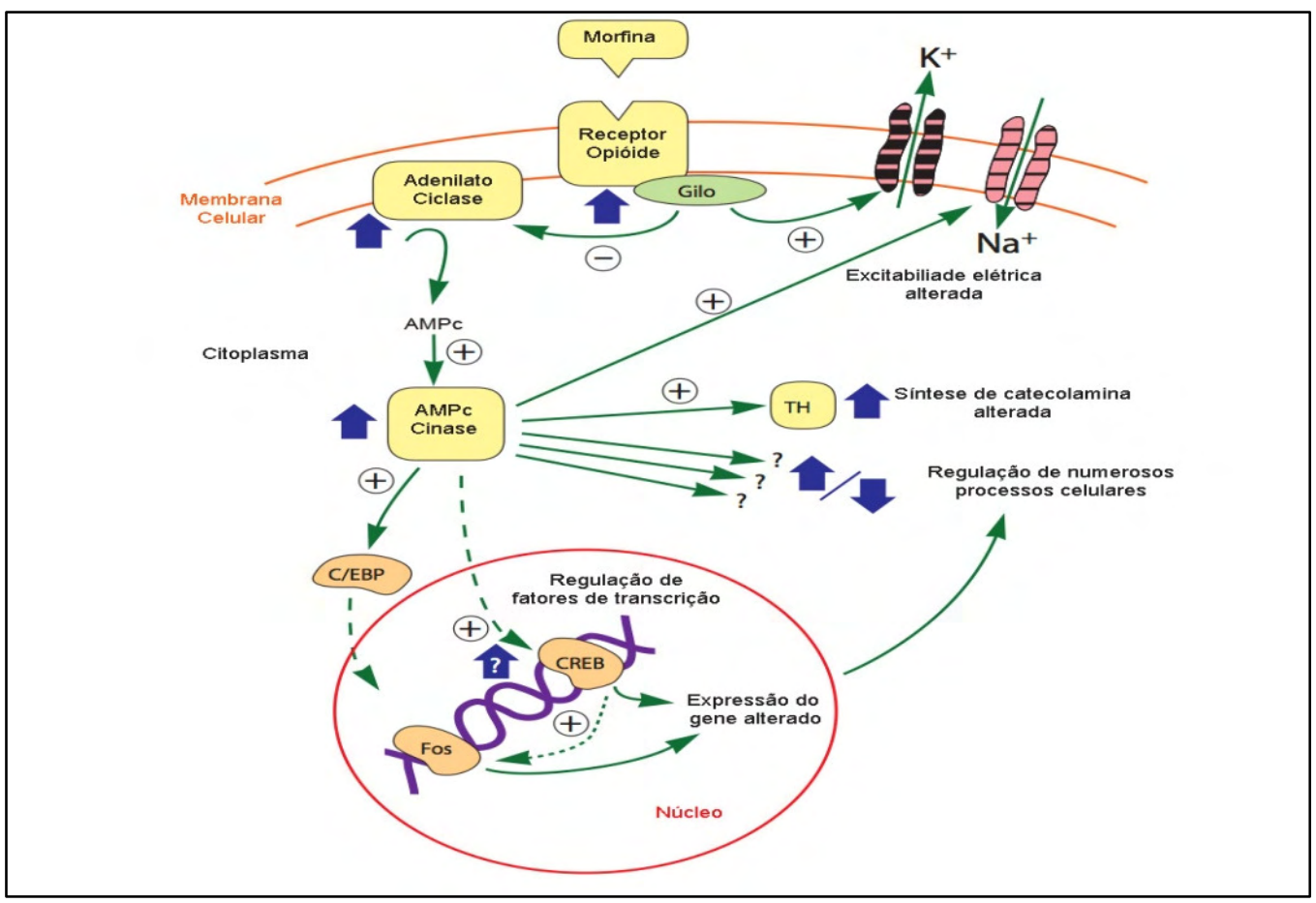

Figura 5 - Ação dos opioides - Adaptado da referência Trescot et al. (2008).

Opioides endógenos e exógenos ativam receptores pré-sinápticos nos neurônios gabaérgicos os quais inibem a liberação de ácido gamaaminobutírico (GABA) na área tegumental ventral (NESTLER, 2001). 


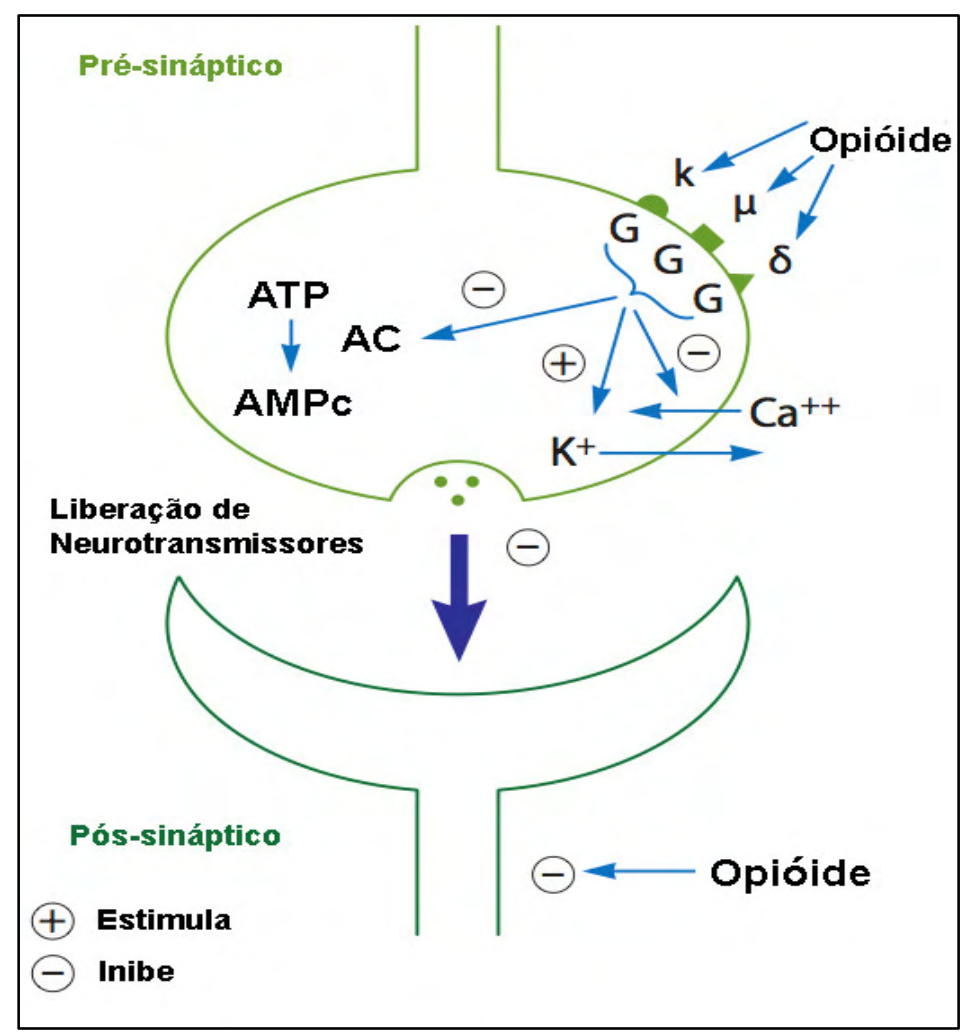

Figura 6 - Localização dos receptores opioides - Adaptado da referência Trescot et al. (2008).

Opioides endógenos e exógenos ativam receptores pré-sinápticos nos neurônios gabaérgicos que inibem a liberação de ácido gamaaminobutírico (GABA) na área tegumental ventral (NESTLER, 2001). A inibição do GABA permite aos neurônios dopaminérgicos atuarem de maneira mais vigorosa. A dopamina extra no núcleo accumbens é intensivamente desejável. A variação dos efeitos dos opioides pode estar relacionada à diferença de afinidade dos mesmos a estes vários receptores.

Os opioides, em graus variáveis, podem antagonizar os receptores $\mathrm{N}$-metil-D-aspartato (NMDA) e ativar os sistemas serotoninérgicos e noradrenérgicos. Sabe-se que a estimulação de receptores NMDA pode 
resultar em dor neuropática e no desenvolvimento de tolerância (MELDRUM, 2003).

É importante lembrar que a analgesia dos opioides é mediada por uma interação complexa entre os receptores $\mu, \delta$ e $\kappa$, sendo que os receptores $\mu$ estão envolvidos predominantemente com a analgesia supraespinhal; e os receptores $\delta$ e $\kappa$, com a analgesia espinhal (PASTERNAK; CHILDERS, 1992).

Os ligantes endógenos são diferentes em suas origens genéticas e expressos em diversas áreas do sistema nervoso central. A $\beta$-endorfina está presente na hipófise anterior, lobo intermediário, em núcleos do hipotálamo basal e medial e nas células do núcleo do trato solitário. As encefalinas são encontradas no sistema nervoso central e periférico, assim como na medula adrenal, no trato digestório, nas lâminas I e II de Redex na medula espinhal, em diversas regiões supraespinhais do sistema nervoso central, em particular, nos corpos celulares do globo pálido, nos núcleos supraópticos e paraventriculares do hipotálamo, na amígdala e no neocórtex. As dinorfinas foram identificadas no intestino, no hipotálamo, na hipófise posterior, no tronco encefálico e na medula espinhal (PASTERNAK, CHILDERS, 1992).

As ligações com o receptor $\mu$ são feitas pela $\beta$-endorfina, metionina-encefalina e dinorfina $A 1-13$. O receptor delta liga-se com $\beta$ endorfina, leucina-encefalina e dinorfina A1-8; o receptor kapa é o alvo principal de ligação das dinorfinas (SIMON, 1991). 


\subsubsection{Classificação dos receptores opioides}

Os receptores opioides atualmente reconhecidos são de quatro tipos, mu, delta, kapa e sigma que diferem entre si nas propriedades farmacológicas, na distribuição no sistema nervoso central e em outros tecidos, na afinidade com os peptídeos opioides e na capacidade de responder a naloxona (Quadro 1).

Quadro 1 - Classificação e efeitos dos receptores opioides

\begin{tabular}{|c|c|c|c|}
\hline Receptor & Efeito & Agonista & Antagonista \\
\hline$\mu(\mathrm{mu})$ & $\begin{array}{l}\text { Analgesia supraespinhal } \\
\text { Depressão ventilatória } \\
\text { Euforia } \\
\text { Dependência e miose }\end{array}$ & $\begin{array}{l}\beta \text { endorfina } \\
\text { Dinorfina A1-13 } \\
\text { Morfina e derivados }\end{array}$ & Naloxona \\
\hline$\delta$ (delta) & $\begin{array}{l}\text { Modulação } \mu \\
\text { Analgesia } \\
\text { Depressão ventilatória }\end{array}$ & $\begin{array}{l}\text { Leu-encefalina } \\
\beta \text { endorfina } \\
\text { Dinorfina A1-8 }\end{array}$ & Naloxona \\
\hline$\kappa$ (kapa) & $\begin{array}{l}\text { Analgesia espinhal } \\
\text { Depressão ventilatória } \\
\text { Sedação e miose }\end{array}$ & $\begin{array}{l}\text { Dinorfina } \\
\text { Morfina } \\
\text { Nalbufina }\end{array}$ & Naloxona \\
\hline Sigma* & $\begin{array}{l}\text { Disforia } \\
\text { Alucinações } \\
\text { Estimulação vasomotora } \\
\text { Midríase }\end{array}$ & $\begin{array}{l}\text { Pentazocina } \\
\text { Fenciclidina }\end{array}$ & \\
\hline
\end{tabular}

Como citado anteriormente, o receptor $\mu$ pode ser dividido em $\mu_{1}$ e $\mu_{2}$. $O$ receptor $\mu_{1}$ tem como principal ação a analgesia e os seus ligantes endógenos são as encefalinas. $O$ receptor $\mu_{2}$ não possui ligantes endógenos e 
de sua ação resulta depressão respiratória, bradicardia, euforia e constipação intestinal (TRESCOT et al., 2008).

Os receptores $\delta$ modulam a atividade do receptor $\mu$. Possuem grande seletividade para encefalinas endógenas e se ligam a fármacos opioides exógenos, o que sugere que os receptores $\mu$ e $\delta$ coexistam em complexos integrados (OLIVEIRA JR., 2001).

Os receptores $\kappa$, quando estimulados, causam analgesia, sedação, disforia e outros efeitos psicomiméticos. A estimulação do receptor $\kappa$ inibe a liberação de vasopressina e promove aumento da diurese. Os ligantes $\kappa$ puro não produzem depressão respiratória (TRESCOT et al., 2008).

\subsubsection{Classificação dos opioides conforme sua ação nos receptores}

De acordo com a sua ação no receptor, os opioides classificam-se em:

- Agonista: morfina, meperidina, fentanil, alfentanil, sufentanil, codeína, metadona e remifentanil;

- Antagonista: naloxona e naltrexona;

- Agonista parcial: buprenorfina;

- Agonista/antagonista: nalbufina, nalorfina.

\subsubsection{Metabolismo dos opioides}

O conhecimento do metabolismo dos opioides é de fundamental importância para a segurança do paciente quando da utilização destes 
fármacos, principalmente em indivíduos idosos e portadores de múltiplas enfermidades.

Metabolismo refere-se ao processo de biotransformação pelo qual fármacos são degradados até serem eliminados do organismo. Embora o metabolismo, em um paciente ou população, implique em uma rápida eliminação do medicamento do organismo, isto pode não ocorrer.

O metabolismo dos opioides resulta na produção de metabólitos ativos e inativos. De fato, metabólitos ativos podem ser mais potentes que o fármaco original. A morfina, o protótipo dos analgésicos opioides, após conjugação com o ácido araquidônico no fígado, é biotransformada em dois distintos metabólitos, a morfina-6-glucuronídeo e a morfina-3-glucuronídeo. A morfina-6-glucuronídeo é mais potente que o fármaco original (McDONOUGH et al., 2006). Portanto, embora a metabolização seja primariamente um processo de eliminação do fármaco do organismo, ela produz elementos intermediários tão ou mais potentes que a substância que o originou.

\subsubsection{Ações farmacológicas dos opioides}

\subsubsection{Analgesia}

O efeito analgésico dos opióides está relacionado à interação destes fármacos com receptores $\mu, \delta$ e $\kappa$ localizados no sistema nervoso central e periférico (INTURRISI, 2002). Os principais locais de ação destes fármacos são os aferentes primários, os neurônios do trato espinotalâmico, os interneurônios, a região intraventricular, a substância cinzenta periaquedutal, o 
núcleo "magno da rafe" e o "lócus ceruleus" (ALMEIDA et al., 2001). Em verdade, acredita-se que os opióides atuem como analgésicos em múltiplos sítios medulares e encefálicos, inibindo diferentes reflexos nociceptivos, os quais estão exemplificados a seguir:

- Aferentes primários - ocorre inibição da liberação de substâncias algogênicas na periferia;

- Neurônios eferentes do trato espinotalâmico e interneurônios - há inibição da propagação do estímulo doloroso, através da atuação dos opióides na região pós-sináptica;

- Região intraventricular, substância cinzenta periaquedutal, núcleo "magno da rafe" e "lócus ceruleus" - observa-se que após estimulação química ou elétrica destas estruturas, a administração de morfina nestes sítios produz analgesia reversível pela naloxona (ALMEIDA et al., 2001).

Tegeder et al., 2003 sugerem que os opióides possuem um mecanismo periférico de analgesia (TEGEDER et al., 2003), o que pode explicar a eficácia desta classe de medicamento em pacientes submetidos a cirurgia ortopédica quando da sua administração por via intra-articular (HRISTENSEN et al., 1996; REUBEN et al., 1998; HANNA et al., 2005; BINNING et al., 2003).

A analgesia periférica dos opióides é clinicamente importante, especialmente nos pacientes com artrite ou outras condições inflamatórias. A utilização periférica de opióides apresenta vantagens quando comparada a 
aplicação sistêmica, já que está associada à ausência de tolerância à terapia opióide e redução dos efeitos adversos (STEIN et al., 1996). Em resumo, a presença de receptores opióides na periferia tem justificado a utilização intraarticular e tópica destes fármacos.

\subsubsection{Euforia e alterações do humor}

Os receptores do tipo $\mu$ são os responsáveis pelo surgimento de euforia e alteração do humor envolvendo neurônios dopaminérgicos do tegumento ventral que se projeta para o núcleo acumbens (ALMEIDA et al., 2001).

\subsubsection{Depressão respiratória}

A relação entre opioide e respiração não é simples. Quando utilizado de maneira inapropriada, os opioides podem induzir depressão respiratória a qual é dependente da sua farmacologia, da freqüência de uso, da via de administração e das características e enfermidades apresentadas pelos pacientes. Baixas doses de opioides podem melhorar a dispneia, embora 0 mecanismo de ação preciso seja desconhecido (DAVIS; CAROL, 1997).

A depressão respiratória é um dos efeitos mais temidos durante o uso dos opioides (OERTEL et al., 2009), entretanto é importante enfatizar que ela é mais comum em extremos de idade e quando há administração de altas doses deste fármaco. A incidência de depressão respiratória é extremamente 
pequena e o uso de opioides em infusão contínua está associado a uma redução da mesma.

Pacientes que fazem uso de opioide apresentam alterações em diferentes aspectos da respiração: frequência, regularidade, volume minuto e trocas gasosas.

O mecanismo envolvido com o surgimento de depressão respiratória pelo uso de opioides é a estimulação de receptores do tipo $\mu$, $\delta$ e $\kappa$ e, em especial, o subtipo $\mu_{2}$. Esta estimulação resulta em inibição dos centros respiratórios no tronco cerebral e redução da resposta dos mesmos ao aumento de dióxido de carbono (McQUEEN, 1983). Acredita-se ainda que ocorra depressão dos centros pontinos e bulbares com redução da frequência respiratória e da responsividade destes aos estímulos elétricos.

É importante enfatizar que a resposta dos quimiorreceptores à hipóxia é preservada, o que implica na necessidade de maior cuidado quando da administração de oxigênio aos pacientes usuários crônicos de opioides, pois isso poderia levar ao surgimento de apneia em um mecanismo semelhante àquele observado em pacientes portadores de doença pulmonar obstrutiva crônica.

\subsubsection{Sedação}

A sedação, na prática clínica, é produzida por fármacos que atuam diminuindo a atividade, a ansiedade e a agitação do paciente, e podem levar à amnésia de eventos dolorosos ou não. No entanto, tais medicamentos, 
em geral, não reduzem a dor (GUINSBURG, 1999), pelo contrário, podem potencializá-la. O conhecimento deste fato estimulou a utilização dos opioides, como a morfina, como sedativos (STOELTING; HILLER, 2006).

Os analgésicos opioides apresentam propriedades farmacológicas semelhantes que incluem analgesia, sedação, inconsciência, supressão da resposta vegetativa e endócrina ao estresse. A sedação, sonolência e inconsciência dependem da dose, estado físico do paciente, associação com outros fármacos depressores do sistema nervoso central e da intensidade dos estímulos nociceptivos (GOZZANI, 1994). Em geral, a sedação, após uso de opioides, é vista como um problema, comumente, no início da terapia.

\subsubsection{Efeitos cardiovasculares}

A estabilidade cardiovascular é bem preservada com o uso de opioides se observando pequena queda da pressão arterial e da resistência vascular periférica em pacientes hipovolêmicos.

Sabidamente, os opioides produzem depressão miocárdica mínima, não interferindo na resposta do coração às catecolaminas, preservando a autorregulação cardíaca, renal e cerebral (GOZZANI, 1994).

Trabalhos desenvolvidos com fentanil ressaltam que este, mesmo quando administrado em doses elevadas, não está associado à presença de alterações significativas nos parâmetros hemodinâmicos (STANLEY 1978; HAMM et al., 1983). Como parte de uma técnica anestésica para procedimento cirúrgico, fentanil em dose analgésica $(2-10 \mathrm{mcg} / \mathrm{kg}$ ) ou anestésica (30 a 100 
$\mathrm{mcg} / \mathrm{kg}$ ), raramente, causa redução na pressão sanguínea arterial, mesmo em pacientes com comprometimento da função ventricular (WYANDS et al., 1983).

Fentanil pode causar bradicardia secundária à estimulação do núcleo vagal central na medula, mas, com a utilização de baixas doses, isto raramente ocorre. A atropina, usualmente, é efetiva no tratamento da bradicardia induzida por opioides. Hipotensão secundária à dilatação venosa e arterial é rara, visto que o fentanil não desencadeia liberação de histamina (ROSOW et al., 1980).

\subsubsection{Convulsões}

A literatura relata a presença de crise convulsiva em modelos animais, comumente observada após administração de altas doses de opioides. Acredita-se que o mecanismo de ação envolvido seja o aumento da excitabilidade de células piramidais no hipocampo, provavelmente pela inibição da liberação de ácido gama-aminobutírico em interneurônios localizados neste local.

\subsubsection{Náusea e vômito}

Náusea e vômito são considerados como mecanismos reflexos de defesa do organismo contra a ingestão de toxinas. Existem inúmeras causas orgânicas conhecidas; dentre elas, destaca-se a utilização de alguns fármacos, como quimioterápicos e medicações opioides. Acredita-se que estas substâncias estimulem as vias aferentes serotoninérgicas relacionadas ao 
nervo vago que se conectam com a zona de gatilho quimiorreceptora localizada na base do quarto ventrículo no cérebro (SPILLER, 2001).

A náusea e o vômito decorrentes da utilização de opioides ocorrem por estimulação direta de receptores específicos localizados na área postrema no bulbo.

\subsubsection{Retenção urinária}

A retenção urinária é comum no período pós-operatório. Comorbidades, tipo de cirurgia e anestesia influenciam o seu desenvolvimento. Trabalhos descrevem que a sua etiologia é multifatorial e que a identificação dos pacientes de risco é fundamental para a sua prevenção (BALDINI et al., 2009).

Opioides sistêmicos administrados por via parenteral têm um efeito direto na função da bexiga através de sua ação em receptores da medula espinhal (BROMAGE et al., 1982; COMBRISSON et al., 1993; LIU et al.,1995). Este efeito é revertido pela naloxona administrada pela via subaracnoidea. Opioides sistêmicos causam retenção urinária pela inibição da liberação de acetilcolina dos neurônios parassimpáticos sacrais que controlam a contratilidade detrussora da bexiga (PETROS et al., 1992).

Autores indicam que os opioides são fármacos que propiciam aumento do tônus e amplitude das contrações do ureter, aumento do tônus do esfíncter externo e do volume vesical, além de inibir o reflexo da micção (ALMEIDA et al., 2001). 


\subsubsection{Prurido}

O prurido é um dos efeitos adversos mais frequentemente associado ao uso de opioides, principalmente quando estes são administrados no neuroeixo. Apesar do prurido estar associado à baixa morbidade, pode proporcionar desconforto intenso ao paciente e prolongar o seu internamento (BROMAGE et al., 1982; CHANEY, 1995).

O mecanismo responsável pelo desenvolvimento do prurido não está plenamente esclarecido. Pesquisas em animais sugerem a existência de um "centro do prurido" localizado inferiormente na medula, com envolvimento do núcleo do trigêmeo neste mecanismo (HU et al., 1981).

Outras teorias aventadas para o aparecimento do prurido se baseiam na liberação de histamina, taquicininas e interleucinas, substâncias que não causam prurido por si só, mas possuem atividade pró-inflamatória que pode sensibilizar as terminações nervosas e resultar em prurido. Acredita-se ainda que a 5-hidroxitriptamina (serotonina) possa ser uma das substâncias reguladoras do prurido por ação direta em seus receptores, mecanismo observado em pacientes com colestase (SNYDER 1977).

\subsubsection{Tolerância e dependência}

Tolerância é definida como a necessidade de aumentar gradativamente a dose de um medicamento para se obter o mesmo efeito inicial. Embora a tolerância seja comum em estudos experimentais, a mesma não é um problema de relevância clínica nos pacientes com exposição aguda 
aos opioides (McQUAY, 1999). Estudos têm demonstrado que antagonistas dos receptores NMDA minimizam o aparecimento de tolerância aos fármacos opioides, por conseguinte, devendo ser utilizados, quando necessários, em associação aos mesmos (ALLEN; DYKSTRA, 2000).

Dependência física, por sua vez, é um fenômeno descrito quando da utilização de fármacos opioides e de não-opioides. Caracteriza-se pelo aparecimento de síndrome de abstinência após a interrupção abrupta da administração do fármaco ou com a administração de antagonistas do mesmo. Em função da possibilidade de desenvolvimento de síndrome de abstinência, recomenda-se a suspensão dos opioides de maneira gradual (ALMEIDA et al., 2001).

A dependência psicológica, ou vício, caracteriza-se pelo uso dos opioides com o intuito de experimentar o seu efeito euforizante, evidenciada, com mais frequência, em pacientes com história prévia de fármacodependência (PORTENOY, 1996).

\subsubsection{Constipação intestinal}

A constipação intestinal é um dos efeitos adversos mais comuns ao uso de opioides, acometendo quase $100 \%$ dos pacientes usuários destes fármacos. Ela é caracterizada pela diminuição da frequência das evacuações, com intervalos maiores que 48 horas, estando associada a um aumento da absorção de água das fezes, com consequente endurecimento das mesmas (FALLON; O’NEILL, 1997). É importante lembrar que o trânsito normal pelo 
cólon gira em torno de 36 horas; e que um período superior a 72 horas, seria compatível com o diagnóstico de constipação intestinal.

Apenas a redução da frequência do número de evacuações não estabelece o diagnóstico de constipação intestinal, pois muitos seres humanos normais defecam uma vez a cada dois ou três dias, sendo este ritmo considerado fisiológico para os mesmos, desde que não haja desconforto significativo.

A ocorrência de evacuação depende de uma série de fatores (MORAIS; TAHAN, 2009) representados principalmente pela distensão do reto pelas fezes, com posterior contração reflexa de sua musculatura e desejo de defecar. Sabe-se que, antes de ser alcançada a pressão que relaxa o esfíncter anal externo, a defecação voluntária pode ser iniciada pelo relaxamento voluntário do esfíncter externo e pela contração dos músculos abdominais auxiliando, assim, o esvaziamento reflexo do reto distendido. A defecação é um reflexo medular que pode ser voluntariamente inibido ao se manter o esfíncter externo contraído, ou facilitado pelo relaxamento do esfíncter e pela contração dos músculos abdominais.

No período perioperatório, a etiologia da constipação é multifatorial e inclui a resposta ao estresse cirúrgico e uma resposta inflamatória aguda associada com a manipulação do intestino (KEHLET, 2001). Opioides endógenos secretados no trato gastrointestinal, em resposta ao estresse cirúrgico, e a administração de opioides exógenos, com o intuito de propiciar analgesia, podem estimular receptores periféricos opioides presentes 
no trato gastrointestinal e causar constipação (HOLZER, 2004; KURZ; SESSLER, 2003).

Os receptores opioides presentes no trato gastrointestinal são do tipo mu, $\delta$ e kappa os quais, quando ativados, inibem a liberação de neurotransmissores excitatórios e estimulam a liberação de neurotransmissores inibitórios de neurônios motores, com isso, resultando em motilidade nãopropulsiva.

Os opioides causam constipação porque mantêm ou aumentam o tônus da musculatura lisa intestinal, pelo fato de suprimir o peristaltismo e por aumentar o tônus esfincteriano na válvula ileocecal e no esfíncter anal, além de reduzir a sensibilidade à distensão retal (FALLON; O'NEILL, 1997).

É importante lembrar que o efeito obstipante dos opioides é dosedependente e se inicia 5 a 25 minutos após a sua administração (ALMEIDA et al., 2001).

\subsubsection{Hiperalgesia induzida por opioides}

As preocupações mais comuns em relação ao uso de opioides são representadas principalmente pela presença de seus efeitos adversos e pela possibilidade de desenvolvimento de dependência física e adição. Entretanto, pesquisas mais recentes têm demonstrado que os opioides também podem estar relacionados à hiperalgesia induzida por opioides (HIO). 
Desde 1880, estudiosos já observavam que a dor é um dos componentes da síndrome de abstinência, sendo mais frequentemente localizada nas articulações, ossos e músculos (HIMMELSBACH, 1941). Embora estes dados tenham sido de caráter puramente observacional, eles estimularam questionamentos acerca da sua etiologia que seria justificada pela presença de alterações no sistema neuronal modulatório da dor, como consequência do uso de opioides (FIST et al., 2004).

Durante as últimas décadas, vários estudiosos interrogaram se a hiperalgesia induzida por opioides era uma consequência da suspensão ou do uso crônico de opioides. Entretanto, somente na década de setenta, estudos experimentais foram desenvolvidos com o intuito de compreender mais profundamente este tema. Estes estudos sugeriram que a utilização de opioides poderia paradoxalmente aumentar a sensibilidade a dor e agravar a dor preexistente.

A hiperalgesia induzida por opioides é definida como a sensibilização nociceptiva causada por exposição a opioides. Trata-se de uma entidade caracterizada pela resposta paradoxal a estes fármacos, pois se apresenta como uma maior sensibilização à dor em pacientes usuários de opioides para o tratamento de um quadro álgico de qualquer etiologia (MAO, 2002; FINE, 2004).

Exemplos práticos de hiperalgesia induzida por opioides são vistos diariamente por profissionais que atuam na área de dor e se traduzem através da presença de dor excessiva em pacientes usuários crônicos de 
opioides ou a pacientes submetidos a procedimentos anestésicos nos quais foram utilizados opioides em infusão contínua ou de maneira intermitente, em doses variáveis (ANGST; CLARK, 2006).

Os possíveis mecanismos envolvidos com a hiperalgesia induzida por opióides ocorrem em nível central e periférico e são representados principalmente por:

- $\quad$ sensibilização de neurônios aferentes primários;

- aumento da liberação e diminuição da recaptação de neurotransmissores excitatórios;

- sensibilização dos neurônios de segunda ordem pelos neurotransmissores excitatórios;

- modificações na medula ventromedial rostral que pode aumentar a facilitação descendente (ANGST \& CLARK, 2006).

\subsection{SUFENTANIL}

O sufentanil é um derivado da fenipiperidina desenvolvido em 1974, agonista de receptores opioides, utilizado preferencialmente na prática anestesiológica, na analgesia e na sedação de pacientes internados em UTI.

O sufentanil é um opioide que pode ser utilizado em procedimentos anestésicos e analgésicos, por via parenteral, sob a forma de bolus ou em infusão contínua. Outras vias, como as espinhais, também podem 
ser utilizadas. Em concentrações plasmáticas adequadas, proporcionam analgesia e controle de reflexos autonômicos.

O sufentanil é um opioide sintético, análogo do fentanil, com potência 5 a 10 vezes maior a este que decorre de sua maior afinidade aos receptores opioides. Apesar de extremamente potente, o sufentanil é considerado um fármaco seguro, pois a sua dose letal chega a ser 25.000 vezes maior que a dose terapêutica (OLIVEIRA JR. et al., 2001).

Trata-se de um opioide de elevada lipossolubilidade, capaz de produzir potente analgesia visceral, particularmente pelo seu efeito junto ao receptor $\mu$. Sua ação analgésica é de curta duração, em torno de quatro horas, o que o torna adequado para uso no período perioperatório (HAMILTON; COHEN, 1995). A solubilidade lipídica (coeficiente octanol/água) do sufentanil é de 1778; enquanto que a da morfina é de 1,4 e a do fentanil é de 813 . A maior solubilidade lipídica deste fármaco, quando comparada a dos outros opioides, permite que o mesmo se mobilize com facilidade através das membranas lipídicas. Como consequência, observa-se um rápido início de ação após injeção venosa (BERNARDS et al., 2003). A solubilidade lipídica desempenha um papel importante na eliminação dos fármacos do organismo. Medicações com alto grau de lipossolubilidade terão meia-vida de eliminação maiores quando comparadas com aqueles com menor solubilidade (CORSSEN et al., 1988; PRYS-ROBERTS; HUG, 1984).

É interessante observar que, apesar de o sufentanil ser mais lipossolúvel que o fentanil, seu volume de distribuição é menor. Esse fenômeno 
ocorre porque o sufentanil liga-se mais fortemente às proteínas plasmáticas, especialmente à $\alpha_{1}$-glicoproteína ácida, dessa forma, permitindo que uma quantidade menor do fármaco fique disponível para ser distribuída, mas que é dependente dos níveis séricos desta proteína (STOELTING, 1997). A percentagem de ligação proteica (albumina e $\alpha_{1}$-glicoproteína ácida) em pH 7,4 do sufentanil é de 93, superior à da morfina, que é de trinta; e a do fentanil, que é de 84. O sufentanil, assim como o fentanil, liga-se principalmente à $\alpha_{1}$ glicoproteína ácida, por sua vez, a morfina se liga principalmente à albumina (STOELTING, 1987). O sufentanil, portanto, possui um alto grau de ligação proteica, o que the permite que uma menor quantidade do mesmo esteja disponível na forma livre, estado no qual há penetração no sistema nervoso central e produção do seu efeito.

A percentagem do sufentanil não-ionizado (em pH 7,4) é de 20, o que contribui para a diminuição da sua habilidade em atravessar membranas, pois moléculas carregadas são repelidas por cargas iguais ou atraídas por cargas opostas (GOZZANI, 1994).

O início de ação é mais rápido e as incidências de taquicardia e hipertensão arterial, em resposta a estímulos nociceptivos, são menores com o sufentanil que com o fentanil (FLACKE et al., 1985).

O sufentanil é mais rapidamente eliminado do organismo e produz menor efeito cumulativo quando comparado ao fentanil. Esta diferença tem relevância clínica ao se planejar a utilização de opioides em infusão contínua para analgesia ou em procedimentos cirúrgicos de longa duração (KAY; 
ROLLY, 1977). Sua meia-vida equivale à aproximadamente metade da meiavida do fentanil (BAILEY; STANLEY, 1986). Sua meia-vida contexto-sensitiva após quatro horas de infusão é de 30min. apresentando meia-vida de eliminação de 2,2 a 4,6 horas e equilíbrio entre o plasma e o encéfalo de 6,2 minutos (STOELTING; HILLER, 2006). Esta meia-vida de eliminação plasmática do sufentanil ocupa posição intermediária entre o fentanil e o alfentanil (BOVILL et al., 1984).

O sufentanil é um fármaco que sofre metabolização hepática e extra-hepática, sendo que as principais vias metabólicas do mesmo são a Odesmetilação e a N-desalquilação. Os metabólitos são excretados pela urina e pela bile, e de 1 a $2 \%$ são encontrados inalterados na urina.

\subsubsection{O sufentanil e as síndromes coronarianas}

O sufentanil é capaz de controlar as respostas excitatórias cardiovasculares à laringoscopia e à intubação traqueal. Na verdade, observase que hipotensão arterial e redução da resistência vascular sistêmica com o sufentanil têm sido relatadas por alguns autores (GHONEIM et al., 1984). 


\section{JUSTIFICATIVA}

A literatura nacional e internacional sobre anestesia no laboratório de hemodinâmica é escassa, principalmente, no que diz respeito à existência de trabalhos com controle metodológico adequado envolvendo os fármacos a serem utilizados e suas possíveis associações. Esta pesquisa poderá contribuir para aumentar o conhecimento nesta área e melhorar o atendimento deste grupo de pacientes, desse modo, munindo o anestesiologista com mais uma opção de fármaco a ser utilizado. 


\section{OBJETIVOS}

\subsection{OBJETIVO PRIMÁRIO}

Avaliar a eficácia do sufentanil e da clonidina como medicação sedativa em pacientes submetidos a procedimento de cateterismo cardíaco, para tanto, comparando os seus efeitos sobre os parâmetros hemodinâmicos apresentados durante o exame.

\subsection{OBJETIVOS SECUNDÁRIOS}

a. Avaliar a qualidade da sedação obtida após a administração do sufentanil e da clonidina.

b. Avaliar o impacto destes fármacos sobre os parâmetros respiratórios (frequência respiratória e SpO2).

c. Observar a presença de efeitos colaterais.

d. Verificar a necessidade de utilização de fármacos complementares.

e. Avaliar a satisfação do paciente com o procedimento anestésico.

f. Avaliar a satisfação do hemodinamicista com o procedimento anestésico. 


\section{PACIENTES E MÉTODOS}

Foram estudados 60 pacientes, de ambos os sexos, com idade compreendida entre 18 e 80 anos, estado físico ASA III, submetidos a cateterismo cardíaco sob sedação. O desenho do estudo foi prospectivo, aleatório e duplo-encoberto, bem como aprovado previamente pelo Comitê de Ética em Pesquisa Prof. Dr. Celso Figueirôa.

Após a assinatura do termo de consentimento livre e esclarecido, os pacientes foram distribuídos de forma aleatória em dois grupos de estudo, com trinta participantes cada, os quais receberam sufentanil $0,1 \mathrm{mcg} / \mathrm{kg}(\mathrm{n}=30)$ ou clonidina $0,5 \mathrm{mcg} / \mathrm{kg} \quad(\mathrm{n}=30)$ por via endovenosa. A cada doente foi administrado, de modo encoberto, o sufentanil ou a clonidina, de acordo com o grupo em que foram alocados. Foi realizado monitoramento durante o período em que o paciente esteve internado no serviço de hemodinâmica, em intervalos de cinco minutos, através da aplicação da escala de Ramsay, da verificação dos parâmetros hemodinâmicos (pressão arterial e frequência cardíaca), da necessidade de utilização de outras medicações sedativas e da presença de complicações e/ou efeitos adversos.

Os critérios de inclusão foram os que se seguem: pacientes submetidos a cateterismo cardíaco, de maneira eletiva, em função de teste de esforço ou cintilografia miocárdica positivo para isquemia. Não participaram do estudo ou foram excluídos os indivíduos com idade inferior 
a 18 e superior a 80 anos, pacientes grávidas ou em período de aleitamento, indicação de dessensibilização aos contrastes utilizados na realização do exame, intolerância ou alergia aos fármacos estudados no protocolo, alteração cognitiva, farmacodependência, uso crônico de opioides ou benzodiazepínicos, obesidade mórbida, história de apneia do sono, portadores de via aérea difícil e hipotensão (caracterizada por pressão arterial inferior a $100 \times 60 \mathrm{mmHg}$ ).

Os fármacos do estudo foram aqueles empregados para a condução da sedação necessária à realização do exame de cateterismo cardíaco. Após serem admitidos no serviço de hemodinâmica, os sujeitos foram entrevistados e selecionados segundo os critérios de inclusão e exclusão. Posteriormente, os mesmos foram encaminhados à sala de procedimento e, após acesso venoso convencional, foram monitorados com cardioscópio na derivação DII, com oxímetro de pulso e com a tomada de medidas de pressão arterial não-invasiva/invasiva a cada cinco minutos. 0 nível de sedação foi avaliado através da utilização da escala de Ramsay (Quadro 2).

Após o início da administração de oxigênio a 100\% sob cateter nasal 2L/min, a sedação foi realizada com sufentanil $(0,1 \mathrm{mcg} / \mathrm{kg})$ ou clonidina $(0,5 \mathrm{mcg} / \mathrm{kg})$ conforme randomização. Quando necessário, foi utilizado midazolam na dose de $0,02 \mathrm{mg} / \mathrm{kg}$ para complementação da sedação. O parâmetro para a administração deste benzodiazepínico foi a classificação pela escala de Ramsay, igual a 1 e/ou níveis pressóricos 
elevados, caracterizados pela presença de pressão arterial superior a $180 \mathrm{X}$ $110 \mathrm{mmHg}$. O momento da administração de midazolam foi registrado. Nenhuma medicação pré-anestésica foi oferecida.

Quadro 2 - Escala de Ramsay (SCHULTE-TAMBUREN et al., 1999).

\begin{tabular}{|l}
\hline ESCALA DE RAMSAY \\
\hline 1. Paciente ansioso, agitado, impaciente ou ambos \\
\hline 2. Paciente cooperativo, orientado e tranquilo \\
\hline 3. Paciente que responde somente a comando verbal \\
glabela ou a um estímulo sonoro auditivo \\
\hline 5. Paciente que demonstra uma resposta débil a um toque leve na \\
glabela ou a um estímulo sonoro auditivo \\
6. Paciente que não responde aos estímulos dos itens 4 ou 5 \\
\end{tabular}

Após o procedimento, o paciente foi encaminhado à sala de recuperação anestésica, local onde foram observados e registrados queixa de dor, nível de sedação, presença de náusea ou vômito, sangramento, alteração do comportamento, tremores, alteração dos níveis pressóricos, arritmia, depressão respiratória, reações alérgicas, dentre outros que ocasionalmente fossem detectados. 
Os pacientes que necessitassem utilizar naloxona ou nalbufina, ou que apresentassem reação alérgica, foram excluídos do trabalho.

\subsection{GRUPOS ESTUDADOS E CÁLCULO AMOSTRAL}

Os pacientes foram distribuídos aleatoriamente em dois grupos de 30 pacientes, respectivamente diferenciados pelos fármacos administrados no momento de início do exame.

Grupo S - O paciente recebeu $1 \mathrm{~mL}$ para cada $10 \mathrm{~kg}$ de peso da solução contendo cloreto de sódio $0,9 \%$ e sufentanil, na concentração de $1 \mathrm{mcg} / \mathrm{ml}$. A velocidade de infusão foi 3 minutos.

Grupo C - O paciente recebeu $1 \mathrm{~mL}$ para cada $10 \mathrm{~kg}$ de peso da solução contendo cloreto de sódio $0,9 \%$ e clonidina, na concentração de $5 \mathrm{mcg} / \mathrm{ml}$. A velocidade de infusão foi 3 minutos.

Nascimento et al. (2006) publicaram, em 2006, um trabalho sobre sedação em pacientes submetidos a cateterismo cardíaco utilizando clonidina. Baseando-se nessa pesquisa, foi idealizada a metodologia empregada no presente estudo. Portanto, para o cálculo do tamanho amostral foram usados os seguintes parâmetros: erro $\alpha$ de $5 \%$, poder de $80 \%$, tendo como diferença de média entre os grupos de $16 \mathrm{mmHg}$ na pressão arterial sistólica, um desvio 
padrão de $20,22 \mathrm{mmHg}$ no grupo controle e de $22,58 \mathrm{mmHg}$ no grupo teste. Com estes parâmetros se chegou a um tamanho amostral mínimo de 30 pacientes para cada grupo.

\section{$4.2 \quad$ ATRIBUTOS ESTUDADOS}

\subsubsection{Dados demográficos}

- Idade, definido em anos completos.

- Peso, medido em quilogramas.

- Altura, medida em metros.

- Sexo, feminino ou masculino.

- Índice de massa corporal medido em quilogramas por metro quadrado.

\subsubsection{Parâmetros estudados}

- Nível de sedação, avaliado de acordo com a escala de Ramsay.

- Frequência cardíaca.

- Pressão arterial sistólica em mmHg.

- Pressão arterial diastólica em mmHg.

- Necessidade de sedação complementar com midazolam - utilizado quando o paciente permanecia com nível de sedação insatisfatório (escore de Ramsay de 1) ou com níveis pressóricos elevados, caracterizados pela presença de pressão arterial superior a 180 X 110 mmHg 10 minutos após o início do procedimento. 
- Necessidade de uso complementar de metoprolol como anti-hipertensivo - utilizado quando o paciente mantinha-se com níveis pressóricos elevados (PA $\geq 180 \times 110 \mathrm{mmHg}) 15$ minutos após a sedação inicial.

- Necessidade de uso de vasodilatadores intracoronários como nitrato de isosorbitol (Monocordil ${ }^{\mathrm{R}}$ ), uma vez que a sua utilização pelo hemodinamicista poderia alterar a interpretação dos dados hemodinâmicos do paciente.

- Necessidade de uso de atropina para tratamento de bradicardia na dose de $20 \mathrm{mcg} / \mathrm{kg}$. Foi considerada bradicardia a presença de frequência cardíaca menor que 50 batimentos por minutos (QUINTIN; GHIGNONE, 2000).

- Incidência da queixa de angina durante o procedimento.

- Saturação periférica da oxi-hemoglobina.

\subsection{DESCRIÇÃO DO PROCEDIMENTO}

\subsubsection{Primeiro período}

- Jejum de 8 horas.

- Instalação de monitorização eletrocardiográfica com seis derivações axiais (DI, DII, DIII, aVL, aVF e aVR).

- Instalação de oximetria de pulso, com colocação de sensor digital em quirodáctilo da mão esquerda. 
- Instalação de venóclise, com cateter 22G introduzido na veia cefálica do membro superior esquerdo.

- Planejamento de reposição de fluidos com a administração venosa contínua da solução de Ringer lactato, na dose de $10 \mathrm{ml} / \mathrm{kg} / \mathrm{h}$ na primeira hora, seguido de $5 \mathrm{ml} / \mathrm{kg} / \mathrm{h}$ no período subsequente, com o objetivo de manter a hidratação do paciente e a reposição do jejum.

- Instalação de oxigênio suplementar por meio de cateter nasal inicialmente $2 \mathrm{~L} / \mathrm{min}$, valor que poderia ser alterado de acordo com a oximetria de pulso.

- Punção da artéria femoral com cateter 6 french ou radial e braquial com 5 french para medida contínua da pressão arterial invasiva.

- Nenhum dos pacientes recebeu medicação pré-anestésica.

\subsubsection{Segundo período}

- Início da sedação com o fármaco determinado randomicamente preparado por outro anestesiologista e administrado segundo o peso do paciente.

- Para a randomização utilizou-se o PEPI [COMPUTER PROGRAMS FOR EPIDEMIOLOGISTS (PEPI) by J.H. Abramson and Paul M. Gahlinger. Version 4.04 x 2001].

- Realizada colheita inicial dos dados: pressão arterial sistólica (PAS) e diastólica (PAD), frequência cardíaca (FC), saturação da hemoglobina $\left(\mathrm{SpO}_{2}\right)$ e nível de sedação pela escala de Ramsay (Ramsay). 
- A cada 5 minutos foram anotados os parâmetros hemodinâmicos (PAS, $\mathrm{PAD}, \mathrm{FC})$, a $\mathrm{FR}$, o valor de $\mathrm{SpO}_{2}$ e o escore determinado pela escala de sedação, acrescidos das possíveis perdas sanguíneas e observações não previstas na ficha.

- Em caso de necessidade de complementar a sedação, ou seja, se o paciente permaneceu com o escore Ramsay 1 , foi utilizado midazolam $0,02 \mathrm{mg} / \mathrm{kg}$ e registrado na ficha.

- Nos pacientes hipertensos, com níveis pressóricos acima de $180 \times 110$ mmHg com sedação insatisfatória (Ramsay 1), foram utilizados midazolam $0,02 \mathrm{mg} / \mathrm{kg}$, seguido de metoprolol $05 \mathrm{mg}$, quando necessário.

- Foram anotados os fármacos vasodilatadores intracoronarianos ou sistêmicos e anti-hipertensivos utilizados pelo paciente.

\subsubsection{Terceiro período}

- Após a condução do paciente para a sala de recuperação anestésica, foram avaliados presença ou ausência de dor anginosa, nível de sedação, presença de náusea e vômito, de euforia ou de agitação, de tontura, existência de algum tipo de sangramento, presença ou ausência de tremores, de hipotensão ou de hipertensão, presença de arritmias, de depressão respiratória, de disforia, de "rush" cutâneo ou de quaisquer outros sintomas não previstos.

- O período avaliação, na sala de recuperação anestésica, foi de, no mínimo, uma hora e trinta minutos e, no máximo, de seis horas. Este 
tempo variável foi consequência das distintas condições clínicas destes pacientes ou do tipo de abordagem utilizada no exame, que poderia ser por via femoral, radial ou braquial.

\subsection{MOMENTOS ESTUDADOS}

Dados relativos à frequência cardíaca, à pressão arterial, à saturação da hemoglobina e aos escores de sedação pela escala de Ramsay foram considerados para análise estatística nos seguintes momentos:

M1 Controle antes do início do exame;

M2 Cinco minutos após a injeção do fármaco;

M3 Início do cateterismo cardíaco;

M4 Final do cateterismo cardíaco;

M5 Trinta minutos após a injeção do fármaco; e

M6 Noventa minutos após a administração do fármaco.

\subsection{TÉCNICA EMPREGADA}

\subsubsection{Preparo do paciente}

Após admissão do paciente, na sala de repouso do laboratório de hemodinâmica, o pesquisador colheu os dados demográficos do paciente, avaliou os critérios de inclusão e exclusão do mesmo e realizou a punção venosa periférica com cateter $22 \mathrm{G}$. 
Neste momento, o paciente foi distribuído conforme lista de randomização do PEPI, previamente determinada, então, preparou-se uma solução contendo sufentanil e clonidina, nas seguintes concentrações: $1 \mathrm{mcg} / \mathrm{ml}$ de sufentanil em uma seringa e $5 \mathrm{mcg} / \mathrm{ml}$ de clonidina em outra seringa, sendo as mesmas identificadas adequadamente. Um segundo anestesiologista era encarregado de trocar a identificação das seringas, assim, a seringa de sufentanil foi denominada grupo $\mathrm{S}$; e a de clonidina, grupo $\mathrm{C}$. Todos os pacientes receberam as soluções em seringas, agulhas e volumes padronizados para que não houvesse identificação do grupo ao qual pertenceria o paciente.

Após esta etapa, o envelope contendo a ficha com dados do paciente, um código da randomização, só conhecido pelo anestesiologista que preparou o envelope, e uma seringa identificada conforme código de identificação foram entregues ao pesquisador que analisou os parâmetros determinados para se atingir os objetivos do estudo.

O paciente foi encaminhado para a sala de exame e, naquele momento, realizou-se a monitorização da pressão arterial invasiva, eletrocardioscopia com seis derivações axiais, utilizada também para medida da frequência cardíaca, e oximetria de pulso para medida da saturação periférica da hemoglobina.

Depois de colhidos os dados iniciais que foram considerados como controle, incluindo-se o escore de sedação determinado pela escala de Ramsay, foi administrado sufentanil ou clonidina durante um período de três 
minutos. A cada cinco minutos, eram registrados os parâmetros avaliados no estudo e, ao final do procedimento, o paciente foi encaminhado para a sala de recuperação anestésica.

\subsubsection{Determinação das pressões arteriais e da frequência cardíaca}

A monitorização invasiva da pressão arterial (PA), pela artéria femoral, radial ou braquial, é rotineira durante a realização de cateterismo cardíaco e é método muito fidedigno de avaliação da pressão sanguínea, por isso, foi utilizada como padrão. Antes da obtenção desta monitorização, a pressão arterial não-invasiva foi o método de mensuração escolhido.

A determinação da frequência cardíaca foi executada por leitura direta dos valores na eletrocardiografia contínua.

\subsection{MÉTODOS ESTATíSTICOS}

Foram utilizados métodos estatísticos para a comparação entre os dois grupos conforme o tipo de variável estudada.

Para variáveis classificatórias categóricas (sim ou não) foi empregada a estatística Qui-Quadrado com o cálculo do $X^{2}$ e p (CURI, 1998); ou exato de Fisher quando os pressupostos do primeiro não fossem atendidos.

Para comparação de variáveis contínuas entre dois grupos foi usado o teste T de student. Quando os presupostos deste não eram atendidos, 
aplicou-se o teste de Mann-Whitney. Para testar a normalidade da amostra foi usado o teste de Kolmogorov-Smirnov.

Na comparação de variáveis contínuas entre os momentos de um mesmo grupo, foi utilizado o teste de Friedman.

Para análise da sedação foi utilizada a escala de Ramsay (escore de classificação ordinal) e empregado o teste não-paramétrico de Friedman para a comparação entre momentos, dentro de cada grupo.

Em todas as análises efetuadas, as estatísticas calculadas foram consideradas significativas quando $p<0,05$. 


\section{RESULTADOS}

O estudo foi realizado durante dois meses, de 01 de julho a 30 de agosto de 2009.

As características demográficas e de avaliação clínica inicial dos grupos estudados constam na Tabela 1, em que se pode observar que não houve diferenças estatisticamente significativas na comparação dos dois grupos no que diz respeito à idade, ao gênero, à altura, ao peso, ao IMC, à $\mathrm{PAS}$, à $\mathrm{PAD}$, à frequência cardíaca, à frequência respiratória, à $\mathrm{SpO}_{2}$ e à escala de sedação de Ramsay.

Tabela 1 - Comparação das características demográficas e de avaliação clínica inicial dos grupos antes da realização do procedimento

\begin{tabular}{lccc}
\hline & Grupo S & Grupo C & P \\
\hline Idade (Média $\pm d p)$ & $60,5 \pm 9,2$ & $63,5 \pm 8,6$ & $0,20 \Psi$ \\
Gênero (\%) & & & \\
$\quad$ Masculino & $40 \%$ & $53,3 \%$ & $0,30 *$ \\
$\quad$ Feminino & $60 \%$ & $46,7 \%$ & \\
Altura (Média $\pm d p)$ & $1,63 \pm 0,07$ & $1,62 \pm 0,07$ & $0,55 \Psi$ \\
Peso (Média $\pm d p)$ & $71,0 \pm 10,7$ & $69,8 \pm 11,0$ & $0,66 \Psi$ \\
IMC (Média $\pm d p)$ & $26,6 \pm 3,8$ & $26,4 \pm 3,8$ & $0,89 \Psi$ \\
PAS (Média $\pm d p)$ & $150,8 \pm 23,4$ & $155,1 \pm 22,7$ & $0,47 \Psi$ \\
PAD (Média $\pm d p)$ & $80,9 \pm 8,3$ & $81,1 \pm 11,9$ & $0,93 \Psi$ \\
FC (Média $\pm d p)$ & $66,2 \pm 11,6$ & $66,0 \pm 10,7$ & $0,95 \Psi$ \\
FR (Média $\pm d p)$ & $96,0 \pm 16,3$ & $99,1 \pm 1,2$ & $0,96 ¥$ \\
SpO ${ }_{2}$ (Média $\left.\pm d p\right)$ & $16,5 \pm 1,9$ & $17,0 \pm 2,3$ & $0,32 ¥$ \\
Ramsay (mediana/mínimo/máximo) & $1 / 2 / 2$ & $1 / 2 / 2$ & $1,0 ¥$ \\
& & & \\
\hline
\end{tabular}

$\mathrm{dp}=$ desvio padrão. *Qui-quadrado. $\Psi$ Teste T de Student. $¥$ Mann-Whitney.

IMC=índice de massa corpórea. PAS=pressão arterial sistêmica. PAD= pressão arterial diastólica. $\mathrm{FC}=$ frequência cardíaca. $\mathrm{FR}$ =frequência respiratória. $\mathrm{SpO}_{2}=$ saturação de oxigênio.

Ramsay= escore de sedação segundo escala de Ramsay 
Nenhuma diferença foi encontrada, nos grupos estudados, com relação às comorbidades e fatores de risco (Tabela 2), sendo a amostra estudada homogênia no tocante a todos os parâmetros em questão.

Tabela 2 - Comparação das morbidades e fatores de risco

\begin{tabular}{lccc}
\hline & Grupo S & Grupo C & P \\
\hline Acidente Vascular Cerebral & $3(10,0 \%)$ & $2(6,7 \%)$ & $1,0 \Omega$ \\
Hipertensão arterial sistêmica & $26(86,7 \%)$ & $26(86,7 \%)$ & $1,0 \Omega$ \\
Diabetes Melitus & $8(26,7 \%)$ & $9(30,0 \%)$ & $0,77^{*}$ \\
Insuficiência Cardíaca Congestiva & $2(6,7 \%)$ & $5(16,7 \%)$ & 0,42 \\
Insuficiência coronariana & $14(46,7 \%)$ & $12(40,0 \%)$ & $0,60^{*}$ \\
Angina & $8(26,7 \%)$ & $6(20,0 \%)$ & $0,54^{*}$ \\
Infarto Agudo do Miocárdio & $6(20,0 \%)$ & $2(6,7 \%)$ & $0,13 \Omega$ \\
Doença Pulmonar Obstrutiva & $1(3,3 \%)$ & - & $1,0 \Omega$ \\
Crônica & & & $0,79^{*}$ \\
Dislipidemia & $13(43,3 \%)$ & $14(46,7 \%)$ & $0,57^{*}$ \\
Tabagismo & $8(26,7 \%)$ & $10(33,3 \%)$ & 0,7 \\
\end{tabular}

${ }^{*}$ Qui-quadrado. $\Omega$ Teste Exato de Fisher.

Os grupos foram semelhantes também em relação às medicações utilizadas para tratamento das morbidades apresentadas (Tabela 3).

Tabela 3 - Frequência de uso de medicamentos em domicílio para as comorbidades apresentadas entre os grupos

\begin{tabular}{lccc}
\hline & Grupo S & Grupo C & p \\
\hline Sinvastatina & $11(36,7 \%)$ & $13(43,3 \%)$ & $0,59^{*}$ \\
Hipoglicemiante & $7(23,3 \%)$ & $5(16,7 \%)$ & $0,51^{*}$ \\
Insulina & $1(3,3 \%)$ & $3(10,0 \%)$ & $0,61 \Omega$ \\
Nitrato & $7(23,3 \%)$ & $5(16,7 \%)$ & $0,51^{*}$ \\
Bloqueador de canais de cálcio & $7(23,3 \%)$ & $6(20,0 \%)$ & $0,75^{*}$ \\
Beta bloqueador & $17(56,7 \%)$ & $12(40,0 \%)$ & $0,19^{*}$ \\
Inibidor da ECA & $16(53,3 \%)$ & $23(76,7 \%)$ & $0,06^{*}$ \\
Ácido acetil salicílico & $20(66,7 \%)$ & $16(53,3 \%)$ & $0,30^{*}$ \\
Diurético & $7(23,3 \%)$ & $7(23,3 \%)$ & $1,0^{*}$
\end{tabular}

${ }^{*}$ Qui-quadrado. $\Omega$ Teste Exato de Fisher. 
A comparação, entre os grupos, das características hemodinâmicas e escala de sedação de Ramsay para cada momento do procedimento demonstra que não houve diferença estatisticamente significante concernente à PAS, à PAD, à frequência cardíaca e à frequência respiratória. Observando a $\mathrm{SpO}_{2}$ e a escala de sedação de Ramsay, houve diferenças estatisticamente significativas em dois momentos. No momento 2, a diferença foi quanto à escala de sedação de Ramsay, indicando que os pacientes que utilizaram o sufentanil apresentaram maior sedação quando comparados aos que fizeram uso de clonidina. Já no momento 6 , houve diferença quanto à $\mathrm{SpO}_{2}$, sinalizando que os pacientes que utilizaram sufentanil exibiram menor valor de $\mathrm{SpO}_{2}$ do que aqueles nos quais se utilizou a clonidina. Entretanto, o valor de $\mathrm{SpO}_{2}$ do grupo $\mathrm{S}$ foi de $97,1 \% \pm 2,2$ contra $98,4 \% \pm 1,8$ no grupo $\mathrm{C}, \mathrm{o}$ que é considerado como valor normal (Tabela 4). 
Tabela 4 - Comparação entre os grupos das características hemodinâmicas e Ramsay para cada momento do procedimento

\begin{tabular}{|c|c|c|c|}
\hline & Grupo S & Grupo C & p \\
\hline \multicolumn{4}{|l|}{ Momento 1 (Média $\pm d p)$} \\
\hline PAS & $150,8 \pm 23,4$ & $155,1 \pm 22,7$ & $0,47 \Psi$ \\
\hline PAD & $80,9 \pm 8,3$ & $81,1 \pm 11,9$ & $0,93 \psi$ \\
\hline $\mathrm{FC}$ & $66,2 \pm 11,6$ & $66,0 \pm 10,7$ & $0,95 \psi$ \\
\hline FR & $16,5 \pm 1,9$ & $17,0 \pm 2,3$ & $0,96 ¥$ \\
\hline $\mathrm{SpO}_{2}$ & $96,0 \pm 16,3$ & $99,1 \pm 1,2$ & $0,32 ¥$ \\
\hline Ramsay (mediana/mínimo/máximo) & $1 / 2 / 2$ & $1 / 2 / 2$ & $1,0 ¥$ \\
\hline \multicolumn{4}{|l|}{ Momento 2 (Média $\pm d p)$} \\
\hline PAS & $150,0 \pm 22,4$ & $151,3 \pm 20,0$ & $0,82 \Psi$ \\
\hline PAD & $81,0 \pm 9,4$ & $79,2 \pm 12,4$ & $0,53 \psi$ \\
\hline $\mathrm{FC}$ & $65,4 \pm 10,7$ & $65,9 \pm 10,1$ & $0,84 \Psi$ \\
\hline FR & $16,5 \pm 2,3$ & $16,7 \pm 2,3$ & $0,65 ¥$ \\
\hline $\mathrm{SpO}_{2}$ & $98,8 \pm 2,6$ & $99,3 \pm 1,3$ & $0,94 ¥$ \\
\hline Ramsay (mediana/mínimo/máximo) & $2 / 1 / 3$ & $2 / 1 / 2$ & $0,02 ¥ £$ \\
\hline \multicolumn{4}{|l|}{ Momento 3 (Média $\pm d p)$} \\
\hline PAS & $148,9 \pm 25,1$ & $147,6 \pm 21,1$ & $0,82 \Psi$ \\
\hline PAD & $80,1 \pm 10,8$ & $78,5 \pm 11,7$ & $0,58 \psi$ \\
\hline $\mathrm{FC}$ & $64,7 \pm 12,6$ & $65,9 \pm 9,7$ & $0,67 \Psi$ \\
\hline $\mathrm{FR}$ & $16,5 \pm 2,3$ & $16,8 \pm 2,2$ & $0,56 ¥$ \\
\hline $\mathrm{SpO}_{2}$ & $98,1 \pm 3,6$ & $99,0 \pm 1,4$ & $0,70 ¥$ \\
\hline Ramsay (mediana/mínimo/máximo) & $2 / 1 / 3$ & $2 / 1 / 2$ & $0,61 ¥$ \\
\hline \multicolumn{4}{|l|}{ Momento 4 (Média $\pm d p)$} \\
\hline PAS & $131,0 \pm 29,7$ & $133,4 \pm 15,7$ & $0,69 \psi$ \\
\hline PAD & $73,1 \pm 9,1$ & $72,9 \pm 11,2$ & $0,93 \Psi$ \\
\hline $\mathrm{FC}$ & $66,6 \pm 10,1$ & $65,2 \pm 9,3$ & $0,56 \psi$ \\
\hline $\mathrm{FR}$ & $16,6 \pm 2,1$ & $16,4 \pm 2,1$ & $0,54 ¥$ \\
\hline $\mathrm{SpO}_{2}$ & $95,5 \pm 16,5$ & $99,1 \pm 1,3$ & $0,39 ¥$ \\
\hline Ramsay (mediana/mínimo/máximo) & $2 / 2 / 3$ & $2 / 1 / 3$ & $0,26 ¥$ \\
\hline \multicolumn{4}{|l|}{ Momento 5 (Média \pm dp) } \\
\hline PAS & $136,9 \pm 19,9$ & $134,7 \pm 15,0$ & $0,64 \Psi$ \\
\hline PAD & $75,2 \pm 10,7$ & $74,1 \pm 11,1$ & $0,68 \psi$ \\
\hline $\mathrm{FC}$ & $66,3 \pm 10,9$ & $63,9 \pm 10,7$ & $0,40 \Psi$ \\
\hline FR & $17,2 \pm 2,2$ & $16,4 \pm 2,1$ & $0,12 ¥$ \\
\hline $\mathrm{SpO}_{2}$ & $97,8 \pm 2,6$ & $98,7 \pm 1,8$ & $0,20 ¥$ \\
\hline Ramsay & $2 / 2 / 3$ & $2 / 1 / 3$ & $0,31 ¥$ \\
\hline \multicolumn{4}{|l|}{ Momento 6 (Média $\pm d p$ ) } \\
\hline PAS & $126,6 \pm 19,0$ & $130,5 \pm 13,9$ & $0,37 \Psi$ \\
\hline PAD & $74,4 \pm 11,8$ & $75,7 \pm 11,3$ & $0,66 \psi$ \\
\hline $\mathrm{FC}$ & $64,1 \pm 10,9$ & $63,0 \pm 8,5$ & $0,67 \Psi$ \\
\hline $\mathrm{FR}$ & $17,2 \pm 2,2$ & $16,9 \pm 1,8$ & $0,63 ¥$ \\
\hline $\mathrm{SpO}_{2}$ & $97,1 \pm 2,2$ & $98,4 \pm 1,8$ & $0,02 \psi £$ \\
\hline Ramsay (mediana/mínimo/máximo) & $2 / 1 / 3$ & $2 / 2 / 3$ & $0,67 ¥$ \\
\hline
\end{tabular}

$\mathrm{dp}=$ desvio padrão. *Qui-quadrado. $\Psi$ Teste T de Student. $¥$ Mann-Whitney. $\{p \leq 0,05$ $P A S=$ pressão arterial sistêmica. $P A D=$ pressão arterial diastólica.

$\mathrm{FC}=$ frequência cardíaca. $\mathrm{FR}=$ frequência respiratória. $\mathrm{SpO}_{2}=$ saturação de oxigênio. Ramsay= escore de sedação segundo escala de Ramsay 
Avaliando de maneira mais detalhada os escores de Ramsay em cada momento dos grupos S e C, observa-se que tanto os pacientes que utilizaram sufentanil quanto os que utilizaram clonidina, em sua maioria, alcançaram nível de sedação satisfatório, devendo-se salientar que o sufentanil tem início de ação mais precoce que a clonidina (Gráfico 1).

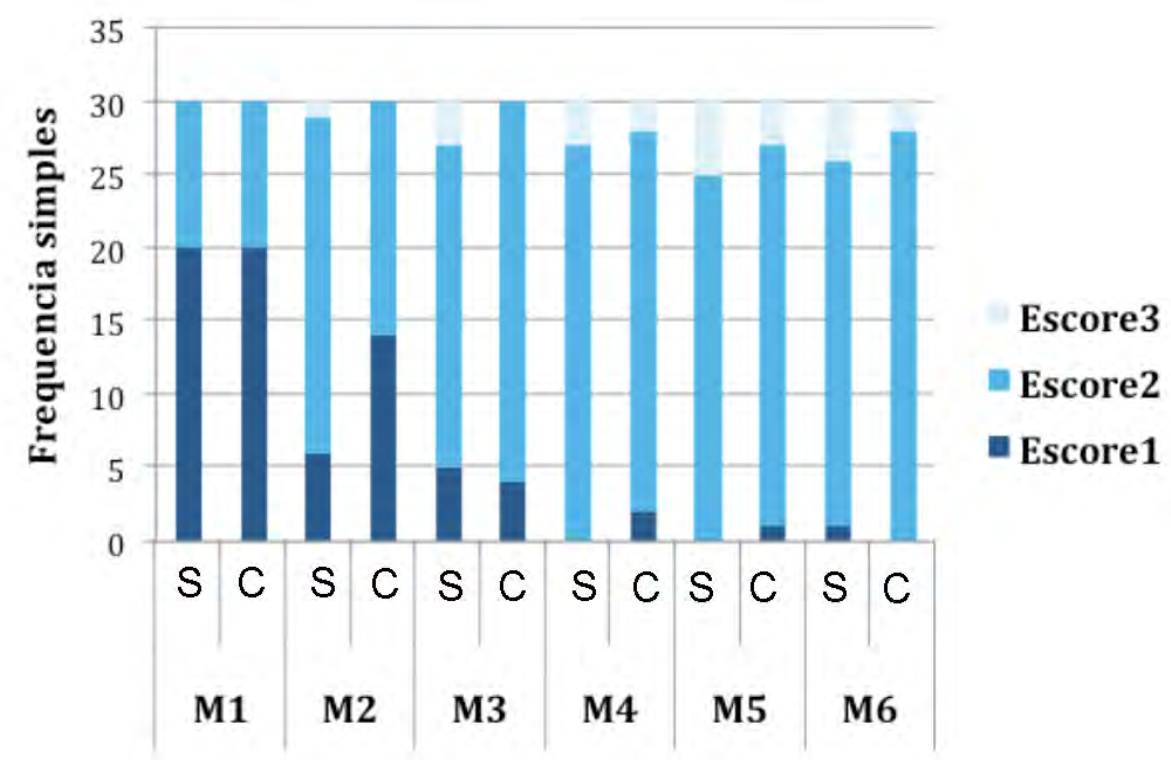

Gráfico 1 - Escores de Ramsay para cada momento dos grupos S e C.

A avaliação dos escores de Ramsay dos grupos, para cada momento, variou. No momento 1 , os grupos foram homogênios. No momento 2, no grupo S, 6 dos pacientes apresentaram escore 1 na escala de Ramsay, 23 deles apresentaram escore 2 e 1 paciente apenas apresentou escore 3. No grupo C, 14 pacientes apresentaram escore 1 na escala de Ramsay e 16 apresentaram escore 2. Estes dados indicam que, no momento 2, os pacientes do grupo A apresentaram mais frequentemente níveis de sedação 2 e 3 pela escala de Ramsay quando comparados aos pacientes grupo B. 
No momento 3 , no grupo $A$, cinco pacientes obtiveram escore 1 na escala de Ramsay; 23 apresentaram escore 2 na escala de Ramsay; e 3 deles assinalaram escore 3 na escala de Ramsay. No grupo B, neste mesmo momento, 4 pacientes apresentaram escore 1 na escala de Ramsay; e 26 pacientes, escore 2 na escala de Ramsay. Nenhum paciente apresentou escore 3 e não houve diferença significativa no que diz respeito à presença de escore 2, que é um nível de sedação almejado, quando da utilização do sufentanil ou da clonidina. Houve um maior número de pacientes com escore 3 no grupo que utilizou o sufentanil, o que também representa nível de sedação adequado. Nos momentos 4, 5 e 6 , os grupos se comportaram de maneira semelhante, havendo maior número de pacientes no escore 2 , o que é desejável (Tabela 5).

Tabela 5 - Frequência de escores de Ramsay dos grupos para cada momento $-\mathrm{n}(\%)$

\begin{tabular}{|c|c|c|c|c|}
\hline & Grupo & Escore1 & Escore2 & Escore3 \\
\hline \multirow{2}{*}{ M1 } & $S$ & $20(66,7)$ & $10(33,3)$ & \\
\hline & C & $20(66,7)$ & $10(33,3)$ & \\
\hline \multirow{2}{*}{ M2 } & $S$ & $6(20,0)$ & $23(76,7)$ & $1(3,3)$ \\
\hline & C & $14(46,7)$ & $16(53,3)$ & \\
\hline \multirow{2}{*}{ M3 } & S & $5(16,7)$ & $22(73,3)$ & $3(10,0)$ \\
\hline & C & $4(13,3)$ & $26(86,7)$ & \\
\hline \multirow{2}{*}{ M4 } & $S$ & & $27(90,0)$ & $3(10,0)$ \\
\hline & C & $2(6,7)$ & $26(86,7)$ & $2(6,7)$ \\
\hline \multirow{2}{*}{ M5 } & S & & $25(83,3)$ & $5(16,7)$ \\
\hline & C & $1(3,3)$ & $26(86,7)$ & $3(10,0)$ \\
\hline \multirow{2}{*}{ M6 } & $S$ & $1(3,3)$ & $25(83,3)$ & $4(13,3)$ \\
\hline & C & & $28(93,3)$ & $2(6,7)$ \\
\hline
\end{tabular}

$\bar{M}=$ momentos. 
A comparação pareada das PAS, entre os momentos dos indivíduos do grupo $\mathrm{S}$, demonstra que houve variação estatisticamente significativa entre os momentos após administração do sufentanil, com valor de $p<0,001$. A PAS apresenta variação dos momentos 1,2 e 3 em relação aos momentos 4, 5 e 6, havendo melhor controle da PAS com o passar do tempo. Não houve diferença entre os momentos 4 e 5 , porém a PAS do momento 5 diferiu estatisticamente do momento 6 , momento que representa o término do estudo (Tabela 6).

Tabela 6 - Comparação das PAS entre os momentos dos indivíduos do Grupo $S$ (média \pm dp)

\begin{tabular}{|c|c|c|c|c|c|c|}
\hline PAS1 & PAS2 & PAS3 & PAS4 & PAS5 & PAS6 & $\mathbf{P}$ \\
\hline $\begin{array}{l}150,8 \pm 23 \\
4\end{array}$ & $\begin{array}{l}150,0 \pm 22 \\
4\end{array}$ & $\begin{array}{l}148,9 \pm 25 \\
1\end{array}$ & $\begin{array}{l}131,0 \pm 29 \\
7\end{array}$ & $\begin{array}{l}136,9 \pm 19 \\
9\end{array}$ & $\begin{array}{l}126,6 \pm 19 \\
0\end{array}$ & $\begin{array}{l}<0,00 \\
1\end{array}$ \\
\hline \multicolumn{2}{|c|}{ Comparações } & \multicolumn{2}{|l|}{$p$} & \multicolumn{2}{|c|}{ Comparações } & $\mathbf{P}$ \\
\hline \multicolumn{2}{|c|}{ PAS1 x PAS2 } & \multicolumn{2}{|l|}{0,29} & \multicolumn{2}{|c|}{ PAS2 x PAS6 } & $\begin{array}{c}<0,00 \\
1\end{array}$ \\
\hline \multicolumn{2}{|c|}{ PAS1 x PAS3 } & \multicolumn{2}{|l|}{0,23} & \multicolumn{2}{|c|}{ PAS3 x PAS4 } & 0,001 \\
\hline \multicolumn{2}{|c|}{ PAS1 x PAS4 } & \multicolumn{2}{|l|}{0,001} & \multicolumn{2}{|c|}{ PAS3 x PAS5 } & 0,041 \\
\hline \multicolumn{2}{|c|}{ PAS1 1 PAS5 } & \multicolumn{2}{|l|}{0,002} & \multicolumn{2}{|c|}{ PAS3 x PAS6 } & $\begin{array}{c}<0,00 \\
1\end{array}$ \\
\hline \multicolumn{2}{|c|}{ PAS1 x PAS6 } & \multicolumn{2}{|l|}{$<0,001$} & \multicolumn{2}{|c|}{ PAS4 x PAS5 } & 0,072 \\
\hline \multicolumn{2}{|c|}{ PAS2 x PAS3 } & \multicolumn{2}{|l|}{0,84} & \multicolumn{2}{|c|}{ PAS4 x PAS6 } & 0,023 \\
\hline \multicolumn{2}{|c|}{ PAS2 x PAS4 } & 0,002 & & \multirow{2}{*}{\multicolumn{2}{|c|}{ PAS5 x PAS6 }} & 0,002 \\
\hline PAS & & 1 & & & & \\
\hline
\end{tabular}

PAS $=$ pressão arterial sistólica. $d p=$ desvio padrão. Teste de Friedmann. PAS1 $=$ PAS no momento 1 ; PAS2 = PAS no momento 2 .

Com relação à comparação pareada da PAD, observa-se uma variação estatisticamente significativa entre os momentos após administração do sufentanil, com valor de $p<0,001$. Houve diferença estatística entre a PAD1 e PAD6, assim, demonstrando que há benefício no uso do sufentanil no que diz respeito ao controle da PAD apenas no momento da alta da SRA (sala de 
recuperação anestésica). Comparando-se os demais momentos se evidencia que há diferença estatisticamente significante entre os valores de PAD2 e PAD4,5,6; PAD3 e PAD4,5,6;PAD4 e PAD5 nos pacientes em que se utilizou o sufentanil, o que é compatível com um melhor resultado do fármaco com o passar do tempo. É importante considerar a ausência de diferença entre os momentos 2 e 3 , que representam, respectivamente, cinco minutos após administração do fármaco e início do procedimento (Tabela 7).

Tabela 7 - Comparação das PAD entre os momentos dos indivíduos do Grupo $S$ (média \pm dp)

\begin{tabular}{lcccccc}
\hline PAD1 & PAD2 & PAD3 & PAD4 & PAD5 & PAD6 & P \\
\hline $80,9 \pm 8,3$ & $81,0 \pm 9,4$ & $80,1 \pm 10,8$ & $73,1 \pm 9,1$ & $75,2 \pm 10,7$ & $74,4 \pm 11,8$ & $<0,001$ \\
& & & & & \\
\hline Comparações & $\mathbf{p}$ & & Comparações & P \\
PAD1 x PAD2 & 0,39 & & PAD2 x PAD6 & 0,023 \\
PAD1 x PAD3 & 0,84 & & PAD3 x PAD4 & 0,016 \\
PAD1 x PAD4 & 0,002 & & PAD3 x PAD5 & 0,016 \\
PAD1 x PAD5 & 0,09 & & PAD3 x PAD6 & 0,028 \\
PAD1 x PAD6 & 0,04 & & PAD4 x PAD5 & 0,019 \\
PAD2 x PAD3 & 0,83 & & PAD4 x PAD6 & 0,84 \\
PAD2 x PAD4 & 0,016 & & PAD5x PAD6 & 0,57 \\
PAD2 x PAD5 & 0,012 & & & &
\end{tabular}

$\overline{\mathrm{PAD}}=$ pressão arterial diastólica. $\mathrm{dp}=$ desvio padrão. Teste de Friedmann.

Na FC, a comparação pareada entre os momentos dos indivíduos do grupo $S$ revelou um $\mathrm{p}$ de 0,27 , demonstrando não haver diferença estatisticamente significativa entre os mesmos. No entanto, na comparação da FC, entre os momentos 1 e $6 ; 4$ e $6 ; 5$ e 6 , observou-se diferença de 0,041 , 0,009 e 0,023 , respectivamente (Tabela 8). 
Tabela 8 - Comparação das FC entre os momentos dos indivíduos do Grupo S (média \pm dp)

\begin{tabular}{|c|c|c|c|c|c|c|}
\hline FC1 & $\overline{\mathrm{FC} 2}$ & FC3 & $\overline{\text { FC4 }}$ & FC5 & FC6 & p \\
\hline $66,2 \pm 11,6$ & $65,4 \pm 10,7$ & $64,7 \pm 12,6$ & $66,6 \pm 10,1$ & $66,3 \pm 10,9$ & $64,1 \pm 10,9$ & 0,27 \\
\hline Comparaç & ões & $p$ & & \multicolumn{2}{|c|}{ Comparações } & $p$ \\
\hline $\mathrm{FC} 1 \times \mathrm{FC} 2$ & & 0,83 & & \multicolumn{2}{|c|}{ FC2 $x$ FC6 } & 0,33 \\
\hline $\mathrm{FC} 1 \times \mathrm{FC} 3$ & & 0,54 & & \multicolumn{2}{|c|}{ FC3 $x$ FC4 } & 1,0 \\
\hline $\mathrm{FC} 1 \times \mathrm{FC} 4$ & & 0,70 & & \multicolumn{2}{|c|}{ FC3 $x$ FC5 } & 0,85 \\
\hline FC1 x FC5 & & 0,24 & & \multicolumn{2}{|c|}{ FC3 $\times$ FC6 } & 0,69 \\
\hline $\mathrm{FC} 1 \times \mathrm{FC} 6$ & & 0,041 & & \multicolumn{2}{|c|}{ FC4 x FC5 } & 0,84 \\
\hline $\mathrm{FC} 2 \times \mathrm{FC} 3$ & & 0,82 & & \multicolumn{2}{|c|}{ FC4 $x$ FC6 } & 0,009 \\
\hline $\mathrm{FC} 2 \times \mathrm{FC} 4$ & & 0,85 & & \multirow{2}{*}{\multicolumn{2}{|c|}{ FC5x FC6 }} & 0,023 \\
\hline FC2 x FC5 & & 0,85 & & & & \\
\hline
\end{tabular}

$\overline{\mathrm{FC}}=$ frequência cardíaca. $\mathrm{dp}=$ desvio padrão. Teste de Friedmann.

A comparação pareada da FR, entre os momentos dos indivíduos do grupo $\mathrm{S}$, também, não evidenciou nenhuma diferença, com valor de $\mathrm{p}$ igual a 0,13. Entretanto, observando a comparação dos momentos isoladamente, verificam-se diferenças entre os momentos 1 e $5 ; 2$ e $5 ; 3$ e $5 ; 5$ e 6 , com valores de $p$ de 0,039, 0,016, 0,033 e 0,018, respectivamente (Tabela 9).

Tabela 9 - Comparação das FR entre os momentos dos indivíduos do Grupo S (média \pm dp)

\begin{tabular}{|c|c|c|c|c|c|c|}
\hline FR1 & FR2 & FR3 & FR4 & FR5 & FR6 & $p$ \\
\hline $16,5 \pm 1,9$ & $16,5 \pm 2,3$ & $16,5 \pm 2,3$ & $16,6 \pm 2,1$ & $17,2 \pm 2,2$ & $17,2 \pm 2,2$ & 0,13 \\
\hline \multicolumn{2}{|c|}{ Comparações } & $\mathbf{P}$ & & \multicolumn{2}{|c|}{ Comparações } & $p$ \\
\hline \multicolumn{2}{|c|}{ FR1 x FR2 } & 0,80 & & \multicolumn{2}{|c|}{$\mathrm{FR} 2 \times \mathrm{FR} 6$} & 0,82 \\
\hline \multicolumn{2}{|c|}{ FR1 $x$ FR3 } & 0,59 & & \multicolumn{2}{|c|}{ FR3 $x$ FR4 } & 0,59 \\
\hline \multicolumn{2}{|c|}{ FR1 $x$ FR4 } & 0,79 & & \multicolumn{2}{|c|}{ FR3 x FR5 } & 0,033 \\
\hline \multicolumn{2}{|c|}{ FR1 $x$ FR5 } & 0,039 & & \multicolumn{2}{|c|}{ FR3 x FR6 } & 1,0 \\
\hline \multicolumn{2}{|c|}{ FR1 $x$ FR6 } & 0,84 & & \multicolumn{2}{|c|}{ FR4 $x$ FR5 } & 0,16 \\
\hline \multicolumn{2}{|c|}{ FR2 x FR3 } & 0,56 & & \multicolumn{2}{|c|}{ FR4 x FR6 } & 0,65 \\
\hline \multicolumn{2}{|c|}{$\mathrm{FR} 2 \times \mathrm{FR} 4$} & 0,46 & & \multicolumn{2}{|c|}{ FR5x FR6 } & 0,018 \\
\hline $\mathrm{FR} 2 \times \mathrm{FR}$ & & 0,016 & & & & \\
\hline
\end{tabular}

$\mathrm{FR}$ = frequência respiratória. $\mathrm{dp}=$ desvio padrão. Teste de Friedmann. 
Com relação ao valor de $\mathrm{SpO}_{2}$ e da escala de Ramsay, na comparação pareada entre os indivíduos do grupo $S$, o valor de $p$ foi inferior a 0,001 para ambos os parâmetros, o que demonstra que o sufentanil teve um efeito redutor de saturação e efeito sedativo após a sua administração. Entretanto, os dados obtidos revelam que o menor valor de SpO2 alcançado foi de $95,5 \% \pm 16,5$, no momento 4 , o qual representa o final do cateterismo cardíaco (Tabela 10).

Pela tabela 11, pode-se verificar que os valores da escala de Ramsay, após a administração do sufentanil, foram de 2 e diferindo apenas do valor do momento 1, que foi de 1, demonstrando que, após a administração do sufentanil, é possível alcançar níveis de sedação que permitem a realização do procedimento (Gráfico 2).

Tabela 10 - Comparação das $\mathrm{SPO}_{2}$ entre os momentos dos indivíduos do Grupo S (média $\pm d p)$

\begin{tabular}{lcccccc}
\hline $\mathrm{SPO}_{2} 1$ & $\mathbf{S P O}_{2} 2$ & $\mathbf{S P O}_{2} 3$ & $\mathbf{S P O}_{2} 4$ & $\mathbf{S P O}_{2} \mathbf{5}$ & $\mathbf{S P O}_{2} 6$ & $\mathbf{P}$ \\
\hline $96,0 \pm 16,3$ & $98,8 \pm 2,6$ & $98,1 \pm 3,6$ & $95,5 \pm 16,5$ & $97,8 \pm 2,6$ & $97,1 \pm 2,2$ & $<0,001$ \\
& & & & & \\
\hline Comparações & $\mathbf{p}$ & & $\mathbf{C o m p a r a c ̧ o ̃ e s ~}$ & $\mathbf{P}$ \\
$\mathrm{SPO}_{2} 1 \times \mathrm{SPO}_{2} 2$ & 0,40 & & $\mathrm{SPO}_{2} 2 \times \mathrm{SPO}_{2} 6$ & 0,001 \\
$\mathrm{SPO}_{2} 1 \times \mathrm{SPO}_{2} 3$ & 0,28 & & $\mathrm{SPO}_{2} 3 \times \mathrm{SPO}_{2} 4$ & 0,62 \\
$\mathrm{SPO}_{2} 1 \times \mathrm{SPO}_{2} 4$ & 0,64 & & $\mathrm{SPO}_{2} 3 \times \mathrm{SPO}_{2} 5$ & 0,13 \\
$\mathrm{SPO}_{2} 1 \times \mathrm{SPO}_{2} 5$ & 0,07 & & $\mathrm{SPO}_{2} 3 \times \mathrm{SPO}_{2} 6$ & 0,004 \\
$\mathrm{SPO}_{2} 1 \times \mathrm{SPO}_{2} 6$ & $<0,001$ & & $\mathrm{SPO}_{2} 4 \times \mathrm{SPO}_{2} 5$ & 0,07 \\
$\mathrm{SPO}_{2} 2 \times \mathrm{SPO}_{2} 3$ & 0,24 & & $\mathrm{SPO}_{2} 4 \times \mathrm{SPO}_{2} 6$ & 0,06 \\
$\mathrm{SPO}_{2} 2 \times \mathrm{SPO}_{2} 4$ & 0,22 & & $\mathrm{SPO}_{2} 5 \times \mathrm{SPO}_{2} 6$ & 0,22 \\
$\mathrm{SPO}_{2} 2 \times \mathrm{SPO}_{2} 5$ & 0,09 & & & & \\
& & & & & \\
\hline
\end{tabular}

$\mathrm{SPO}_{2}=$ Saturação de oxigênio. $\mathrm{dp}=$ desvio padrão. Teste de Friedmann. 
Tabela 11 - Comparação dos escores das escalas de sedação de Ramsay entre os momentos dos indivíduos do Grupo S (mediana)

\begin{tabular}{|c|c|c|c|c|c|c|}
\hline Ramsay 1 & Ramsay2 & Ramsay3 & Ramsay4 & Ramsay 5 & Ramsay 6 & $p$ \\
\hline 1 & 2 & 2 & 2 & 2 & 2 & $<0,001$ \\
\hline Comparaçc & & p & & \multicolumn{2}{|c|}{ Comparações } & $\mathbf{p}$ \\
\hline Ramsay $1 x$ & Ramsay 2 & $<0,001$ & & \multicolumn{2}{|c|}{ Ramsay 2 x Ramsay 6} & 0,02 \\
\hline Ramsay $1 x$ & Ramsay 3 & $<0,001$ & & \multicolumn{2}{|c|}{ Ramsay $3 \times$ Ramsay 4} & 0,09 \\
\hline Ramsay $1 \times$ & Ramsay 4 & $<0,001$ & & \multicolumn{2}{|c|}{ Ramsay 3 x Ramsay 5} & 0,02 \\
\hline Ramsay $1 x$ & Ramsay 5 & $<0,001$ & & \multicolumn{2}{|c|}{ Ramsay 3 x Ramsay 6} & 0,25 \\
\hline Ramsay $1 x$ & Ramsay 6 & $<0,001$ & & \multicolumn{2}{|c|}{ Ramsay 4 x Ramsay 5} & 0,15 \\
\hline Ramsay $2 x$ & Ramsay 3 & 0,18 & & \multicolumn{2}{|c|}{ Ramsay 4 x Ramsay 6} & 1,00 \\
\hline Ramsay $2 x$ & Ramsay 4 & 0,008 & & \multirow{2}{*}{\multicolumn{2}{|c|}{ Ramsay 5x Ramsay 6}} & 0,53 \\
\hline Ramsay $2 x$ & Ramsay 5 & 0,003 & & & & \\
\hline
\end{tabular}

$\mathrm{SPO}_{2}=$ Saturação de oxigênio. $\mathrm{dp}=$ desvio padrão. Teste de Friedmann.

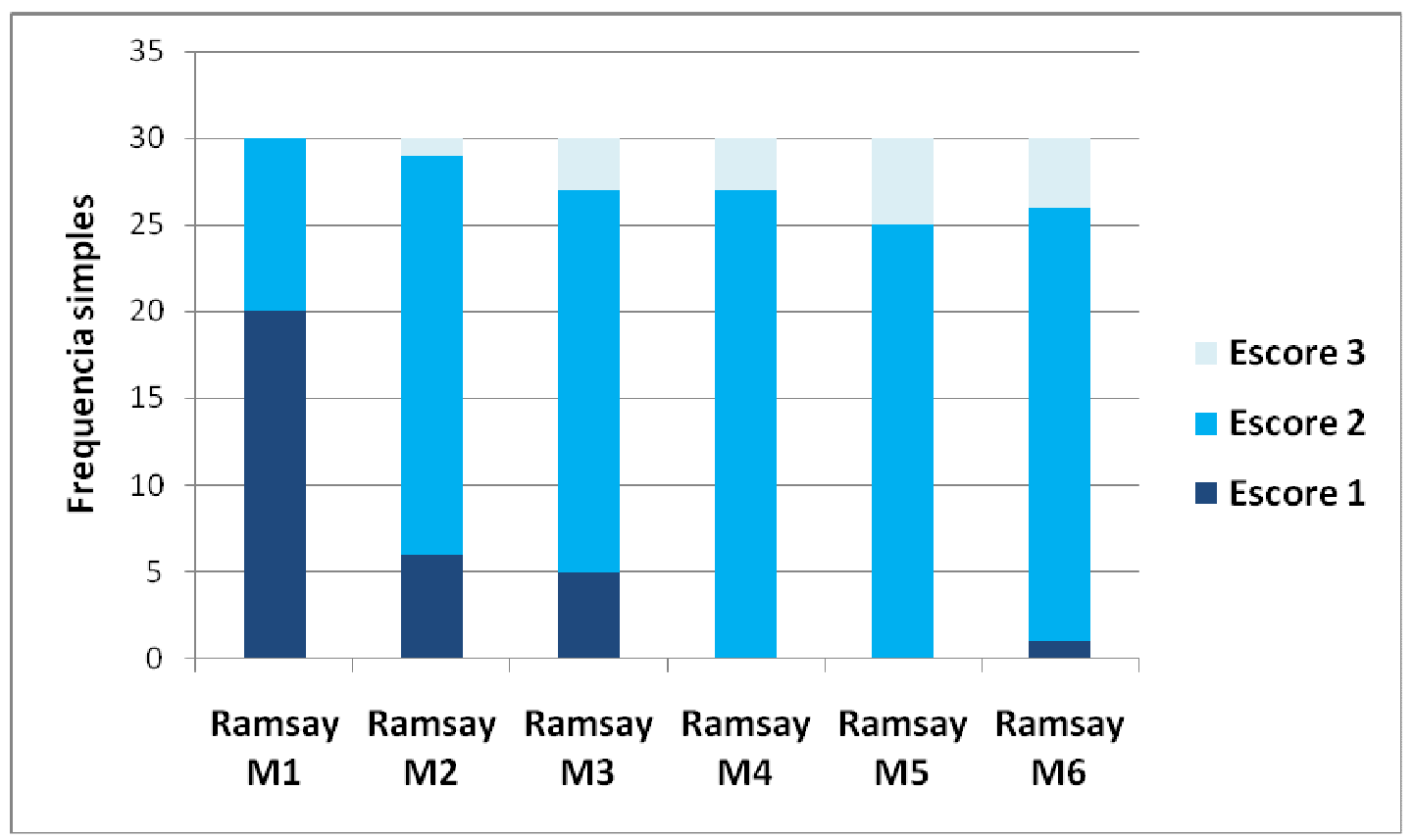

Gráfico 2 - Escores de Ramsay para cada momento do grupo S. 
Quanto ao grupo C, ao se observar a comparação pareada das PAS e PAD, verifica-se um valor de $p$ inferior a 0,001 , em todos os momentos estudados, indicando uma redução das mesmas após a administração de clonidina (Tabela 12 e 13).

Tabela 12 - Comparação das PAS entre os momentos dos indivíduos do Grupo C (média \pm dp)

\begin{tabular}{|c|c|c|c|c|c|}
\hline PAS2 & PAS3 & PAS4 & PAS5 & PAS6 & $\mathbf{p}$ \\
\hline $155,1 \pm 22,7 \quad 151,3 \pm 20,0$ & $147,6 \pm 21,1$ & $133,4 \pm 15,7$ & $134,7 \pm 15,0$ & $130,5 \pm 13,9$ & $<0,001$ \\
\hline Comparações & $\mathbf{P}$ & & Compa & ações & $p$ \\
\hline PAS1 x PAS2 & 0,84 & & PAS2 & PAS6 & $<0,001$ \\
\hline PAS1 x PAS3 & 0,04 & & PAS3 & PAS4 & $<0,001$ \\
\hline PAS1 1 PAS4 & $<0,001$ & & PAS3 & PAS5 & $<0,001$ \\
\hline PAS1 x PAS5 & $<0,001$ & & PAS3 & PAS6 & $<0,001$ \\
\hline PAS1 x PAS6 & $<0,001$ & & PAS4 & PAS5 & 0,55 \\
\hline PAS2 x PAS3 & 0,06 & & PAS4 & PAS6 & 0,41 \\
\hline PAS2 $\times$ PAS4 & $<0,001$ & & PAS5> & PAS6 & 0,57 \\
\hline PAS2 x PAS5 & $<0,001$ & & & & \\
\hline
\end{tabular}

PAS $=$ pressão arterial sistólica. $d p=$ desvio padrão. Teste de Friedmann .

Tabela 13 - Comparação das PAD entre os momentos dos indivíduos do Grupo C (média \pm dp)

\begin{tabular}{lcccccc}
\hline PAD1 & PAD2 & PAD3 & PAD4 & PAD5 & PAD6 & $\mathbf{p}$ \\
\hline $81,1 \pm 11,9$ & $79,2 \pm 12,4$ & $78,5 \pm 11,7$ & $72,9 \pm 11,2$ & $74,1 \pm 11,1$ & $75,7 \pm 11,3$ & $<0,001$ \\
& & & & & \\
\hline Comparações & $\mathbf{p}$ & & Comparações & $\mathbf{p}$ \\
PAD1 x PAD2 & 0,014 & & PAD2 x PAD6 & 0,56 \\
PAD1 x PAD3 & 0,023 & & PAD3 x PAD4 & 0,06 \\
PAD1 x PAD4 & $<0,001$ & & PAD3 x PAD5 & 0,005 \\
PAD1 x PAD5 & $<0,001$ & & PAD3 x PAD6 & 0,24 \\
PAD1 x PAD6 & 0,012 & & PAD4 x PAD5 & 0,83 \\
PAD2 x PAD3 & 0,47 & & PAD4 x PAD6 & 0,07 \\
PAD2 x PAD4 & 0,07 & & PAD5x PAD6 & 0,33 \\
PAD2 x PAD5 & 0,016 & & &
\end{tabular}

PAD = pressão arterial diastólica. $\mathrm{dp}=$ desvio padrão. Teste de Friedmann. 
A comparação pareada da $\mathrm{FC}$, entre os momentos estudados no grupo $C$, assinala um $p$ de 0,04 , o que é compatível com uma redução da FC estatisticamente significativa após a administração da clonidina. Observandose os momentos isoladamente, verifica-se que ocorre uma diferença estatística na comparação dos momentos 1 e 5; 2 e 5; 3 e 5; 3 e 6, sendo o momento 5 equivalente a 30 minutos após a administração da clonidina, o que corresponde ao pico de ação da mesma (Tabela 14).

Tabela 14 - Comparação das FC entre os momentos dos indivíduos do Grupo C (média \pm dp)

\begin{tabular}{lcccccc}
\hline FC1 & FC2 & FC3 & FC4 & FC5 & FC6 & P \\
\hline $66,0 \pm 10,7$ & $65,9 \pm 10,1$ & $65,9 \pm 9,7$ & $65,2 \pm 9,3$ & $63,9 \pm 10,7$ & $63,0 \pm 8,5$ & 0,04 \\
& & & & & \\
\hline Comparações & $\mathbf{p}$ & & Comparações & P \\
FC1 x FC2 & 0,56 & & FC2 x FC6 & 0,12 \\
FC1 x FC3 & 0,33 & & FC3 x FC4 & 0,13 \\
FC1 x FC4 & 0,56 & & FC3 x FC5 & 0,03 \\
FC1 x FC5 & 0,01 & & FC3 x FC6 & 0,01 \\
FC1 x FC6 & 0,27 & & FC4 x FC5 & 0,55 \\
FC2 x FC3 & 0,63 & & FC4 x FC6 & 0,70 \\
FC2 x FC4 & 0,17 & & FC5x FC6 & 1,00 \\
FC2 x FC5 & 0,04 & & & \\
\end{tabular}

$\overline{F C}$ = frequência cardíaca. $d p=$ desvio padrão. Teste de Friedmann.

Quanto à FR, a comparação entre os momentos dos indivíduos do grupo C evidencia um valor de $p$ de 0,28 , o que não tem significância estatística, entretanto, avaliando-se cada momento isoladamente, conclui-se que ocorre uma diferença da FR do momento 4 em comparação ao momento 6, equivalente a 0,012 , com um valor de FR de $16,9 \pm 1,8$, o qual encontra-se dentro da faixa fisiologicamente normal (Tabela 15). 
Tabela 15 - Comparação das FR entre os momentos dos indivíduos do Grupo C (média \pm dp)

\begin{tabular}{|c|c|c|c|c|c|}
\hline FR2 & FR3 & FR4 & FR5 & FR6 & $\mathbf{p}$ \\
\hline $17,0 \pm 2,3 \quad 16,7 \pm 2,3$ & $16,8 \pm 2,2$ & $16,4 \pm 2,1$ & $16,4 \pm 2,1$ & $16,9 \pm 1,8$ & 0,28 \\
\hline Comparações & $\mathbf{P}$ & \multicolumn{3}{|c|}{ Comparações } & $p$ \\
\hline FR1 $x$ FR2 & 0,61 & \multicolumn{3}{|c|}{$\mathrm{FR} 2 \times \mathrm{FR} 6$} & 1,00 \\
\hline FR1 $x$ FR3 & 0,63 & \multicolumn{3}{|c|}{$\mathrm{FR} 3 \times \mathrm{FR} 4$} & 0,18 \\
\hline FR1 1 FR4 & 0,37 & \multicolumn{3}{|c|}{ FR3 x FR5 } & 0,18 \\
\hline FR1 1 FR5 & 0,27 & \multicolumn{3}{|c|}{ FR3 $x$ FR6 } & 0,65 \\
\hline FR1 1 FR6 & 0,83 & \multicolumn{3}{|c|}{ FR4 $x$ FR5 } & 0,63 \\
\hline FR2 x FR3 & 0,56 & \multicolumn{3}{|c|}{ FR4 $x$ FR6 } & 0,012 \\
\hline $\mathrm{FR} 2 \times \mathrm{FR} 4$ & 0,29 & \multirow{2}{*}{\multicolumn{3}{|c|}{ FR5x FR6 }} & 0,06 \\
\hline FR2 x FR5 & 0,37 & & & & \\
\hline
\end{tabular}

FR = frequência Respiratória. $d p=$ desvio padrão. Teste de Friedmann.

Em relação à comparação dos valores de $\mathrm{SpO}_{2}$, entre os momentos dos indivíduos do grupo $C$, o valor de $p$ foi de 0,28 , não havendo diferença estatística na comparação entre os momentos isoladamente (Tabela 16).

Tabela 16 - Comparação das $\mathrm{SPO}_{2}$ entre os momentos dos indivíduos do Grupo C (média \pm dp)

\begin{tabular}{lcccccc}
\hline $\mathbf{S P O}_{2} 1$ & $\mathbf{S P O}_{2} 2$ & $\mathbf{S P O}_{2} \mathbf{3}$ & $\mathbf{S P O}_{2} \mathbf{4}$ & $\mathbf{S P O}_{2} \mathbf{5}$ & $\mathbf{S P O}_{2} 6$ & $\mathbf{p}$ \\
\hline $99,1 \pm 1,2$ & $99,3 \pm 1,3$ & $99,0 \pm 1,4$ & $99,1 \pm 1,3$ & $98,7 \pm 1,8$ & $98,4 \pm 1,8$ & 0,28 \\
& & & & & \\
\hline Comparações & $\mathbf{P}$ & & Comparações & $\mathbf{p}$ \\
$\mathrm{SPO}_{2} 1 \times \mathrm{SPO}_{2} 2$ & 0,36 & & $\mathrm{SPO}_{2} 2 \times \mathrm{SPO}_{2} 6$ & 0,02 \\
$\mathrm{SPO}_{2} 1 \times \mathrm{SPO}_{2} 3$ & 0,31 & & $\mathrm{SPO}_{2} 3 \times \mathrm{SPO}_{2} 4$ & 1,00 \\
$\mathrm{SPO}_{2} 1 \times \mathrm{SPO}_{2} 4$ & 0,65 & & $\mathrm{SPO}_{2} 3 \times \mathrm{SPO}_{2} 5$ & 0,61 \\
$\mathrm{SPO}_{2} 1 \times \mathrm{SPO}_{2} 5$ & 0,82 & & $\mathrm{SPO}_{2} 3 \times \mathrm{SPO}_{2} 6$ & 0,18 \\
$\mathrm{SPO}_{2} 1 \times \mathrm{SPO}_{2} 6$ & 0,15 & & $\mathrm{SPO}_{2} 4 \times \mathrm{SPO}_{2} 5$ & 0,43 \\
$\mathrm{SPO}_{2} 2 \times \mathrm{SPO}_{2} 3$ & 0,06 & & $\mathrm{SPO}_{2} 4 \times \mathrm{SPO}_{2} 6$ & 0,51 \\
$\mathrm{SPO}_{2} 2 \times \mathrm{SPO}_{2} 4$ & 0,15 & & $\mathrm{SPO}_{2} 5 \times \mathrm{SPO}_{2} 6$ & 0,39 \\
$\mathrm{SPO}_{2} 2 \times \mathrm{SPO}_{2} 5$ & 0,28 & & & &
\end{tabular}

$\mathrm{SPO}_{2}=$ Saturação de oxigênio. $\mathrm{dp}=$ desvio padrão. Teste de Friedmann. 
A comparação pareada da escala de Ramsay, entre os momentos dos indivíduos do grupo B, evidencia um valor de p inferior a 0,001 (Tabela 17), com mediana dos escores de sedação segundo a escala de Ramsay de 1 no momento 1; e de 2 nos demais momentos. No gráfico 3, pode-se observar valores de sedação segundo a escala de Ramsay que variam de 1 a 3 , havendo predominância dos valores 2 e 3 a partir do momento 2, que representa a administração da clonidina, demonstrando um nível de sedação desejável para a realização do cateterismo cardíaco na maioria dos pacientes (Gráfico 3).

Tabela 17 - Comparação das Ramsay entre os momentos dos indivíduos do Grupo C (mediana)

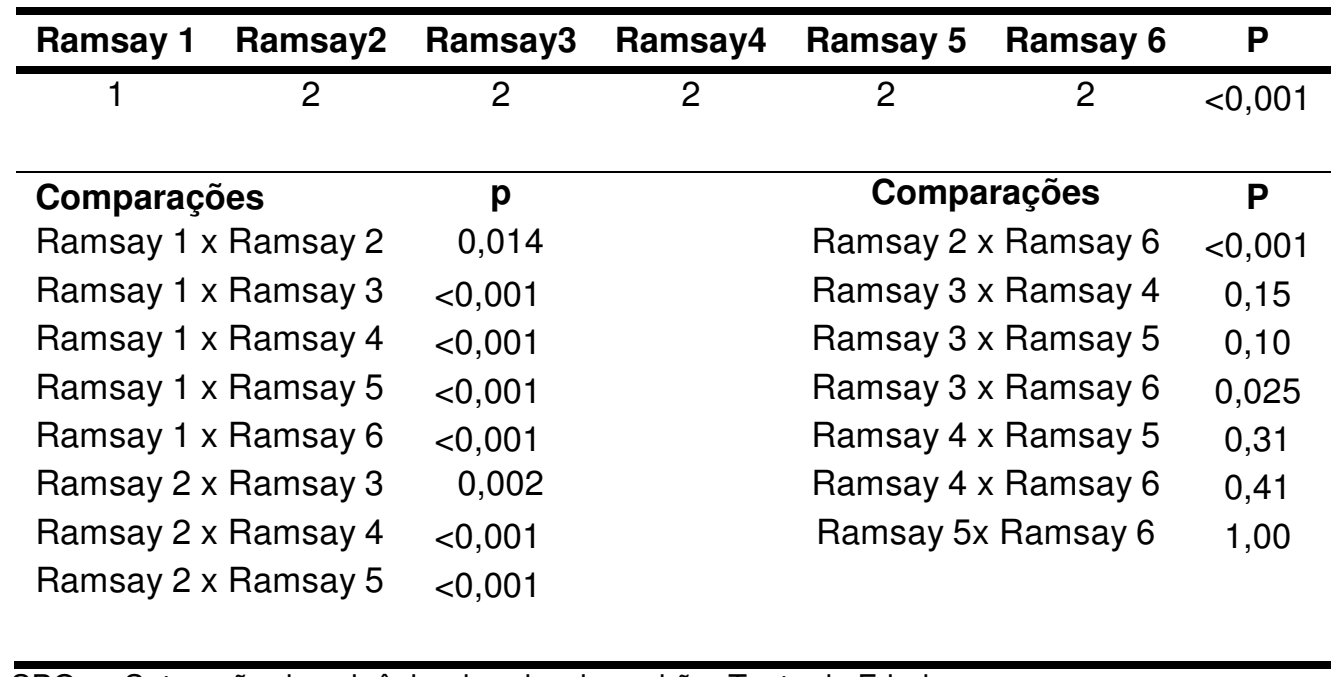

$\mathrm{SPO}_{2}$ = Saturação de oxigênio. $\mathrm{dp}=$ desvio padrão. Teste de Friedmann. 


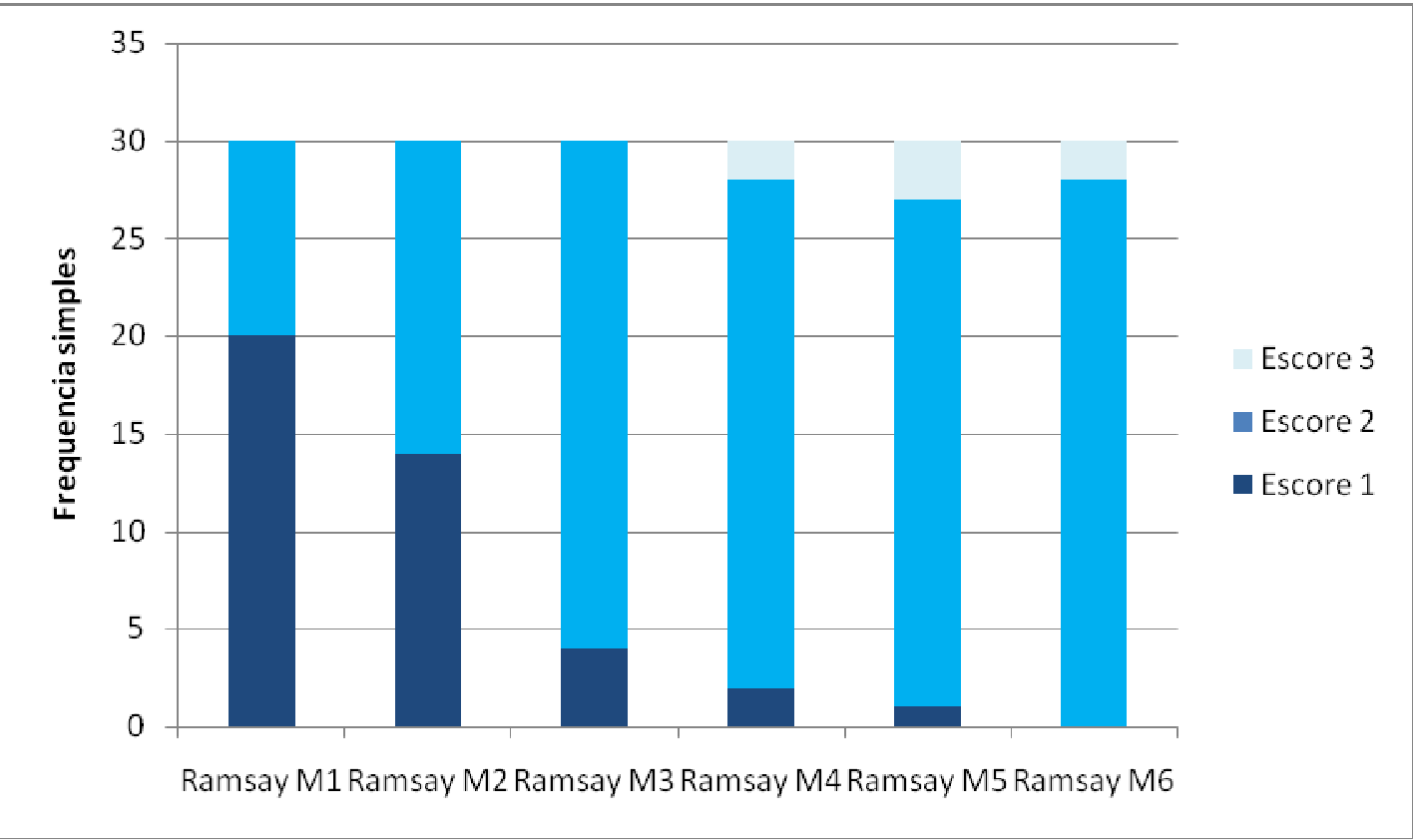

Gráfico 3 - Escores de Ramsay para cada momento do grupo C.

Nenhum dos pacientes dos dois grupos apresentou depressão respiratória ou alergia durante o procedimento.

Sete pacientes do grupo $\mathrm{S}$, mas nenhum paciente do grupo $\mathrm{C}$, apresentaram náusea e vômito durante o período de observação indicando uma incidência de 23,3\% de náusea e vômito no grupo sufentanil, com valor de $\mathrm{p}$ de 0,01 pelo teste Exato de Fisher, quando comparado com o grupo clonidina.

Um paciente do grupo $S(3,3 \%)$ apresentou retenção urinária contra nenhum do grupo C, com valor de p de 1 pelo teste Exato de Fisher.

Quanto à presença de dor, observa-se que apenas um paciente do $C(3,3 \%)$ apresentou dor de pequena intensidade contra nenhum do grupo $\mathrm{S}$, com valor de $\mathrm{p}$ de 1 pelo teste Exato de Fisher.

Houve satisfação do hemodinamicista quanto à técnica empregada em todos os pacientes estudados, não havendo diferença entre os 
dois grupos (Gráfico 4). Entretanto, nem todos os pacientes submetidos à sedação com sufentanil ficaram satisfeitos com o procedimento. Vinte e oito pacientes do grupo sufentanil $(93,3 \%)$ e trinta pacientes do grupo clonidina (100\%) apresentaram-se satisfeitos quanto ao procedimento anestésico, após a aplicação do teste Exato de Fisher (Gráfico 5).

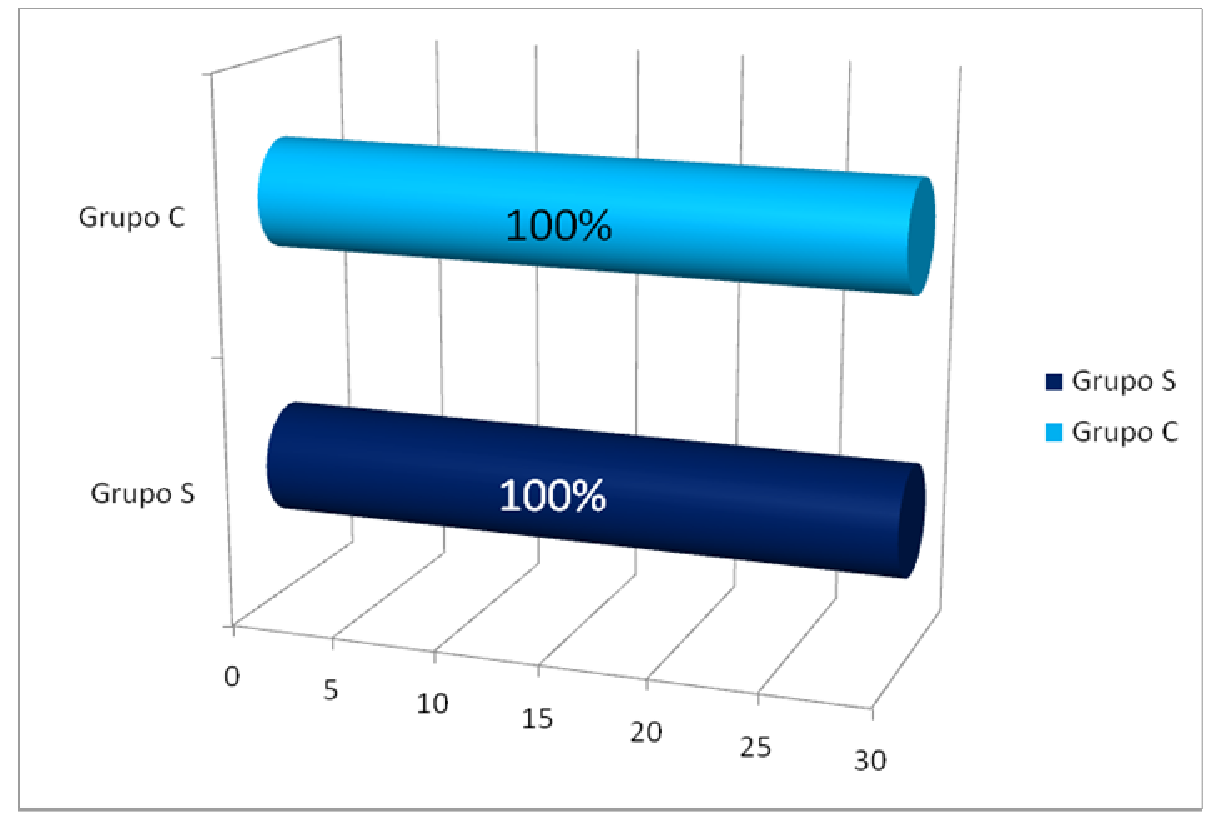

Gráfico 4 - Satisfação do hemodinamicista quanto ao fármaco empregado.

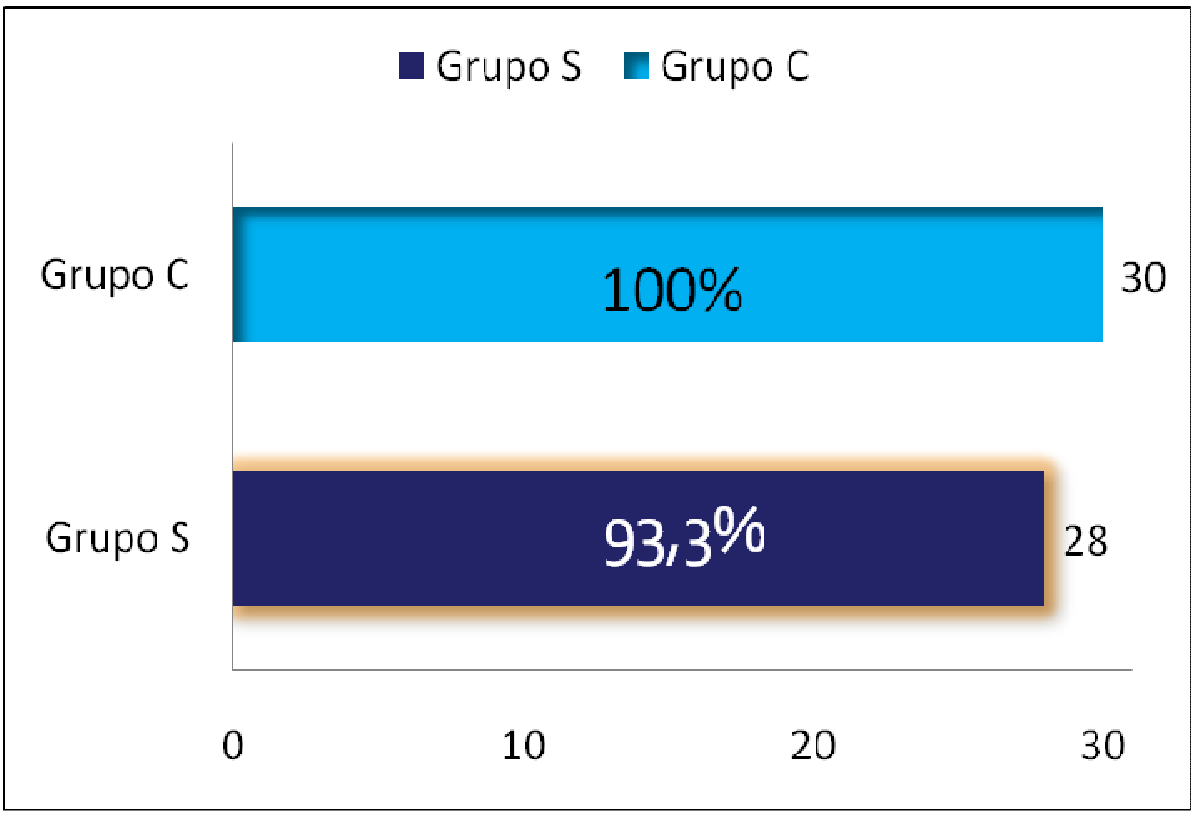

Gráfico 5 - Satisfação dos pacientes quanto ao procedimento $(p=0,49)$. 
Quanto ao valor de $\mathrm{SpO}_{2}$, observa-se uma queda da mesma em 16 pacientes do grupo $S(53,3 \%)$ e em 6 pacientes do grupo $C(20 \%)$, com valor de $\mathrm{p}$ de 0,007 pelo teste de Qui-quadrado, marcando uma diferença estatisticamente significante da saturação no grupo sufentanil quando comparado ao grupo clonidina (Gráfico 6).

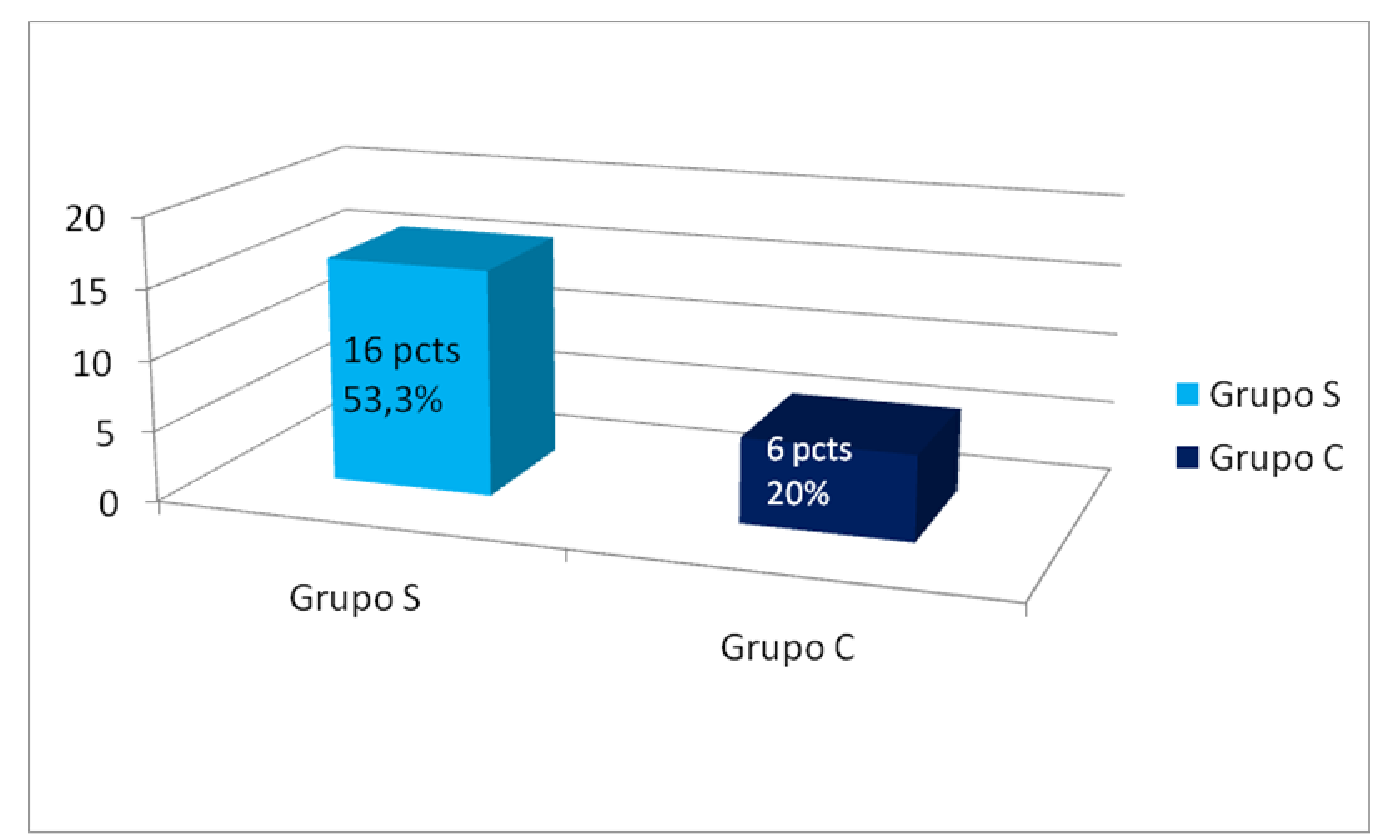

Gráfico 6 - Queda de Saturação dos pacientes durante o procedimento $(p=0,007)$.

Quatro pacientes no grupo $S$ e 3 pacientes no grupo $C$ necessitaram fazer uso de midazolam para suplementação da sedação. Sete pacientes do grupo $\mathrm{S}$ utilizaram metoclopramida para tratamento de náusea e vômito e 1 paciente do grupo C utilizou dipirona para controle da dor. A utilização de atropina foi semelhante nos dois grupos. Quanto aos demais fármacos, não houve necessidade de utilização dos mesmos. 


\section{DISCUSSÃO}

\subsection{DISCUSSÃO DA METODOLOGIA}

\subsubsection{A cineangiocoronariografia}

A escolha do laboratório de hemodinâmica para a realização deste trabalho ocorreu em função da carência de ensaios clínicos, duplamente encobertos e randomizados com a abordagem deste tema. Ao se avaliar 0 perfil dos pacientes que são submetidos ao procedimento de cateterismo cardíaco, observa-se que os mesmos, em geral, são portadores de comorbidades, tais como HAS, DM e doença pulmonar obstrutiva crônica. Portanto, beneficiar-se-iam da utilização de fármacos que possuíssem efeito ansiolítico e, consequentemente, diminuiriam as respostas danosas do estresse. Desta forma, permite-se a realização do cateterismo com menores riscos.

Com o advento de novos fármacos, possibilita-se a realização de procedimentos diagnósticos com maior conforto para o paciente e com menor impacto sobre os seus parâmetros hemodinâmicos. Apesar deste trabalho ter sido realizado com uma população muito restrita, representada por pacientes submetidos a cateterismo cardíaco, os seus resultados poderão ser extrapolados para outras situações cuja sedação leve seja desejada. Em vista disso, a realização deste trabalho permitirá a avaliação de fármacos sedativos que poderão ser eventualmente utilizados na sala de hemodinâmica, assim como fora dela. 


\subsubsection{Momentos determinados para observação dos dados}

Foram selecionados seis momentos para avaliação dos dados obtidos.

O M1 foi considerado o controle, que corresponde ao período que antecede o início do exame, importante para definir o perfil dos pacientes submetidos ao cateterismo cardíaco no laboratório de hemodinâmica.

O M2 ocorre cinco minutos após a administração do fármaco e representa o pico de ação do sufentanil. O M3 coincide com o início do cateterismo cardíaco; enquanto que o M4 com o final do procedimento. Os dados também foram coletados nos M5 e M6 que correspondem, respectivamente, a 30 e a 90 minutos após a administração dos fármacos sedativos. É importante ressaltar que estes momentos se relacionam com o pico de ação da clonidina e com a alta da SRA. A alta ocorreu em um tempo que foi considerado suficiente para contemplar eventuais complicações do procedimento.

\subsection{DISCUSSÃO DOS RESULTADOS}

Este estudo avaliou a eficácia do sufentanil versus clonidina como medicação sedativa em pacientes submetidos a cateterismo cardíaco com testes positivos para isquemia coronariana, comparando os seus efeitos sobre os parâmetros hemodinâmicos apresentados durante o exame. A escolha destes fármacos foi pautada em estudos previamente realizados, nos quais, verificou-se o benefício da clonidina como medicação pré-anestésica e como 
adjuvante em pacientes submetidos aos procedimentos cirúrgicos cardiológicos e não-cardiológicos, reduzindo a incidência de isquemia miocárdica (DORMAN et al., 1993).

Nascimento et al. demonstraram o benefício da clonidina em pacientes submetidos à cateterismo cardíaco, quando comparada a um grupo controle sem sedação. Aqueles pacientes que foram sedados com este fármaco apresentaram menor variação da pressão arterial e da freqüência cardíaca (NASCIMENTO et al., 2006). Apesar de não haver estudos publicados que abordem a utilização do sufentanil no laboratório de hemodinâmica sabese que este tem sido administrado como coadjuvante em procedimento anestésicos e analgésicos, sendo também indicado para sedação em pacientes adultos e pediatricos (SILVIA et al., 2007), dentro e fora do centro cirúrgico.Após análise estatística, observou-se que os grupos, do presente estudo, foram semelhantes em relação aos dados antropométricos, aos parâmetros hemodinâmicos, a comorbidades, aos fatores de risco e à utilização prévia de medicações, tendo os grupos distribuição normal e equivalente com relação a todos estes dados (Tabelas 1, 2 e 3), o que atesta a homogeneidade dos grupos antes da interferência do pesquisador.

Os indivíduos inclusos no estudo eram, em sua maioria, idosos, de ambos os sexos, com IMC de $26,6 \mathrm{~kg} \pm 3,8$ e $26,4 \pm 3,8$ e com comorbidades como HAS, ICO, DM e DPOC, dessa forma, compatíveis com o perfil de população esperada, pois alguns estudos relatam que os pacientes submetidos ao cateterismo cardíaco, em sua maioria, são pacientes complexos, com idade elevada e com inúmeras comorbidades (SHOOK; GROSS, 2007). 
No estudo em foco, detecta-se um comportamento semelhante dos parâmetros hemodinâmicos, em ambos os grupos, comprovado estatisticamente pelos valores observados da PAS, da PAD e da frequência cardíaca. Considerando-se os valores de PAS, de PAD e da frequência cardíaca mensurados nos M1 e M3 que representam, respectivamente, os períodos anteriores à administração do sufentanil e da clonidina e ao início do cateterismo cardíaco, observa-se uma similaridade de comportamento nos dois grupos.

Desta forma, pode-se afirmar que, para esta população estudada, o sufentanil exibiu características semelhantes as da clonidina no sentido de bloquear as alterações hemodinâmicas, usualmente observadas, após o início dos procedimentos intervencionistas. Isto sugere que os fármacos utilizados foram efetivos em bloquear a resposta simpática cardiovascular nos pacientes submetidos ao cateterismo cardíaco. Sabe-se que o controle dos parâmetros hemodinâmicos reduz a incidência de isquemia miocárdica e mortalidade pósoperatória em pacientes que possuem fatores de risco para doença coronariana (WALLACE et al., 1998).

Os resultados obtidos demonstram similar eficácia do sufentanil e da clonidina em relação à proteção do sistema cardiovascular, evitando a presença de hipertensão, de hipotensão e de taquicardia, elementos considerados como de risco para a descompensação de doença cardíaca preexistente (MANTZ, 2000; WALLACE et al,. 2004) o que é uma constante no laboratório de hemodinâmica. 
É importante lembrar que os locais que possuem receptores opioides, como os centros reguladores do sistema cardiovascular no SNC, a medula espinhal, o sistema nervoso simpático, os núcleos vagais e a medula adrenal, contribuem para que os opioides atenuem ou eliminem significativas respostas hemodinâmicas aos estímulos nocivos. Deste modo, esses agentes utilizados em anestesia produzem depressão cardíaca desprezível, com mínimo ou nenhum decréscimo na pré e pós-carga, pouca depressão dos grandes vasos e barorreceptores atriais e nenhum efeito na motricidade coronariana (BAILEY; EGAN, 1997). O sufentanil, como opioide potente, tem sido de grande valia como fármaco que provê analgesia e sedação perioperatórias com mínimo efeito hemodinâmico deletério (NOCITI et al., 1995).

Por sua vez, a clonidina, por ser um agonista alfa-2 adrenérgico, proporciona estabilidade hemodinâmica por meio da redução dose-dependente da pressão arterial e frequência cardíaca, impedindo a ocorrência de taquicardia e de hipertensão arterial durante seu uso (AANTAA, 1991). Entretanto, a sua administração deve ser feita de forma lenta a fim de evitar a ocorrência de efeitos indesejáveis, tais como o aumento momentâneo na pressão arterial em decorrência do estímulo dos receptores alfa-2 agonistas da musculatura lisa vascular e bradicardia reflexa (BLOOR et al., 1992).

Os parâmetros respiratórios avaliados foram frequência respiratória e $\mathrm{SpO}_{2}$. A frequência respiratória foi similar nos dois grupos, porém os pacientes se comportaram de maneira diferente no que diz respeito a $\mathrm{SpO}_{2}$, visto que, no M6, o valor de $\mathrm{p}$ foi de 0,02 , indicando que, no momento da alta 
do RPA, o sufentanil está associado a menor valor de $\mathrm{SpO}_{2}$ quando comparado com a clonidina. O valor de $\mathrm{SpO}_{2}$ do Grupo S, no $\mathrm{M6}$, foi de $97,1 \% \pm 2,2$ contra $98,4 \% \pm 1,8$, o que é considerado como valor normal (Tabela 4). Deve-se observar que o M6 representa o final do estudo, estando o paciente submetido a menor estimulação. Este achado é compatível com os dados de literatura que demonstram que a depressão respiratória é rara em pacientes submetidos a procedimentos cirúrgicos e diagnósticos (RIBEIRO et al., 2002). Apesar de rara, a depressão respiratória merece atenção em função da sua gravidade e do fato de ser um dos maiores temores dos usuários e prescritores de opioides.

Os opioides interferem com a função respiratória de maneira dose-dependente, com isso, proporcionando aumento da pressão parcial de dióxido de carbono no sangue arterial e deslocamento da curva de resposta ao $\mathrm{CO}_{2}$. Os agonistas opioides atuam no centro respiratório no bulbo, podendo aumentar a pausa respiratória e reduzir a sensibilidade central ao aumento de $\mathrm{CO}_{2}$ (GOZZANI, 1994). A depressão respiratória decorrente do uso de opioides é dose-dependente, tendo a sua incidência aumentada proporcionalmente ao aumento deste fármaco. Neste estudo, o sufentanil foi administrado na dose de $0,1 \mathrm{mcg} / \mathrm{kg} / \mathrm{min}$, considerada pequena e improvável de causar depressão respiratória.

Os efeitos respiratórios da clonidina são bastante debatidos, mas o consenso é que os agonistas alfa-2 adrenérgicos estão associados à depressão respiratória mínima (BELLEVILLE et al., 1992); e este estudo confirma isto. Os agonistas alfa-2 adrenérgicos, apesar de estarem presentes 
no cérebro, não possuem um papel no controle central da respiração (HALL et al., 2001).

Avaliando-se os valores da escala de Ramsay, verifica-se que, no M2, os pacientes que utilizaram sufentanil apresentaram maior nível de sedação quando comparados com aqueles que utilizaram clonidina (Tabela 3). O M2 representa cinco minutos após a administração do fármaco, o que é compatível com o pico de ação do sufentanil, o qual é sabidamente de três a cinco minutos. Entretanto, ao se observar os escores da escala de Ramsay em cada momento, de maneira mais detalhada nos dois grupos, verifica-se que os pacientes, em sua maioria, alcançaram nível de sedação satisfatório, sendo que o sufentanil esteve associado a um início de ação mais precoce quando comparado com a clonidina, o que pode ser justificado pelo fato do sufentanil ter ação praticamente imediata após a sua aplicação. A clonidina tem início de ação com cinco minutos.

A escala de Ramsay foi elaborada há 25 anos, apesar disso, ela continua sendo a melhor forma de avaliar, de maneira subjetiva, os níveis de sedação (SCHULTE-TAMBUREN et al., 1999).

O sítio para ação sedativa dos agonistas alfa-2 adrenérgicos encontra-se no "locus coeruleus" do tronco cerebral; e este, quando estimulado, leva à inibição da regulação do sono e vigília (MAZE; TRANQUILLI, 1991). As principais vias noradrenérgicas ascendentes e descendentes originam-se desta importante área. A ativação dos receptores alfa-2, no "locus coeruleus", produz supressão de sua atividade, resultando em aumento da 
atividade de interneurônios inibitórios, como a via do ácido $\gamma$-aminobutírico (GABA), o que determina depressão do SNC (BRAZ et al., 2002).

Vários autores descrevem a eficácia da clonidina como fármaco sedativo (KNIGHT et al., 2005; FUJII et al., 2000; AMBROSE et al., 2000). Em alguns estudos, quando utilizada para sedação leve, a clonidina teve resultados comparáveis ao fentanil, evitando doses extras de sedativos (REIMER et al., 1998). Sabe-se que os receptores alfa-2 adrenérgicos têm parte de sua ação farmacológica através da ativação dos mesmos canais de potássio que os receptores opioides (JACOBI et al., 2002), o que poderia justificar o comportamento semelhante da clonidina em relação aos opioides atinentemente à sedação. Neste estudo, a sedação obtida com a clonidina foi semelhante a do sufentanil. Todavia, deve-se ressaltar que a dose utilizada da clonidina foi de $0,5 \mathrm{mcg} / \mathrm{kg}$, o que é inferior ao preconizado na literatura para sedação profunda, que corresponde a valores entre 2 e $6 \mathrm{mcg} / \mathrm{kg} / \mathrm{dose}$ (KRESS et al., 2000).

É importante observar que a sedação promovida pela clonidina é dose-dependente e que o nível de sedação desejado para a realização de cateterismo cardíaco é leve, o que corresponde ao nível 2 e 3 da escala de Ramsay, fato que justifica a administração de menores doses deste fármaco.

O sufentanil, por sua vez, exerce efeito sedativo ao atuar sobre receptores opioides localizados no sistema nervoso central, efeito este atribuído à sua ligação com receptores do tipo kapa (TRESCOT et al., 2008). A sedação decorrente do uso de sufentanil é dose-dependente. Estudos que avaliaram as ações dos opioides sobre o sistema nervoso central 
demonstraram que, em doses relativamente baixas $(0,35 \mathrm{mcg} / \mathrm{kg})$, o sufentanil promove uma maior incidência de sono quando comparado ao fentanil $(3,5$ $\mathrm{mcg} / \mathrm{kg})$.

\subsubsection{Comparação pareada dos parâmetros utilizados para cada fármaco}

\subsubsection{Pressão arterial}

A comparação pareada das PAS e PAD entre os momentos, nos grupos S e C, revelou que houve variação significativa entre os mesmos nos dois grupos, tanto após a administração de sufentanil quanto após a administração de clonidina, evidenciando que estes fármacos foram efetivos no controle da pressão arterial. É importante observar que os valores alcançados de PAS e PAD estavam dentro da faixa fisiológica.

A ativação dos receptores alfa-2 adrenérgicos pré-sinápticos, nas terminações nervosas periféricas, inibe a exocitose da noradrenalina, explicando, parcialmente, o efeito hipotensor da clonidina (DECKERT et al., 1991).

Pesquisas relacionam os receptores imidazólicos com a ação hipotensora da clonidina através da ligação da mesma a receptores I1 localizados no sistema nervoso central (REIS et al., 1989). A estimulação dos receptores I1 e alfa-2 adrenérgicos produz respostas fisiológicas semelhantes em relação à atividade hipotensora, havendo uma correlação com o número de receptores imidazólicos ocupados, mas não com o número de receptores alfa-2 adrenérgicos (REIS et al., 1992). 
Quanto ao sufentanil, sabe-se que este exerce efeito mínimo sobre a pressão arterial. Um estudo realizado por Dumaresq et al. 1997, no intuito avaliar a eficácia clínica do sufentanil em pacientes submetidos a anestesia geral para a realização de cirurgias de médio e grande porte, demonstrou que o sufentanil, na dose de 1 e $2 \mathrm{mcg} / \mathrm{kg}$, esteve associado à estabilidade hemodinâmica, mesmo quando outros fármacos com potencial para alteração da pressão arterial foram administrados (DUMARESQ et al., 1997).

\subsubsection{Frequência cardíaca}

Analisando-se o comportamento da FC, verifica-se que a comparação pareada entre os momentos dos indivíduos do grupo $S$ demonstrou não haver uma variação significativa do parâmetro em questão, dado que é compatível com os achados de literatura. O sufentanil, mesmo em doses elevadas, está associado à estabilidade hemodinâmica, podendo ser utilizado com segurança em pacientes coronariopatas (GOZZANI, 1994).

Os pacientes do grupo $\mathrm{C}$ apresentaram uma tendência à bradicardia, com valor de $p$ de 0,04. Apesar de haver uma queda da frequência cardíaca, observa-se que esta não é acentuada, o que pode ser justificado pela atenuação, e não eliminação, do aumento da concentração plasmática de epinefrina em resposta ao estresse. A literatura descreve que os agonistas alfa2 adrenérgicos reduzem a frequência cardíaca ao proporcionar redução da concentração plasmática de norepinefrina e de outros hormônios de estresse em mais de 90\% (KALLIO et al., 1989). 
É importante lembrar que a rápida administração da clonidina pode reduzir a frequência cardíaca ao estimular receptores alfa-2 da musculatura lisa vascular periférica, então, causando aumento da pressão arterial e bradicardia reflexa e que este efeito pode ser evitado pela administração lenta deste fármaco (TALKE, 2000).

A clonidina provoca diminuição gradual e dose-dependente da frequência cardíaca. A bradicardia tem início minutos após a sua administração, podendo atingir um pico em até 60 minutos (KARHUVAARA et al., 1991; NASCIMENTO et al., 2006), fato que justificou o acompanhamento do paciente por, pelo menos, 90 minutos após a aplicação da mesma.

Apesar de a clonidina estar associada à redução da frequência cardíaca e de a bradicardia ser facilmente reversível pela administração de atropina (TALKE, 2000), poucos pacientes do grupo C necessitaram fazer uso deste fármaco. Este fato é interessante, pois a labilidade da frequência cardíaca é algo indesejável nos pacientes coronariopatas, os quais poderiam apresentar aumento do consumo de oxigênio e descompensação da sua doença de base (WALLACE, 2006).

\subsubsection{Frequência respiratória}

$\mathrm{Na}$ avaliação da FR, a comparação pareada entre os momentos dos indivíduos do grupo S e C não evidenciou diferença. Como esperado, os pacientes que participaram deste estudo não apresentaram queda da frequência respiratória após o uso de clonidina ou sufentanil, a qual só tem sido 
relatada após administração de doses elevadas desses dois fármacos. Ezri et al. (1998), em sua pesquisa, detectaram a ocorrência de bradipneia após aplicação de clonidina na dose de $5 \mathrm{mcg} / \mathrm{kg}$, o que corresponde a dez vezes a dose administrada neste estudo.

\subsubsection{Sedação}

Os valores das escalas de Ramsay e de $\mathrm{SpO}_{2}$ variaram significativamente entre os momentos, nos pacientes do grupo $S$, demonstrando que o sufentanil tem efeito sedativo, e está associado a queda de $\mathrm{SpO}_{2}$, entretanto a queda de $\mathrm{SpO}_{2}$ apresentada não compromete a segurança da utilização deste fármaco, visto que o valor de $\mathrm{SpO}_{2}$ variou entre $95,5 \% \pm 16,5$ e $98,8 \% \pm 2,6$.

No Grupo C, houve variação no valor da escala de Ramsay, variação esta que não esteve acompanhada da modificação de $\mathrm{SpO}_{2}$, assim, evidenciando que, mesmo em baixa dose, a clonidina estabelece sedação efetiva sem associação com queda da saturação.

Os resultados obtidos favorecem a utilização de sufentanil e clonidina como fármacos sedativos. Apesar de haver-se ciência de que sedação não, necessariamente, significa ansiólise, estudos têm associado a clonidina e outros agonistas alfa-2 adrenérgicos a este efeito o qual é comparável ao observado após a utilização de benzodiazepínicos. O efeito ansiolítico da clonidina está associado à ação deste fármaco em receptores específicos localizados no sistema nervoso central (NAGUIB; YAKSH, 1994), 
não se comportando de maneira dose-dependente (SODERPALM; ENGEL, 1988).

\subsubsection{Outros parâmetros avaliados}

\subsection{Náusea e vômito}

Os pacientes do Grupo S apresentaram uma incidência de náusea e vômito de $23,3 \%$ contra nenhum paciente do grupo clonidina. Tal fato demonstra que a incidência de náusea e vômito encontrada no grupo sufentanil foi semelhante àquela descrita em literatura. Sabe-se que náusea e vômito perioperatórios (NVPO) são frequentes, principalmente no período pósoperatório, com prevalência estimada em 20 a 30\% (ABREU, 2006; NEUSA et al., 2005; CARVALHO et al., 1999), estando asssociados a desconforto para o paciente e a complicações, como desidratação, elevação da pressão intracraniana e intraocular, pneumonite aspirativa, distúrbios eletrolíticos e até mesmo rotura esofágica (SCHMIDT; BAGATINI, 1997; KU; ONG, 2003). A etiologia da NVPO é multifatorial, e sua presença se justifica pelo comprometimento de diversos neurotransmissores em vias neurais específicas, como vias dopaminérgicas, serotoninérgicas, histaminérgicas e colinérgicas. Dentre os fármacos capazes de desencadear NVPO, opioides como o sufentanil ganham destaque cujo uso se considera como fator de risco principal, juntamente com sexo feminino, abstinência ao tabagismo e história prévia de náusea e vômito (THOMAS et al., 2002; SINCLAIR et al., 1999). Neste trabalho, não foi pesquisada a presença destes fatores de risco, 
entretanto os grupos foram considerados homogênios segundo os outros parâmetros.

É importante observar que os opioides podem desencadear náusea e vômito ao estimular as vias aferentes serotoninérgicas relacionadas ao nervo vago que se conectam com a zona de gatilho quimiorreceptora, localizada na base do quarto ventrículo no cérebro, e ao atuar como agonistas parciais dos receptores dopaminérgicos, localizados nesta mesma zona quimiorreceptora (MALAN, 2000).

\subsection{Retenção urinária}

Um paciente do Grupo S apresentou retenção urinária; todavia nenhum paciente do Grupo C evoluiu com queixas relacionadas ao aparelho urinário. Apesar da pequena incidência deste evento, que foi de 3,3\%, este dado merece ser comentado, pois se sabe que a mesma encontra-se relacionada a retardo na alta hospitalar, após a realização de procedimentos ambulatoriais.

Como citado anteriormente, a retenção urinária é comum após anestesia e cirurgia, sendo relatada uma incidência de 5 a $70 \%$ deste evento adverso no período pós-operatório imediato. Este valor é superior ao encontrado neste estudo, fato que pode ser justificado pela pequena dose de opioide administrada. Acredita-se que a presença de retenção urinária seja um efeito dose-dependente, pois trabalhos realizados, com pacientes submetidos à colecistectomia e apendicectomia, evidenciam que a incidência de retenção urinária pós-operatória é proporcional ao montante de opioide utilizado 
(PETROS, 1993). É importante lembrar que os agonistas e os antagonistas alfa-2 adrenérgicos alteram a função da bexiga ao atuarem em receptores alfa2 presentes na musculatura lisa do trato urinário inferior e superior (DURANT; YAKSH, 1988; EVRON et al., 1984; HAMAYA et al., 1994). Gentili et al, 1996 analisaram os efeitos da clonidina sobre a função da bexiga e, assim como neste estudo, perceberam que a clonidina está relacionada a menor incidência de retenção urinária pós-operatória quando comparada ao opioide (GENTILI; BONNET, 1996). Possíveis mecanismos envolvidos com a ação da clonidina são: redução do fluxo simpático no cordão espinha e efeito inibitório supraespinhal, desse modo, reduzindo o tônus do esfíncter uretral interno (HAMAYA et al., 1994).

\subsection{Dor}

A dor não foi observada em nenhum paciente do Grupo S, porém a sua incidência no Grupo C foi de 3,3\%. Sabe-se que o procedimento de cateterismo cardíaco, em geral, não está associado à grande estímulo álgico e que, quando este está presente, é de pequena intensidade.

Neste estudo, o objetivo primário da administração do sufentanil não foi o controle da dor, entretanto as suas propriedades analgésicas já são bem estabelecidas. O mecanismo analgésico do sufentanil é semelhante ao de qualquer outro opioide, ocorrendo após a sua ligação a receptores específicos localizados ao nível central e periférico (INTURRISI, 2002). 
A clonidina, apesar de ser um fármaco agonista alfa-2, apresenta propriedades analgésicas as quais estão associadas a estruturas presentes na medula espinhal (BOUAZIZ et al., 1995) e em sítios supraespinhais. Ambrose e col., 2000 descreveram a utilização de clonidina, em UTI, como substituta da morfina em pacientes que se tornaram tolerantes aos opioides ou que apresentaram dificuldade de sedação, assim, observando uma boa resposta com mínimos efeitos adversos (AMBROSE et al., 2000).

\subsection{Satisfação do paciente}

Ao se avaliar a satisfação do paciente, observou-se que $100 \%$ dos pacientes do Grupo C e 93,3\% dos pacientes do Grupo A referiram estarem satisfeitos com o procedimento anestésico. Não foi questionado ao paciente o porquê de sua insatisfação, entretanto os pacientes do grupo sufentanil apresentaram maior incidência de náusea e vômito quando comparados com os pacientes do grupo clonidina. Estudos referem que náusea e vômito representam causa frequente de insatisfação e de retardo da alta hospitalar em pacientes submetidos a procedimentos ambulatoriais (WU et al., 2002; SINCLAIR et al., 1999).

\subsection{Satisfação do hemodinamicista}

Todos os hemodinamicistas mostraram-se satisfeitos quanto ao procedimento anestésico realizado, justificado pela demonstração de nível de sedação adequado com mínimos efeitos adversos. 


\section{CONCLUSÃO}

Após os resultados encontrados, concluiu-se que:

1. os grupos estudados foram homogênios quanto aos dados antropométicos e características clínicas;

2. de uma maneira geral, o sufentanil proporcionou aos pacientes sedação equivalente à clonidina, porém o sufentanil esteve associado a maior queda da saturação de oxigênio, dentro de uma faixa considerada como normal;

3. o sufentanil e a clonidina, quando comparados entre si, apresentaram comportamento semelhante concernente às alterações da PAS, PAD, FC e FR;

4. a sedação associada ao sufentanil foi mais precoce quando comparada a da clonidina;

5. o sufentanil esteve associado à maior incidência de náusea e vômito quando comparado à clonidina;

6. os hemodinamicistas ficaram igualmente satisfeitos com os fármacos sedativos utilizados para a sedação dos pacientes durante 0 procedimento de cateterismo cardíaco; e

7. os pacientes que utilizaram clonidina se demonstraram mais satisfeitos com o procedimento anestésico quando comparados com aqueles que utilizaram a clonidina. 


\section{REFERÊNCIAS}

Aantaa R. Assessment of the sedative effects of dexmedetomidine, nad $_{2}-$ adrenoceptor agonist, with analysis of saccadic eye movements. Pharmacol Toxicol. 1991;68:394-8.

Aantaa R, Jaakola ML, Kallio A et al. Reduction of the minimum alveolar concentration of isoflurane by dexmedetomidine. Anesthesiology. 1997;86:1055-60.

Abreu MP. Controle de náuseas e vômitos - antieméticos. Em: Cangiani LM, Posso IP, Potério GMB et al. Ed. Tratado de Anestesiologia SAESP. São Paulo: Atheneu; 2006. p. 1361-72.

Allen RM, Dykstra LA. Role of morphine maintenance dose in the development of tolerance and its attenuation by an NMDA receptor antagonist. Psychopharmacology. 2000;148:59-65.

Almeida JR, Almeida MB, Oliveira JO et al. Efeitos terapêuticos e colaterais dos opiáceos. Em: Oliveira JO. Opiáceos o Estado D’arte. São Paulo: LEMAR; 2001. p. 31-45.

Alves TCA, Braz JRC, Vianna PTG. Alfa-2 agonistas em anestesiologia: aspectos clínicos e farmacológicos. Rev Bras Anestesiol. 2000; 50:396-404.

Ambrose C, Sale S, Howells R et al. Intravenous clonidine infusion in critically ill children: dose-dependent sedative effects and cardiovascular stability. $\mathrm{Br} J$ Anaesth. 2000;84:794-6.

Angst MS, Clark JD. Opioid-induced hyperalgesia: a qualitative systematic review. Anesthesiology. 2006;104:570-87.

Bailey PL, Egan TD. Fentanyl and congeners. In: White PF. Intravenous anesthesia. Baltimore: Williams \& Wilkins; 1997. p. 213-45. 
Bailey PL, Stanley TH. Pharmacology of intravenous narcotic anesthetic. In: Miller RD, ed. Anesthesia. $2^{\text {nd }}$ ed. New York: Churchill Livingstone; 1986. $p$. 745-98.

Baldini G, Bagry H, Aprikian A, Carli F, Phil M. Postoperative urinary retention: anesthetic and perioperative considerations. Anesthesiology. 2009;110:113957.

Belleville JP, Wards DS, Bloor BC et al. Effects of intravenous dexmedetomidine in humans. I. Sedation, ventilation and metabolic rate. Anesthesiology. 1992;77:1125-33

Bernards CM, Shen DD, Sterling ES et al. Epidural, cerebrospinal fluid, and plasma pharmacokinetics of epidural opioids: effect of epinephrine. Anesthesiology. 2003;99:466-75.

Binning S, Coggins S, Davidson A et al. Comparison of two dosing regimes of morphine-6-glucuronide versus morphine for analgesia following total hip replacement [abstract]. Proceedings of the $4^{\text {th }}$ Congress of EFIC; 2003. Prague; 2003. T587.

Birnbaumer L. G proteins in signal transdution. ANN Rev Pharmacol Toxicol. 1990; 30:675-705.

Bloor BC, Ward DS, Maze M et al. Effects of intravenous dexmedetomidine in humans. Anesthesiology. 1992; 77:1134-42.

Bonnet F, Darmon PL. Interférence entre lês médicaments cardio-vasculaires ET Lànesthésie: IV Les Agonistes alpha 2-adrenergiques. In: Coriat P. Les Contraintes Circulatoires et le Risque Cardiaque de L'Ànesthésie, Paris: Arnette; 1997. p. 291-305.

Bouaziz $\mathrm{H}$, Hewitt $\mathrm{C}$, Eisenach JC. Subarachnoid neostigmine potentiation of alfa-2 adrenergic agonist analgesia. Dexmedetomidine versus clonidine. Reg Anesth. 1995; 20:121-7. 
Bovill JG, Sebel OS, Blackburn CL et al. The pharmacokinetics of sufentanil in surgical patients. Anesthesiology. 1984; 61:502-6.

Brain DS. Cardiac catheterization, angiography, intervention. $7^{\text {th }}$ ed., 2006.

Braz LG, Vianna PTG, Braz JRC et al. Níveis de sedação determinados pela clonidina e midazolam na medicação pré-anestésica. Avaliação clínica e eletroencefálica bispectral. Rev Bras Anestesiol. 2002;52:9-18.

Bromage PR, Camporesi EM, Durant PA et al. Non respiratory side effects of epidural morphine. Anesth Analg. 1982;61:490-5.

Bylund DB. Subtypes of $\alpha 2$-adrenoceptores: pharmacological and molecular biological evidence converge. Trends Pharmacol Sci. 1988;9:356-61.

Carvalho WA, Vianna PTG, Braz JRC. Náuseas e vômito em anestesia: fisiopatologia e tratamento. Rev Bras Anestesiol 1999;49:65-79.

Casey PJ, Gilman AG. G protein involviment in receptor-effector coupling. J Biol Chem. 1988; 263:2577-80.

Cavalcanti IR, Assad AR, Lacerda MA. Anestesia para procedimentos fora do centro cirúrgico. $1^{\underline{a}}$ ed. Rio de Janeiro: Sociedade de Anestesiologia do Estado do Rio de Janeiro (SAERJ); 2007.

Chaney MA. Side effects of intrathecal and epidural opioids. Can J Anaesth. 1995;42:891-903.

Chahl LA. Opioids. mechanism of action. Aust Prescr. 1996;19:63-5.

Clapham DE, Neer EJ. New roles for G protein $\beta \gamma$-dimmer's in transmembrane signaling. Nature. 1993;365:403-6.

Combrisson H, Robain G, Cotard JP. Comparative effects of xylazine and propofol on the urethral pressure profile of healthy dogs. Am J Vet Res. 1993; 54:1986-9 
Correa SC, Nacif CC, R, Maze M. A hypnotic response to dexmedetomidine, an $\alpha_{2}$-agonist, is mediated in the locus coeruleus in rats. Anesthesiology. 1992; 76:948-52.

Correa SC, Nacif CC, Reid K et al. Inhibition of adenyl cyclase in the locus coeruleus mediates the hypnotic response to na alpha 2 agonist in the rat. $J$ Pharmacol Exp Ther. 1992;263:1046-9.

Correa SC, Reid K, Maze M et al. Pertussis toxin mediated ribosylation of G proteins blocks the hypnotic response to an $\alpha_{2}$-agonist in the locus coeruleus of the rat. Pharmacol Biochem Behav. 1999;43:723-7.

Corssen G, Reves JG, Stanley TH. Intravenous anesthesia and analgesia. Philadelphia: Lea and Febiger; 1988.

Cucchiaro G, Dagher C. Side-effects of postoperative epidural analgesia in children: a randomized study comparing morphine and clonidine. Paediatric Anaesth. 2003;13:318-23.

Curi, PR. Metodologia e análise da pesquisa em ciências biologicas. $2^{\underline{a}}$ ed. Botucatu: Tipomic; 1998.

Davis MP, LeGrand SB, Lagman R. Look before leaping. Support Care Cancer. 2005;13:769-74.

Davis CL, Carol L. ABC of palliative care: Breathlessness, cough, and other respiratory problems. BMJ. 1997;315:931-4.

Deckert V, Lachaud V, Parini A et al. Contribution of alpha 2-adrenoceptors to the central cardiovascular effects of clonidine and S 8350 in anaesthetized rats. Clin Exp Pharm Physiol. 1991;18:401-8. 
De Jonga A, Timmermans PB, Van Zweiten PA. Participation of cardiac presynaptic a2-adrenoceptors in the bradycardiac effects of clonidine and analogues. Naunyn Schmiedebergs Arch Pharmacol. 1981;137:8-12.

De Negri $P$, Ivane $G$, Visconti $C$ et al. The dose-response relationship for clonidine added to a post-operative continous epidural infusion of ropivacaine in children. Anesth Analg. 2001; 93:71-6.

Dorman BH, Zucker JR, Verrier ED et al. Clonidine improves perioperative myocardial ischemia, reduces anesthetic requirement, and alters hemodynamic parameters in patients undergoing coronary artery bypass surgery. J Cardiothorac Vasc Anesth. 1993;7:386-95.

Dumaresq DMH, Lima OS, Feijó F et al. Sufentanil: avaliação clínica. Rev Bras Anestesiol. 1997; 47:2:123-7.

Durant PA, Yaksh TL. Drug effects on urinary bladder tone during spinal morphine-induced inhibition of the micturition reflex in unanesthetized rats. Anesthesiology. 1988;68:325-34.

Dyck JB, Maze M, Haack $C$ et al. The pharmacokinetics and hemodynamic effects of intravenous and intramuscular dexmedetomidine hydrochloride in adult human volunteers. Anesthesiology. 1993;78:813-52.

Dyck JB, Shafer SL. Dexmedetomidine pharmacokinetics and pharmacodynamics. Stanford Univers School of Medicine. 2000;1:1-5.

Eisenach JC, De Kock M, Klimscha W. a2-adrenergic agonists for regional anesthesia. Anesthesiology. 1996;85:655-74.

Ezri T, Szmunk P, Shklar B et al. Oral clonidine premedication does not prolong analgesia after herniorrhaphy under subarachnoid anesthesia. J Clin Anesth. 1998;10:474-81. 
Ernsberger P, Meeley MP, Mann JJ et al. Clonidine binds to imidazole binding sites as well as alpha2-adrenoceptores in the ventrolateral medulla. Eur $\mathrm{J}$ Pharmacol. 1987;134:1-13.

Evron S, Samueloff A, Sadovsky E et al. The effect ofphenoxybenzamine on postoperative urinary complications during extraduralmorphine analgesia. Eur $\mathrm{J}$ Anaesthesiol. 1984;1:45-54.

Fallon M, O'Neill B. ABC of palliative care: Constipation and diarrhoea. BMJ. 1997;315:1293-6.

Fairbanks CA, Stone LS, Kitto KF. Alpha(2C)-adrenergic receptors mediate spinal analgesia and adrenergic-opioid synergy. J Pharmacol Exp Ther. 2002; 300:282-90.

Fallon M; O'Neill B. ABC of palliative care: Constipation and diarrhea. BMJ. 1997;315:1293-6.

Fine PG. Opioid insights: Opioid-induced hyperalgesia and opioid rotation. J Pain Palliat Care Pharmacother. 2004;18:75-9.

Fist MB, Frances A, Pincus HA. DSM-IV-TR Guidebook: The Essential Companion to the Diagnostic and Statistical Manual of Mental Disorders. $4^{\text {th }}$ ed. Washington: American Psychiatric Publishing, Inc.; 2004.

Flacke JW, Bloor BC, Kripke BJ. Comparasion of morphine, meperidine, fentanyl and sufentanil in balanced anesthesia: a double-blind study. Anesth Analg. 1985;64:897-910.

Flack JW, Bloor BC, Flack WE et al. Reducednarcotic requirements by clonidine with improvement hemodynamic and adrenergic stability in patient undergoing coronary surgery. Anesthesiology. 1987;67:11-9.

Fujii $\mathrm{Y}$, Saitoh $\mathrm{Y}$, Tanaka $\mathrm{H}$ et al. Pretreatment with oral clonidine attenuates cardiovascular responses to tracheal extubation in children. Paediatr Anaesth. 2000;10:65-7. 
Gentili M, Bonnet F. Spinal clonidine produces less urinary retention thanspinal morphine. Br J Anaesth. 1996;76:872-3.

Gertler R, Brown HC, Mitchell DH et al. Dexmedetomidine: a novel sedativeanalgesic agent. BUMC Proceedings. 2001;14:13-21.

Ghignone M, Calvillo O, Quintin L. Anesthesia and hypertension: the effect of clonidine on perioperative hemodynamics and isoflurane requeriments. Anesthesiology.1987;67:3-10.

Ghoneim MM, Dhanaraj J, Choi WW. Comparison of four opioid analgesic as supplements to nitrous oxide anesthesia. Anesth Analg. 1984;63:405-12.

Goldstein A, Lowney LI, Pal BK. Steriospecific and nonspecific interactions of the morphine congener levorphanol in subcellular fractions of mause brain. Proc Nati Acad Sci USA. 1971;68:1742-7.

Gozzani JL. Opióides e Antagonistas. Rev Bras Anestesiol. 1994;44:65-73.

Gross JB, Bailey PL, Connis RT et al. American Society of Anesthesiologists Task Force on Sedation and Analgesia by Non-Anesthesiologists. Practice guidelines for sedation and analgesia by non-anesthesiologists. Anesthesiology. 2002;96:1004-17.

Guinsburg R. Avaliação e tratamento da dor no recém nascido. J Pediatr. 1999;75:149-60.

Hall JE, Uhrich TD, Ebert TJ. Sedative, analgesic and cognitive effects os clonidine infusion in humans. Br J Anaesth. 2001;86:5-11.

Hamaya $Y$, Nishikawa T, Dohi S. Diuretic effect of clonidine during isoflurane, nitrous oxide, and oxygen anesthesia. Anesthesiology. 1994;81:811-9.

Hamm D, Freeman B, Pellam G et al. The effect of fentanyl on left ventricular function. Anesthesiology. 1983;59:A37. 
Hamilton CL, Cohen SE. High sensory block after intrathecal sufentanil for labor analgesia. Anesthesiology. 1995; 83:1118-21.

Hanna MH, Elliott KM, Fung M. Randomized, double-blind study of the analgesic efficacy of morphine-6-glucuronide versus morphine sulphate for postoperative pain in major surgery. Anesthesiology. 2005;102:815-21.

Hayashi Y, Maze M. Alpha 2 adenoceptor agonist and anaesthesia. $\mathrm{Br} \mathrm{J}$ Anaesth. 1993;71:108-18.

Himmelsbach CK. The morphine abstinence syndrome, its nature and treatment. Ann Intern Med. 1941;15:829-39.

Hoffman BB, Lefkowitz RJ. Cathecolamines an sympathomimetic drugs and adrenergic receptor antagonists. In: Hardman JG, Limbird LE, Mollinoff PB et al. The Pharmacological Basis of Therapeutics. $9^{\text {th }}$ ed. New York: Goodman and Gilman's; 1996. p. 199-248.

Holzer P. Opioids and opioid receptors in the enteric nervous system: from a problem in opioid analgesia to a possible new prokinetic therapy in humans. Neurosci Lett. 2004; 361:192-5.

Hristensen $\mathrm{O}$, Christensen $\mathrm{P}$, Sonnenschein $\mathrm{C}$ et al. Analgesic effect of intraarticular morphine. A controlled, randomized and double-blind study. Acta Anaesthesiol Scand. 1996; 40:842-7.

Hu JW, Dostrovsky JO, Sessle BJ. Functional properties of neurons in cat trigeminal subnucleus caudalis (medullary dorsal horn). I. Responses to oralfacial noxious and nonnoxious stimuli and projections to thalamus and subnucleus oralis. J Neurophysiol. 1981; 45:173-92.

Ihalainen JÁ, Tanila $H$. In vivo regulation of dopamine and noradrenaline release by alpha2A-adrenoceptores in the mause nucleus accumbens. $J$ Neurochem. 2004; 91:49-56. 
Inturrisi CE. Clinical pharmacology of opioids for pain. Clin J Pain. 2002; 18(suppl4): S3-S13.

Jacobi J, Fraser GL, Coursin BD et al. Clinical practice guidelines for sustained use of sedatives and analgesics in the critically ill adult. Crit Care Med. 2002; 30:119-41.

Jonge A, Timmermans PB, Van Zweiten PA. Participation of cardiac presynaptic a2-adrenoreceptors in the bradycardic effects of clonidine and analogues. Naunyn Schmiedebergs Arch Pharmacol. 1981;137:8-12.

Kallio A, Scheinin M, Koulu M et al. Effects of dexmedetomidine, a selective alpha 2-adrenoceptor agonist, on hemodynamic control mechanims. Clin Pharmacol Ther. 1989; 46:33-42.

Karhuvaara S, Kallio A, Salonen M et al. Rapid reversal of alpha 2adrenoceptor agonist effects by atipamezole in human volunteers. $\mathrm{Br} \mathrm{J}$ Clin Pharmacol. 1991; 31:160-5.

Kahn ZP, Ferguson CN, Jones RM. Alfa-2 and imidazoline receptor agonists: their pharmacology and therapeutic role. Anaesthesia. 1999; 54:146-65.

Kay B, Rolly G. Duration of action of analgesic supplements to anaesthesia. A Double blind comparison betwee morphine, fentanyl and sufentanil. Acta Anaesthesiol Belg. 1977; 28:25-32.

Kehlet H, Holte K. Review of postoperative ileus. Am J Surg. 2001;182:3S-10S.

Knight G, Ramelet AS, Duncan A et al. Analgesia e sedação em UTIP. Em: Piva JP, Garcia PCR. Medicina Intensiva em Pediatria. Rio de Janeiro: Revinter; 2005. p. 733-52.

Kress JP, Pohlman AS, O'Conner MF et al. Daily Interruption of sedative infusions in critically ill patients undergoing mechanical ventilation. $N$ Engl $J$ Med. 2000; 342:1471-7. 
Ku CM, Ong BC. Postoperative nausea and vomiting: a review of current literature. Singapore Med J. 2003; 44: 366-74.

Kubo T, Misu Y. Pharmacological characterization on the a-adrenoceptor responsabile for a decrease of blood pressure in the nucleus tractus solitarii of the rat. Naunyn Schmiedebergs Arch Pharmacol. 1981;317:120-5.

Kurz A, Sessler DI. Opioid-induced bowel dysfunction: patho-physiology and potential new therapies. Drugs. 2003; 63:649-71.

Langer SZ, Cavero I, Massingham R. Recent developments in noradrenergic neurotransmission and its relevance to the mechanism of action of certain antihypertensive agents. Hypertension. 1980; 2:372-82.

Lent R. Os chips neurais - processamento de informação e transmissão de mensagens através das sinapses. Em: Lent R. Cem bilhões de neurônios: conceitos fundamentais de neurociência. São Paulo: Atheneu; 2004. p. 99-132.

Linkre, Desai K, Hein L. Cardiovascular regulation in mice lacking alpha2adrenergic receptor subtypes b and c. Science. 1996; 273:803-5.

Liu N, Bonnet F, Delaunay L et al. Partial reversal of the effects of extradural clonidine by oral yohimbine in postoperative patients. $\mathrm{Br} \mathrm{J}$ Anaesth. 1993; 70:515-8.

Liu S, Chiu AA, Carpenter $\mathrm{RL}$ et al. Fentanyl prolongs lidocaine spinal anesthesia without prolonging recovery. Anesth Analg. 1995;80:730-4.

Mao J. Opioid-induced abnormal pain sensitivity: Implications in clinical opioid therapy. Pain. 2002; 100:213-7.

McCleane G, Smith H. Opioids for persistent noncancer pain. Med Clin N Am. 2007;91:177-97.

McDonough PC,Levine $\mathrm{P}$, Vorce $\mathrm{S}$ et al. D. The detection of hydromorphone in pain patients chronically treated with morphine. J Anal Toxicol. 2006;30:1-5. 
McQuay H. Opioids in pain management. Lancet. 1999; 353:2229-32.

McQueen DS. Opioid peptide interations with respiratory and circulation systems. Br Med Bull. 1983;39:77-82.

Macmillan LB, Hein L, Smith MS. Central hypotensive effects of the alpha2aadrenergic receptor subtype. Science. 1996;273:801-3.

Makarisisk $\mathrm{P}$, Handy DE, Jonhs $\mathrm{C}$. Role of the alpha2B-adrenergic receptor in the development of salt-induced hypertension. Hypertension. 1999;33:14-7.

Malan TP. Opioid pharmacology: new insights and clinical relevance. ASA Refresher Course. 2000;28:109-19.

Mangano DT, Browner WS, Hollenberg M et al. Association of perioperative myocardial ischemia with cardiac morbidity and mortality in men undergoing noncardiac surgery. The Study of Perioperative Ischemia Research Group. N Engl J Med. 1990;323:1781-8.

Mangano DT, Goldman L. Preoperative assessment of patients with known or suspected coronary disease. N Engl J Med. 1995;333:1750-6.

Mantz J. Alpha 2 -adrenoceptor agonists: analgesia, sedation, anxiolysis, haemodinamics, respiratory funcitions and weaning. In: Alpha $2_{2}$-adrenoceptor agonists in anesthesia and intensive care. Baillieres Clin Anaesthesiol. 2000; 14:433-48.

Martin WR. Pharmacology of opioids. Pharmacol Rev. 1983;35:283-303.

Maze M, Tranquilli W. Alpha-2 adrenoreceptor agonists: defining the role in clinical anesthesia. Anesthesiology. 1991;74:581-605.

Meldrum ML. A capsule history of pain management. JAMA. 2003;290:2470-5.

McQuay H. Opioids in pain management. Lancet. 1999;353:2229-32.

Morais MB, Tahan S. Constipação intestinal. Pediatr Mod. 2009;45:79-98. 
Nascimento JS, Modolo NSP, Carvalho HG et al. Clonidina na cineangiocoronariografia: efeitos sedativos sobre a pressão artéria e a freqüência cardíaca. Arq Bras Cardiol. 2006;87:603-8.

Naguib M, Yaksh TL. Antinoceptive effects of spinal cholinesterase inhibition and isobalographic analysis of the interaction with $\mu$ and $\alpha_{2}$ receptor systems. Anesthesiology. 1994;80:1338-48.

Nestler EJ. Molecular basis on longterm plasticity underlying addiction. Nat Rev Neurosci. 2001;2:119-28.

Neusa L, Cristina F, Aida N et al. Náuseas e vômitos no pós-operatório: uma revisão do "pequeno-grande" problema. Rev Bras Anesthesiol. 2005;55:575-85.

Nishikawa T, Dohi S. Oral conidine blunts the heart rate response to intravenous atropine in humans. Anesthesiology. 1991;75:217-22.

Nishikawa T, Kimura T, Taguchi $\mathrm{N}$ et al. Oral clonidine preanesthetic medication augments the pressor response to intravenous ephedrine in awake or anesthetized patients. Anesthesiology. 1991;74:705-10.

Nishina K, Mikawa K, Shiga $\mathrm{M}$ et al. Clonidine in paediatric anaesthesia. Paediath. 1999;9:182-202.

Nociti JR, Serzedo PS, Nunes AM et al. Sufentanil em infusão venosa contínua para cirurgias abdominais. Rev Bras Anestesiol. 1995;45:235-43.

Oertel BG, Felden L, Tran $P$ et al. Selective antagonismo $f$ opioid-induced ventilatory depression by na ampakine in humans without loss of opioid analgesia. Clinical Pharmacology \& Therapeutics. 2009;194.

Oliveira Jr JO. Receptores opiáceos. Em: Oliveira JO. Opiáceos o Estado d’Arte. São Paulo: LEMAR; 2001. p. 47-53.

Oliveira Jr JO, Serrano SC, Almeida MB et al. Opiáceos fortes. Em Oliveira Jr JO. Opiáceos o Estado d’Arte. São Paulo: LEMAR; 2001. p. 55-71. 
Ooi R, Pattison J, Feldman AS. The effects of intravenous clonidine on ventilation. Anaesthesia. 1991;46:632-3.

Pasternak GW, Childers SR. Opiáceos, peptídeos opióides e seus receptores. Em: Shoemaker WC. Tratado de Terapia Intensiva. São Paulo: Panamericana; 1992. p. 1198-214.

Penon C, Ecoffey C, Cohen SE. Ventilatory response to carbon dioxide after epidural clonidine injection. Anesth Analg. 1991;72:761-4.

Petros JG, Mallen JK, Howe $\mathrm{K}$ et al. Patient-controlled analgesia and postoperative urinary retention after open appendectomy. Surg Gynecol Obstet. 1993;177:172-5.

Petros JG, Rimm EB, Robillard RJ. Factors influencing urinary tract retention after elective open cholecystectomy. Surg Gynecol Obstet. 1992;174:497-500.

Portenoy RK. Opioid therapy for chronic nonmalignant pain: a review of the critical issues. J Pain Symptom Manage. 1996;11:203-17.

PRACTICE GUIDELINES FOR ACUTE PAIN MANAGEMENT IN THE PERIOPERATIVE SETTING: na updated report by the American Society of Anesthesiologists Task Force on Acute Pain Management. Anesthesiology. 2004:100:1573-81.

Prys-Roberts C, Hug CC. Pharmacokinetics of anesthesia. London: Blackwell Scientific Publications; 1984.

Quintin L, Bonnet F, Macquin I et al. Aortic surgery: effect of clonidine on intraoperative catecholaminergic and circulatory stability. Acta Anaesthesiol Scand. 1990;34:132-7.

Quintin L, Ghignone M. Risk associated with perioperative use of alpha $2^{-}$ adrenoceptor agonists. Balieres Clin Anaesthesiol. 2000;14:347-68. 
Reimer EJ, Dunn GS, Montgomery CJ et al. The effectiveness of clonidine as na analgesic in paediatric adenotonsillectomy. Can J Anaesth. 1998;45:1162-7.

Reis DJ, Ruggiero DA, Morrison SF. The C1 area of the rostro-ventrolateral medulla oblongata. A critical brainstemregion for control of resting and reflex integration of arterial pressure. Am J Hypertens. 1989;2:368-74.

Reis DJ, Regunathan S, Meeley MP. Imidazole receptors and clonidinedisplacing substance in relationship to controlo $f$ blood pressure, neuroprotection and adrenomedullary secretion. Am J Hypertens. 1992;5:51-7.

Reuben SS, Stein Rb, Cohen MA et al. Intraarticular morphine in multimodal analgesic management of postoperative pain after ambulatory anterior cruciate ligament repair. Anesth Analg. 1998;86:374-8.

Ribeiro S, Schmidt AP, Schmidt SRG. O uso de opióides no tratamento da dor crônica não oncológica: o papel da metadona. Rev. Bras Anestesiol. 2002 52:5: 644-51.

Rosow CE, Moss J, Philbin DM, Savarese SS. Histamine in human plasma following administration de morphine or fentanyl (abstr) In: Rugheimer E, Wawersik J, Zindler M, Eds. Proceedings of the $7^{\text {th }}$ World Congress of Anesthesiologists, September 14-21, 1980. Princeton: Excerpta Medica, 1980.

Ruffolo Jr RR. Distribution and function of peripheral adrenoceptores on the cardiovascular system. Pharmachol Biochem Behav. 1985;22:827-33.

Scholz J, Tonner PH. a2-adrenoceptor agonist in anaesthesia: a new paradigm. Curr Opin Anaesthesiol. 2000;13:437-42.

Schulte-Tamburen AM, Scheier J, Briegel $\mathrm{J}$ et al. Comparison of five sedation scoring systems by means of auditory evoked potentials. Intensive Care Med. 1999;25:377-82. 
Scott JC, Ponganis K, Stanski DR. EEG quantitation of narcotic effect. The comparative phamacodynamics of fentanyl and alfentanil. Anesthesiology. 1985;62:234-41.

Scott JC, Cooke JE, Stanski DR. Electroencephalographic quantitation of opioid effect: Comparative pharmacodynamics of fentanyl and sufentanil. Anesthesiology. 1991;74: 34-42.

Shook DC, Gross W. Offsite anesthesiology in the cardiac catheterization lab. Curr Opin Anaesthesiol. 2007;20:352-8.

Schmidt A, Bagatini A. Náusea e vômito pós-operatório: fisiopatologia, profilaxia e tratamento. Rev Bras Anestesiol. 1997; 47:326-34.

Schulte-Tamburen AM, Scheier J, Briegel J et al. Comparison of five sedation scoring systems by means of auditory evoked potentials. Intensive Care Med. 1999;25:377-82.

Silvia YP, Gomez RS, Máximo TA et al. Sedação e analgesia em neonatologia. Rev Bras Anestesiol. 2007;57: 5: 575-8.

Simon EJ. Opioid peptides and their receptors. In Estafanous FG. Opioids in Anesthesia II. Boston: Butterworth-Heinemann; 1991. p. 20-32.

Sinclair DR, Chung F, Mezei G. Can postoperative nausea and vomiting be predicted? Anesthesiology. 1999;91:109-18.

Smania MC, Garcia PCR. Clonidina como droga sedativa e analgésica em pediatria. Scientia Medica. 2005;15:270-73.

Sinclair DR, Chung F, Mezei G. Can postoperative nausea and vomiting be predicted? Anesthesiology. 1999;91:109-18.

Soderpalm B, Engel JA. Biphasic effects of clonidine on conflict behavior: involvement of different alpha-adrenoceptors. Pharmacol Biochem Behav. 1988;30:371-477. 
Spiller RC. ABC of the upper gastrointestinal tract: Anorexia, nausea, vomiting, and pain. BMJ. 2001;323:1354-7.

Stanley TH, Webster. Anesthetic requirements and cardiovascular effects of fentanyl-oxygen anesthesia in man. Anesth Analg 1978;57: 411.

Stein C, Pflüger M, Yassouridis A et al. No tolerance to peripheral morphine analgesia in presence of opioid expression in inflamed synovia. J Clin Invest 1996;98:793-9.

Stoelting RK. Opioid agonists and antagonists. In: Stoetting RK. Pharmacology \& Physiology in Anesthetic Practice. Philadelphia: JB Lippincott Company; 1987. p. 69-101.

Stoelting RK, Hiller SC. Barbiturates. In: Stoelting RK, Hiller SC. Pharmacology \& Physiology in Anesthetic Practice, $4^{\text {th }}$ Ed. Philadelphia: Lippincott Williams \& Wilkins; 2006: p. 127-39.

Strandhoy JW. Role of alpha2 receptors in the regulation of renal function. $\mathrm{J}$ Cardiovasc Pharmacol 1985;7:S28-S33.

Snyder SH. Opiate receptors in the brain. N Eng J Med. 1977;296:266-71.

Takada K, Clark DJ, Davies MF et al. Meperidine exert agonist activity at the [alpha] ${ }_{2 \mathrm{~B}}$-Adrenoceptor subtype. Anesthesiology. 2002;96:1420-6.

Talke P. Pharmacodynamics of alpha $_{2}$ adrenoceptor agonists. Alpha2adrenoceptor agonists in anaesthesia and intensive Care. Baillières Clin Anaesthesiol. 2000;14: 271-83.

Tegeder I, Meier S, Burian M et al. Peripheral opioid analgesia in experimental human pain models. Brain. 2003;126:1092-102.

Thomas R, Jones NA, Strike P. The value of risk score for predicting postoperative nausea and vomiting when used to compare patient groups in a randomised controlled trial. Anaesthesia. 2002;57:1119-28. 
Trescot AM, Datta S, Lee Marion et al. Opioid Pharmacology. Pain Physician. 2008:11:S133-53 (Opioid Special Issue).

Tryba M, Gehling M. Clonidina -a potent analgesic adjuvant. Curr Op Anaesthesiol. 2002;15:511-7.

Wallace A, Layug B, Tateo I et al. Hollenberg M, Browner W, Miller D, Mangano DT. Prophylatic atenolo reduces postoperative myocardial ischemia. McSPI Research Group. Anesthesiology. 1998;88:7-17.

Wallace AW, Galindez D, Salahieh A et al. Effect of clonidine on cardiovascular morbidity and mortality after noncardiac surgery. Anesthesiology. 2004;101:284-93.

Wallace AW. Clonidine and modification of perioperative outcome.Curr Opin Anaesthesiol. 2006;19:411-7.

WORLD HEALTH ORGANIZATION. Cancer Pain Relief: With a Guide to Opioid Availability. $2^{\text {nd }}$ Ed. Geneva, Switzerland: WHO Office of Publication; 1996.

Wu CL, Berenholtz SM, Pronovost PJ et al. Systematic review and analysis of post-discharge symptoms after outpatient surgery. Anesthesiology. 2002;96:994-1003.

Wyands JE, Wong P, Whalley DG et al. Oxygen-fentanyl anesthesia in patients with poor left ventricular function: hemodynamics and plasma fentanyl concentrations. Anesth Analg. 1983; 62:476. 